JOINT TRANSPORTATION RESEARCH PROGRAM

FHWA/IN/JTRP-2010/20

Final Report

REFINE PROCESS TO IDENTIFY, EVALUATE, AND ADOPT NEW TECHNOLOGIES AND IDENTIFY NEW PROVEN TECHNOLOGIES FOR INDIANA

Joseph V. Sinfield

September 2010 


\section{TECHNICAL Summary}

INDOT Research

Technology Transfer and Project Implementation Information

TRB Subject Code:

Publication No.: FHWA/IN/JTRP-2010/20, SPR-3235

September 2010

Final Report

\section{Refine Process to Identify, Evaluate, and Adopt New Technologies and Identify New Proven Technologies for Indiana}

\section{Introduction}

Identifying, evaluating and adopting the latest proven technologies is crucial to ensure the efficiency, quality, cost effectiveness, and safety of INDOT operations. While focused efforts to understand and employ new technologies for the benefit of INDOT have been pursued successfully in the past, there remains an opportunity to develop a robust approach to need identification and related technology selection and adoption that is more "continuous" in nature and capable of helping the organization keep pace with the rapid rate of technological change. In response, this study builds on the decades of work that has been carried out on this topic in the transportation sector and complements these efforts with insights from a wide variety of successful organizations in other fields to put forward a comprehensive approach to identify, evaluate, and adopt new "proven" and/or "ready to use" technologies that have the potential to improve INDOT's ability to perform its multifaceted mission.

\section{Findings}

This study recommends a process to ensure effective technology adoption by INDOT which encompasses need identification, solution identification, solution evaluation, and staged solution implementation, and incorporates several novel features, namely: a new means of assessing INDOT needs that leverages a survey of end-user "jobs-to-be-done" to focus technology adoption efforts; a web-based mechanism to link INDOT needs and potential solutions that is based on leading systems in the commercial sector; provision for "champions" that will provide idea "ownership" in the technology adoption process and help overcome traditional adoption barriers; centralization of evaluation activities to drive efficiencies across INDOT and eliminate redundant efforts; and, a unique assumption-driven approach to implementation that optimizes resources and includes a tiered marketing strategy to build awareness and encourage broad adoption of technologies. In addition, recommendations for a governance structure that can guide the technology adoption process and ensure its ongoing effectiveness are also defined. Overall, the results of this work provide the foundation for a capability in technology awareness and adoption that could benefit INDOT operations for many years to come

\section{Implementation}

The initial stages of the recommended technology adoption process (needs identification and solution identification) were piloted as part of this study. This activity called attention to a series of INDOT-specific needs and associated highpotential technology-based solutions that if pursued could directly enhance INDOT operations. Going forward it is recommended that 
INDOT pursue and promote these needs and related technologies as appropriate, perform an annual "jobs-to-be-done" survey building on this effort to continuously refine its view of needs, develop a robust methodology to track technology evaluation and implementation efforts, and recruit technology scouts/change agents to identify and promote available technologies in close collaboration with the INDOT Research and Development and Innovation and Enhancement divisions.

\section{Contacts}

For more information:

Prof. Joseph V. Sinfield

Principal Investigator

School of Civil Engineering

Purdue University

West Lafayette IN 47907

Phone: (765) 496-2742

E-mail: jvs@purdue.edu
Indiana Department of Transportation

Division of Research

1205 Montgomery Street

P.O. Box 2279

West Lafayette, IN 47906

Phone: (765) 463-1521

Fax: (765) 497-1665

\section{Purdue University}

Joint Transportation Research Program

School of Civil Engineering

West Lafayette, IN 47907-1284

Phone: (765) 494-9310

Fax: (765) 496-7996

E:mail: jtrp@ecn.purdue.edu 
Final Report

FHWA/IN/JTRP-2010/20

\title{
REFINE PROCESS TO IDENTIFY, EVALUATE, AND ADOPT NEW TECHNOLOGIES AND IDENTIFY NEW PROVEN TECHNOLOGIES FOR INDIANA
}

\author{
by \\ Joseph V. Sinfield \\ Principal Investigator \\ Assistant Professor \\ School of Civil Engineering \\ Purdue University \\ Joint Transportation Research Program \\ SPR-3235

\begin{abstract}
Conducted in Cooperation with the
Indiana Department of Transportation and the U.S. Department of Transportation

Federal Highway Administration
\end{abstract}

The contents of this report reflect the views of the authors, who are responsible for the facts and the accuracy of the data presented herein. The contents do not necessarily reflect the official views or policies of the Indiana Department of Transportation or the Federal Highway Administration at the time of publication. The report does not constitute a standard, specification, or regulation.

Purdue University

West Lafayette, IN 47906

September 2010 


\begin{tabular}{|c|c|c|}
\hline $\begin{array}{l}\text { 1. Report No. } \\
\text { FHWA/IN/JTRP-2010/20 }\end{array}$ & 2. Government Accession No. & 3. Recipient's Catalog No. \\
\hline \multirow{2}{*}{\multicolumn{2}{|c|}{$\begin{array}{l}\text { 4. Title and Subtitle } \\
\text { Refine Process to Identify, Evaluate, and Adopt New Technologies and Identify New } \\
\text { Proven Technologies for Indiana }\end{array}$}} & $\begin{array}{l}\text { 5. } \quad \text { Report Date } \\
\text { September } 2010\end{array}$ \\
\hline & & 6. Performing Organization Code \\
\hline \multicolumn{2}{|c|}{$\begin{array}{l}\text { 7. Author(s) } \\
\text { Joe Sinfield } \\
\text { Assistant Professor of Civil Engineering, Purdue University }\end{array}$} & $\begin{array}{l}\text { 8. Performing Organization Report No. } \\
\text { FHWA/IN/JTRP-2010/20 } \\
\end{array}$ \\
\hline \multirow{2}{*}{\multicolumn{2}{|c|}{$\begin{array}{l}\text { 9. Performing Organization Name and Address } \\
\text { Joint Transportation Research Program } \\
\text { Purdue University } \\
550 \text { Stadium Mall Drive } \\
\text { West Lafayette, IN 47907-2051 }\end{array}$}} & 10. Work Unit No. \\
\hline & & $\begin{array}{l}\text { 11. Contract or Grant No. } \\
\text { SPR-3235 }\end{array}$ \\
\hline \multirow{2}{*}{\multicolumn{2}{|c|}{$\begin{array}{l}\text { 12. Sponsoring Agency Name and Address } \\
\text { Indiana Department of Transportation } \\
\text { State Office Building } \\
100 \text { North Senate Avenue } \\
\text { Indianapolis, IN } 46204\end{array}$}} & $\begin{array}{l}\text { 13. Type of Report and Period Covered } \\
\text { Final Report }\end{array}$ \\
\hline & & 14. Sponsoring Agency Code \\
\hline
\end{tabular}

\section{Supplementary Notes}

Prepared in cooperation with the Indiana Department of Transportation and Federal Highway Administration.

16. Abstract

Identifying, evaluating and adopting the latest proven technologies is crucial to ensure the efficiency, quality, cost effectiveness, and safety of INDOT operations. While focused efforts to understand and employ new technologies for the benefit of INDOT have been pursued successfully in the past, there remains an opportunity to develop a robust approach to need identification and related technology selection and adoption that is more "continuous" in nature and capable of helping the organization keep pace with the rapid rate of technological change. In response, this study builds on the more than 40 years of work that has been carried out on this topic in the transportation sector and complements these efforts with insights from a wide variety of successful organizations in other fields to put forward a comprehensive approach to identify, evaluate, and adopt new "proven" and/or "ready to use" technologies that have the potential to improve INDOT's ability to perform its multifaceted mission. This proposed process, which encompasses need identification, solution identification, solution evaluation, and staged solution implementation, incorporates several novel features to ensure effective technology adoption, namely: a new means of assessing INDOT needs that relies upon a survey of end-user "jobs-to-be-done" to focus technology adoption efforts; a web-based mechanism to link INDOT needs and potential solutions that is based on leading systems in the commercial sector; provision for "champions" that will provide idea "ownership" in the technology adoption process and help overcome traditional barriers; centralization of evaluation activities to drive efficiencies across INDOT and eliminate redundant efforts; and, a unique assumption-driven approach to implementation that optimizes resources and includes a tiered marketing strategy to build awareness and encourage broad adoption of technologies. In addition, this report provides recommendations for a governance structure that can guide the technology adoption process and ensure its on-going effectiveness. A pilot of the initial stages of the proposed process (needs identification and solution identification) is also presented which calls attention to a series of INDOT-specific needs and associated high-potential technology-based solutions that if pursued could directly enhance INDOT operations. Overall, the results of this work provide the foundation for a capability in technology awareness and adoption that will benefit INDOT operations for many years to come.

\section{Key Words}

Technology transfer, technology evaluation, technology adoption, commercially available technologies, technology needs assessment

\section{Distribution Statement}

No restrictions. This document is available to the public through the National Technical Information Service, Springfield, VA 22161
19. Security Classif. (of this report)

Unclassified
20. Security Classif. (of this page)

Unclassified
21. No. of Pages

97 
TABLE OF CONTENTS

PREFACE AND PROJECT OVERVIEW

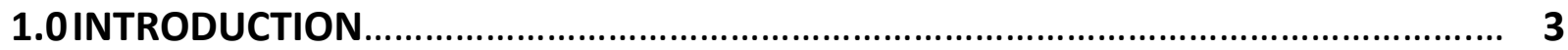

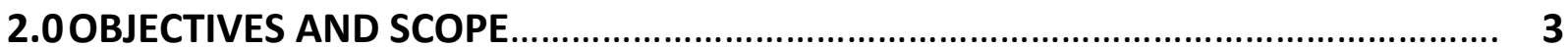

SECTION I - A PROCESS TO IDENTIFY, EVALUATE AND ADOPT NEW TECHNOLOGIES

1.0INTRODUCTION

2.0 TECHNOLOGY ADOPTION AS DISCUSSED IN TRANSPORTATION

SECTOR LITERATURE.................................................................................... 4

3.0 TECHNOLOGY ADOPTION PROCESSES EMPLOYED BY STATE DOTS..................... 6

4.0TECHNOLOGY ADOPTION IN OTHER INDUSTRIES ................................................. 8

5.0RECOMMENDED BEST-OF-BREED TECHNOLOGY ADOPTION

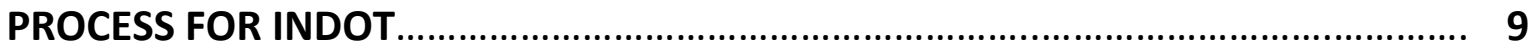

5.1 Identifying INDOT's Needs............................................................................. 10

5.2 Identifying relevant, ready-to-use solutions....................................................... 13

5.3 Linking INDOT's needs and solutions................................................................ 16

5.4 Championing New Technologies...................................................................... 18

5.5 Evaluating New Technologies...................................................................... 18

5.6 Facilitating Staged Implementation............................................................... 22

6.0 SUMMARY OF TECHNOLOGY ADOPTION CHALLENGES AND

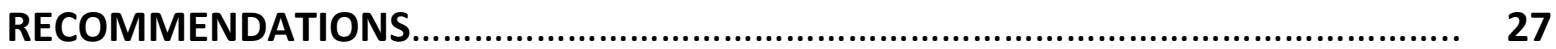

SECTION II: GOVERNING AND SUPPORTING INDOT'S BEST-OF-BREED PROCESS..... 29

SECTION III: TECHNOLOGIES OF INTEREST FOR INDOT

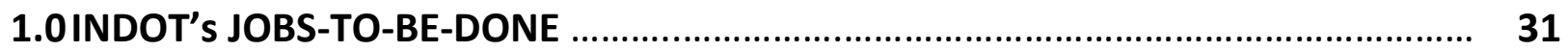

2.0 HIGH-POTENTIAL SOLUTIONS FOR INDOT NEEDS................................................ 36

BENEFITS OF STUDY AND RECOMMENDATIONS FOR USE OF FINDINGS................... 40

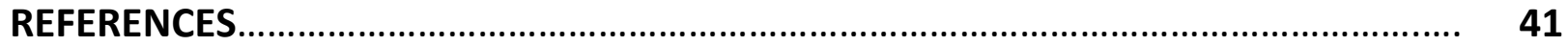

APPENDIX A: DOT Survey Participants

APPENDIX B: State-specific Approaches to Technology Adoption Process Phases

APPENDIX C: Job Surveys Employed for INDOT Need Identification

APPENDIX D: Marketing Templates

APPENDIX E: Complete Listing of Job-survey Results 


\section{PREFACE - PROJECT OVERVIEW}

\subsection{INTRODUCTION}

Identifying, evaluating and adopting the latest proven technologies is crucial to ensure the efficiency, quality, cost effectiveness, and safety of INDOT operations. While focused efforts to understand and employ new technologies for the benefit of INDOT have been pursued successfully in the past, there remains an opportunity to develop a robust approach to need identification and related technology selection and adoption that is more "continuous" in nature and capable of helping the organization keep pace with the rapid rate of technological change.

The challenges of gaining awareness of technological developments and embracing those that are relevant to an organization's success are neither new, nor unique to the transportation sector. In a report for the United Nations Development Program, Lall (2001) states that "Learning to use new technologies, even those in existence elsewhere, needs investment by the user to create new skills, organizations, information and institutional support...[which] involve[s] risk, effort and time." All organizations, and arguably all individuals, face these challenges on a routine basis. As such, sources of insight into the best means to manage this problem are numerous and broad based. It was the goal of this study to build on the more than 40 years of work that has been carried out on this topic in the transportation sector and to complement these efforts with insights from a wide variety of successful organizations in other fields.

\subsection{OBJECTIVES AND SCOPE}

With the above background in mind, the specific objectives of this effort were threefold:

1. Put forward a comprehensive approach to identify, evaluate, and adopt new "proven" and/or "ready to use" technologies that have the potential to improve INDOT's ability to perform its multifaceted mission

2. Define an appropriate governance structure that can guide the technology adoption process and ensure its effectiveness on a continuous basis

3. Pilot the initial phases of the defined approach to perform a technology scan to identify and addresses current high-priority INDOT needs

Perspectives on each of these three objectives are detailed in the report sections that follow. Section I examines approaches to technology adoption put forward in literature and in practice within and beyond the transportation sector and puts forward a recommendation for a "best-of-breed" technology adoption process for INDOT. Section II draws on insights from both DOTs and major corporations to recommend a governance structure that can facilitate successful application of the prescribed process. Finally, Section III identifies specific technologies of interest for INDOT by employing the early phases of the recommended process.

\section{SECTION I - A PROCESS TO IDENTIFY, EVALUATE AND ADOPT NEW TECHNOLOGIES 1.0 INTRODUCTION}

Three major sources of information were utilized to develop a robust process to identify, evaluate, and adopt new proven technologies. First, a comprehensive literature review was performed to understand work on DOT technology adoption practices that has been pursued by other researchers and practitioners in the transportation arena (see Table I-1 for studies of particular significance). Second, a 
survey and follow-up interviews were carried out directly with personnel from state DOTs to gain firsthand insight into currently employed technology adoption processes on a state by state basis. Finally, technology adoption practices in industries beyond transportation were also examined to identify means to overcome challenges identified with existing practices within the transportation sector.

\subsection{TECHNOLOGY ADOPTION AS DISCUSSED IN TRANSPORTATION SECTOR LITERATURE}

In transportation circles, the management of technological change has traditionally been examined under the moniker of "tech transfer". Multiple authors have pinpointed the use of this language in the transportation context (e.g., Schmitt et al. 1985, Wallace et al. 1998) and, more recently, Harder and Benke (2005) synthesized it as follows:

Technology transfer [encompasses] activities leading to the adoption of a new-to-theuser product or procedure by any user or group of users. New-to-the-user means any improvement over existing technologies or processes and not only a recent invention or research result. Technology transfer includes research results implementation and product or process deployment. In addition, ... [it] also includes the complex process of change, a comprehensive achievement dealing with cultural as well as technical issues.

Despite this deservedly broad definition, technology transfer initiatives have been primarily investigated in the context of research dissemination. A research-based approach to tech transfer is a perspective that can artificially inflate the required significance of a "relevant" technology, limit the breadth of investigation for new solutions, and under-leverage the efforts technology vendors expend to market their wares. Further, as noted by Harder and Benke (2005), while three processes appear to be employed in the transportation sector to facilitate technology transfer - R\&D unit led push, TAP-led push, and operating unit led pull - only the first two have been approached systematically, with the latter typically treated on an ad hoc basis.

A multitude of studies have been carried out in this context, and some of the more notable efforts of the last decade are summarized below:

\begin{tabular}{|c|c|c|}
\hline Year & Initiative & Sponsor \\
\hline 2008 & $\begin{array}{l}\text { National Cooperative Highway Research Program (NCHRP): An Implementation } \\
\text { Survey (NCHRP, 2008) }\end{array}$ & NCHRP \\
\hline 2005 & $\begin{array}{l}\text { NCHRP Synthesis 355: Transportation Technology Transfer: Successes, } \\
\text { Challenges, and Needs (Harder and Benke, 2005) }\end{array}$ & AASHTO and FHWA \\
\hline 2005 & $\begin{array}{l}\text { Technology Transfer Toolbox: A Research Implementation How-To Guide } \\
\text { (TPF, 2005) }\end{array}$ & $\begin{array}{l}\text { Transportation Pooled Fund } \\
\text { Program (TPF) }\end{array}$ \\
\hline 2004 & Technology Transfer Toolbox Scoping Study (Harder, 2004) & $\begin{array}{l}\text { TRB Committee on Technology } \\
\text { Transfer and FHWA }\end{array}$ \\
\hline 2004 & $\begin{array}{l}\text { AASHTO Research Implementation and Performance Measures Workshop } \\
\text { Presentations (ConnDOT, 2004) }\end{array}$ & $\begin{array}{l}\text { Connecticut Department of } \\
\text { Transportation }\end{array}$ \\
\hline 2003 & Technology Transfer Toolbox, Concept for Phased Development (Toole, 2003) & FHWA \\
\hline 2001 & Peer Exchange: A Value-added Program Management Tool (Harder, 2001) & NCHRP \\
\hline 2000 & $\begin{array}{l}\text { NCHRP Report 442, Systems Approach to Evaluating innovations for Integration } \\
\text { into Highway Practice (NCHRP, 2000) }\end{array}$ & NCHRP \\
\hline 1999 & $\begin{array}{l}\text { Managing Technology Transfer: A Strategy for the Federal Highway } \\
\text { Administration-Special Report } 256 \text { (TRB, 1999) }\end{array}$ & TRB and FHWA \\
\hline
\end{tabular}

Table I-1: Recent studies on technology transfer in the transportation sector.

In addition, there have been a host of state driven research implementation programs that place a heavy emphasis on adoption of research-derived technology. For instance, WisDOT R\&L (2007) provides a recent synthesis of these research implementation programs. 
Collectively, these initiatives call attention to a variety of factors that facilitate successful transfer of technology from its source to end users. These insights were synthesized by Harder and Benke (2005), who indicated that "...successful technology transfer occurs when:

- There is a push of technology into a user environment;

- A champion is associated with the research and technology transfer effort;

- Pilots and demonstrations allow hands-on learning;

- Senior management support attracts attention, leads by example, and gives guidance to the effort;

- Early involvement of the user allows early resolution of problems and prepares the user for fully embracing the innovation;

- There is a technology transfer or implementation plan to identify strategies and tactics;

- Qualified people are in lead roles;

- Partnerships leverage resources and attract the right participants;

- There is progress monitoring and committed funding;

- A focus area exists for technology transfer efforts;

- Emphasis is on marketing and communications; and

- Benefits of the technology meet users' needs."

These success factors represent an agglomeration of findings from multiple case studies; and while programs such as the Local Technical Assistance Program (LTAP), the Tribal Technical Assistance Program (TTAP), the AASHTO Technology Implementation Group (TIG), FHWA's Priority, Market-Ready Technologies initiative, and the state oriented Peer Exchange Program successfully encompass subsets of the traits outlined above, this collection of traits is rarely, if ever, found in one programmatic approach deployed by Departments of Transportation (DOTs).

Despite the many technology transfer successes of DOT's, NCHRP, FHWA and others, the transportation industry has still faced obstacles to technology adoption and consistently appears less efficient than desired. The same studies that highlighted key criteria for success in technology transfer in the transportation sector, also call attention to several challenges that should be addressed to further enhance this process. Specifically, any newly developed process should account for the following (TRB, 1999; Harder and Benke, 2005; IDOT, 2007):

- A historical bias in existing processes toward the transfer of research by-products rather than commercial / ready to use technologies (with limited exceptions discussed later)

- A generally introspective view of technological options steeped heavily in transportation sector experience

- A lack of a systematic means to pursue operating unit driven (pull) technology transfer (despite well structured processes for R\&D- and TAP-led push)

- A need to better index information and enable more effective "finding tools"

- A lack of "transfer agents" that can link technologies and users in the transportation community - key players that are vital and commonplace in the private sector (e.g., venture capitalists, business incubators)

- Limited utilization of diffusion and transfer methodologies employed in other sectors/industries

There are two sides to the challenges outlined above. On one side, there is a need to better manage the expectations of stakeholders in the transportation industry as technology adoption is indeed a challenging problem and one that few organizations perform effectively on a continuous basis. On the other side, there is almost always opportunity to improve, often by learning from others. The former point calls attention to the need for any technology adoption process to closely engage senior leadership - a point revisited in detail in subsequent parts of this report. The latter point opens the 
door for insights that may be gained from other industries, particularly on a step-by-step basis within an overarching process that enables technology adoption. Both of these perspectives are revisited in the discussion of the recommended "best-of-breed" process put forward in Section I-5.0.

\subsection{TECHNOLOGY ADOPTION PROCESSES EMPLOYED BY STATE DOTS}

The technology adoption success factors and challenges outlined in the literature described above are echoed by many involved in these processes at state DOTs today. For this project, the PI and his team reached out to all 50 DOTs to build a thorough and complete representation of what other DOTs do to identify, evaluate, and adopt new technologies. Significant input was received from 18 states. Appendix A provides a listing of the specific personnel from the state DOTs that participated in a questionnaire and/or follow-up conversation for this effort.

Based on this input, four major technology adoption process steps appear to be common across nearly all organizations (see Figure I-1), namely: 1) need identification, 2) solution identification, 3) solution evaluation and 4) solution implementation. Need identification refers to the processes used to understand the needs of end users of technology - that is, those who play critical roles in the various functional units of the DOT. Solution identification makes reference to the process of identifying potentially relevant technologies that may satisfy currently unaddressed needs. Solution evaluation entails the process of assessing the effectiveness of identified technologies when employed in actual DOT contexts through experiments and/or field trials. Finally, implementation involves diffusion of an effective innovation throughout the organization to those end users that it can benefit.

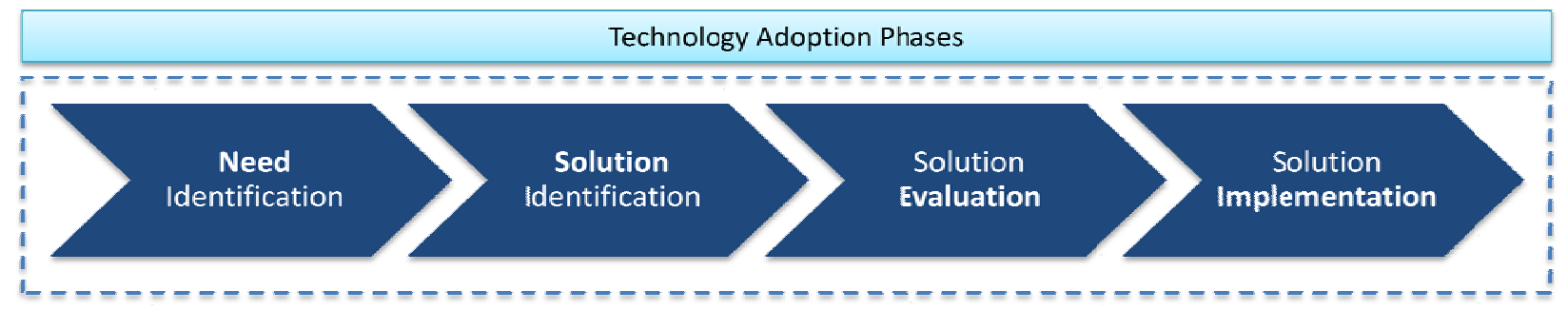

Figure I-1: Common phases of DOT technology adoption processes.

Despite the conceptually similar view of the technology adoption process across DOTs, the means by which each step is pursued vary greatly state to state. Figure I-2 provides an overview of the methods employed in each phase of the process by a small sampling of the states studied in this effort. For example, SCDOT reports that they conduct a "topic solicitation meeting" in partnership with the Transportation Technology Transfer Service (T3S) at Clemson University to identify needs from a broad base of representatives (experts) from SCDOT, FHWA, USGS, industry, and academia. Solutions to specific needs can be identified in a decentralized fashion through peer exchange or can be pursued through the department's SPR Research Program in which a Research and Development Executive Committee (RDEC) ballots and approves topics for funding as research projects. End users are involved early in research driven evaluation efforts and expert groups are engaged to determine the effectiveness of examined solutions. Solutions move through evaluation with the benefit of a Steering and Implementation Committee that guides overall research of the new solution and facilitates followup for implementation. In contrast, Kansas DOT primarily identifies needs through the examination of failures or based on new research findings. A champion is then sought to drive the pursuit of new solutions through a decentralized, department-based process of exploration, evaluation, and implementation. The Montana DOT identifies needs on the basis of decentralized departmental recommendations. Individual departments then engage the DOT's research arm and carry out solution 
identification and evaluation which may entail a research project or experimentation. Adoption is typically addressed on a department area basis. Finally, the Oregon DOT compliments its "top-down" strategic priorities with a "bottom-up" solicitation of user needs. Their research arm is then engaged in solution identification and evaluation for priority needs as defined by Expert Task Groups. No formalized implementation methods were reported. (See Appendix B for additional insight into state specific approaches to each process phase).

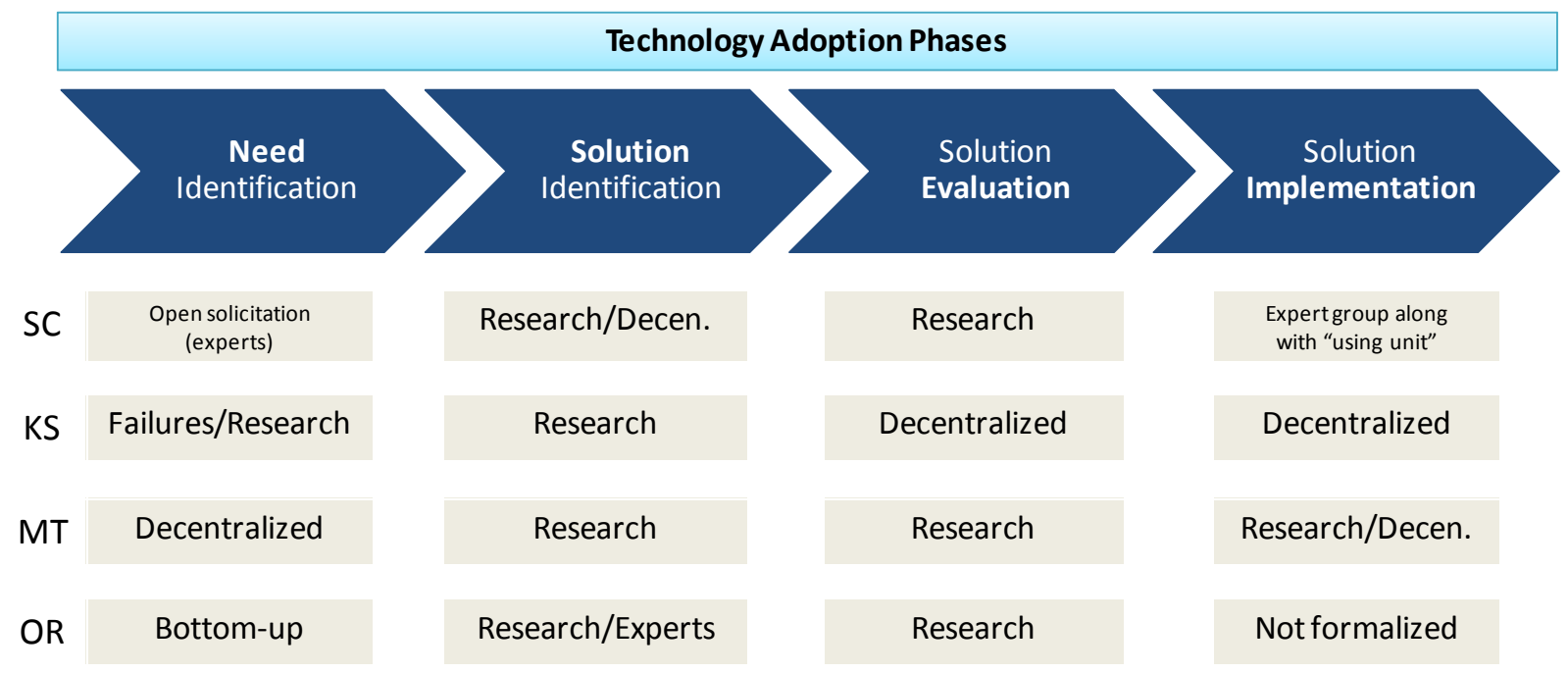

Figure I-2: Sample of state-specific approaches to technology adoption.

When the state DOTs are examined in aggregate, it is clear that there is a substantial range in current approaches to each of the technology adoption process phases as summarized in Figure I-3. Needs may be identified formally by defined expert groups, explored through open solicitation and/or direct interactions with functional area personnel (bottom-up), result as mentioned earlier from research efforts, be the byproduct of failure analysis, or stem from truly informal information networks. Approaches to solution identification are similarly varied across states. Solutions today are most commonly identified through research efforts (a method that has its limitations as discussed earlier), but may also be sought in a decentralized fashion by specific units, districts, or functional areas, organized through an expert group or panel, or simply tie to the recommendations of national programs (e.g., AASHTO TIG, FHWA). Solution evaluation is most often carried out as a research effort, but can also be based on the experiences and opinions of centralized expert groups, be pursued in a decentralized district or functional area, or rely on the findings of other DOTs that may have examined similar issues (this latter option is quite rare, as states do not appear to fully embrace the findings of their peers due to the (well founded) belief that state specific circumstances require independent solution trials). Finally, solution implementation is also pursued in myriad ways. In many states the "research" arm of the organization takes responsibility for driving implementation, but in others expert groups are relied upon to convey the merits of new, proven solutions to relevant end users, or areas are encouraged to be proactive in seeking new solutions in a decentralized manner. Still others struggle with this phase of activity and either did not report a formalized approach or acknowledged that they do not have one. Overall, this overview demonstrates that there is no standard, best-practice process for technology adoption among DOTs. 


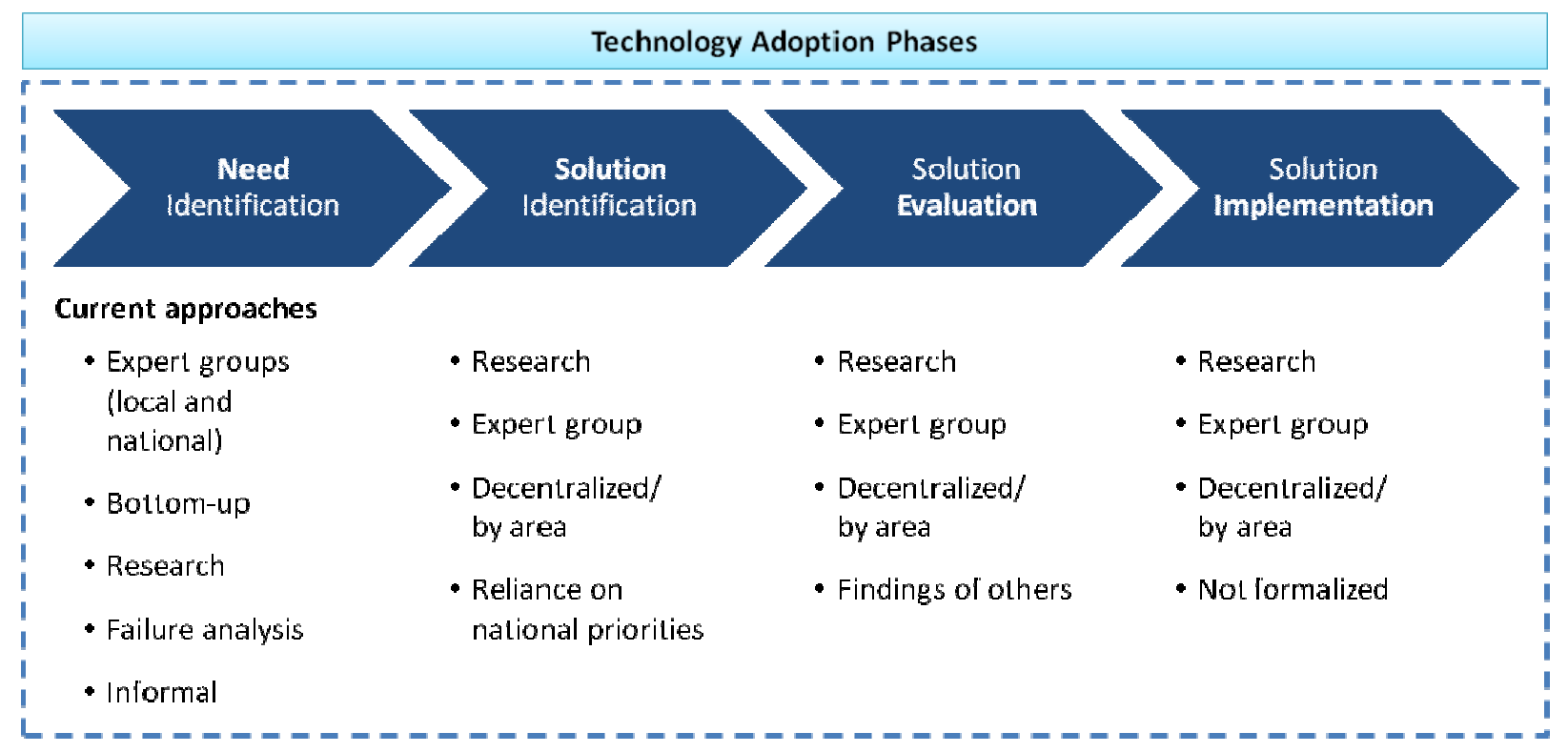

Figure I-3: Range of approaches to key phases of technology adoption process.

\subsection{TECHNOLOGY ADOPTION IN OTHER INDUSTRIES}

As mentioned at the outset of this report, the technology adoption challenge is not unique to the transportation sector. As a result, insight into means to overcome the challenges faced in transportation can potentially be derived from other industries and schools of thought that tackle related challenges. A synthesis of best practice principles employed in literally dozens of other industries to successfully pursue and adopt new innovation (often involving new technology) by Anthony et al. (2008) calls attention to the fact that each stage of the overarching technology adoption process can be supported by concepts common in other fields. For example:

- Need identification: The identification of end-user needs is the focus of market research science as well as studies of emerging technologies. These fields emphasize that effective need identification requires diligence on two fronts. First, needs as perceived by both leadership and end-users must be well understood and monitored. Second, available, relevant, technologies must be monitored within and beyond an organization's sector to maintain awareness of opportunities for improvement (e.g., enhanced performance, cost effectiveness, and/or safety).

- Solution identification: Linking (new) solutions to needs is at the core of fields such as market research, emerging technology analysis, knowledge management, data mining, and open innovation. Across all of these disciplines there is an emphasis on organized classification of needs, clear definition of the attributes and capabilities of solutions, and encouragement of network effects to facilitate connections between needs and the most appropriate solutions.

- Solution evaluation: The evaluation of new ideas and solutions is the foundation of entrepreneurial business building efforts and the focus of discovery driven planning in the field of business strategy. These management disciplines call attention to the importance of early identification and testing of the assumptions that must be true for a new solution to deliver its promised benefits.

- Solution implementation: Implementation represents broad acceptance and use of a new solution. This concept is central to product adoption theory and marketing science, both of which indicate that successful implementation requires staged use of a new solution and iterative cycles of feedback and revision to develop a population of "early adopters" that can 
credibly encourage adoption of the solution and its ultimate diffusion across a broader population.

Table I-2 below outlines the links between phases of the technology adoption process and relevant schools of thought. These principles will be revisited as the individual technology adoption process steps are explored in detail in subsequent sections of the report.

\begin{tabular}{|c|c|c|c|}
\hline Need identification & Solution identification & Solution evaluation & Solution implementation \\
\hline \multicolumn{4}{|c|}{ Market research science } \\
\hline \multicolumn{4}{|c|}{ Emerging Technology Analysis } \\
\hline \multicolumn{4}{|c|}{ Knowledge Mgmt. } \\
\hline \multicolumn{4}{|c|}{ Data Mining } \\
\hline \multicolumn{4}{|c|}{ Open innovation } \\
\hline & & \multirow{2}{*}{\multicolumn{2}{|c|}{$\begin{array}{l}\text { Discovery Driven Planning } \\
\text { Entrepreneurial Business Building }\end{array}$}} \\
\hline & & & \\
\hline & & & Adoption Theory \\
\hline & & & Mrktng. Science \\
\hline \multicolumn{4}{|c|}{ Innovation Best Practice / Technology Transfer Best Practice } \\
\hline
\end{tabular}

Table I-2: Schools of thought pertinent to the technology adoption process

\subsection{RECOMMENDED BEST-OF-BREED TECHNOLOGY ADOPTION PROCESS FOR INDOT}

Building on the insights into success factors and challenges of technology adoption described above, the following sections outline a recommended "best-of-breed" technology adoption process for INDOT inspired by a range of disciplines including and beyond transportation. For clarity the process is first introduced at a high level, and then each process phase is explored in greater detail.

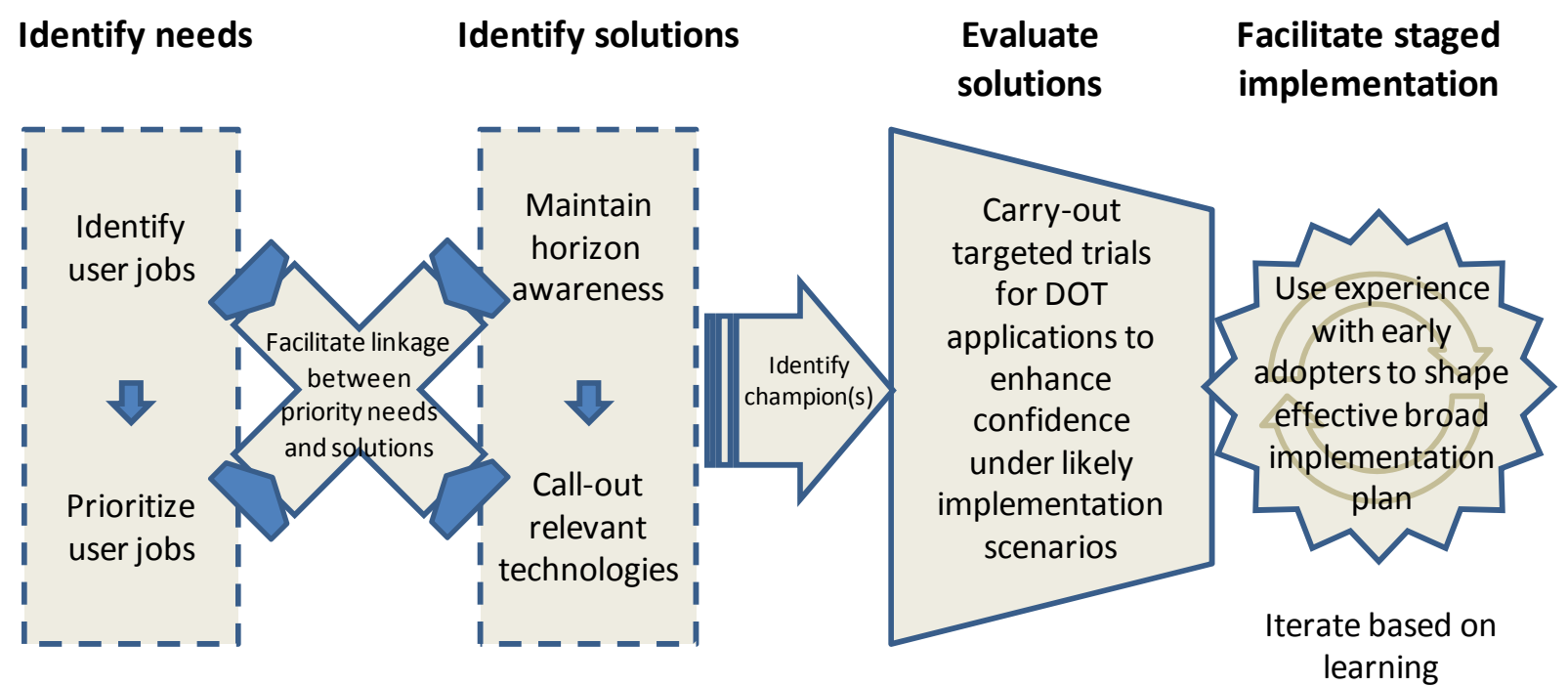

Fund, support and guide overall process through advisory group

Figure I-4: Recommended best-of-breed technology adoption process. 
At a macro-level the recommended technology adoption process is illustrated in Figure I-4 and includes the following major activities:

- Identify needs: In this phase of the process, user needs (hereafter referred to as "jobs" explained in detail below) are periodically evaluated in conjunction with continuous monitoring of the technology landscape. This dual focus enables identification of needs as perceived by DOT personnel, as well as awareness of situations in which new technologies create a "need" (or opportunity) for improvement over current practices.

- Identify solutions: The emphasis in this phase of activity is on rapidly facilitating connections between proven or ready to use technologies (hereafter referred to as "solutions") and important, unsatisfied jobs (needs).

- Identify champions: Success in the adoption of a solution to address a critical job requires a champion that supports both the causal need and the identified solution to muster support at senior and end-user levels and to navigate the remainder of the adoption process.

- Evaluate solutions: In this phase, emphasis is placed on carrying-out targeted trials of identified solutions to important and unsatisfied jobs in representative DOT settings and contexts to enhance confidence under likely implementation scenarios

- Facilitate staged implementation: In the final phase, solutions that emerge successfully from evaluation are put to use in a staged process that emphasizes application by early adopters whose experience with the solution will provide credible evidence of its merits and encourage broader adoption across INDOT.

Each of these phases of activity is described in detail below.

\subsection{Identifying INDOT's needs}

The first aspect of the technology adoption challenge, and first step in the proposed best-of-breed process focuses on identifying INDOT's needs. These needs may stem from expressed dissatisfaction of leaders or other personnel with currently available means to carry out day-to-day activities (i.e., "needs" the organization is aware of), or may stem from awareness of new solutions that could foster marked improvements beyond currently achievable levels of performance, cost-effectiveness, or safety in INDOT activities. Currently, based on the review of literature, DOT activities, and best-practice in other industries performed for this study, DOT efforts to provide this insight face four major challenges:

- Need-identification processes employed by many DOTs are research driven and thus call attention to issues that are unlikely to have commercially ready solutions

- The primary source of input on needs for most DOTs is the leadership team, and those in senior roles may not be aware of important day-to-day needs of general personnel

- States are unable to rely on national need identification, for example through federal programs, as these efforts, while valuable, lack state-specific context and can thus overlook needs that are particularly important for a given state or highlight needs that are not necessarily relevant

- Awareness of opportunities for technology improvements tends to reside among a limited number of inefficiently networked individuals and is often limited to developments within the transportation sector

These issues, which are in many ways interrelated, are discussed in the context of INDOT below and recommendations are put forward to address them. 
INDOT has a highly effective process to identify research needs to address major challenges faced by functional areas throughout the organization, which is part of the triennial research planning exercise. "Needs" in the research initiative are "bubbled up" through the INDOT organization via a series of areaspecific focus groups involving functional area experts in the transportation sector as well as pertinent faculty (typically from Purdue). By design, this process is primarily focused on addressing problems for which there is no easily foreseeable solution, and thus research activity or a focused scan of literature is required to identify and shape state-of-the-art solutions.

While critical to the long-term effectiveness of the organization, the research orientation of the process and "senior/expert level" sourcing of needs, can have a tendency to miss the everyday challenges faced by personnel. There is a risk that these challenges may not be deemed significant enough to garner the attention of supervisory personnel or are inevitably de-prioritized relative to other issues when viewed through a research-oriented lens. Further, by its very nature, this process tends to foster "from-scratch" research-based development of solutions to posed challenges (which are subsequently managed through traditional technology transfer processes), rather than investigation of commercially ready solutions.

In contrast, for the task of identifying opportunities to adopt proven/user-ready solutions, lessons from corporate market research settings offer potentially valuable means to complement the strategic research initiatives. In a corporate setting, even for business-to-business organizations that may operate very early in a value chain, there is no better source of "needs" understanding than the end-user (Anthony and Sinfield, 2007). To this end, it is extremely valuable to go directly to personnel throughout INDOT and determine what they need.

Despite the desire to better understand what individuals "need", market research science has shown that often individuals have trouble articulating their needs. All too often, if individuals are asked "what they need", they tend to provide views on solutions - views that may be either uninformed, or biased by experience with solutions currently at their disposal.

To combat these challenges and still gain a robust view of true "needs", many organizations (e.g., Johnson \& Johnson, Procter \& Gamble, Motorola, Intuit) often employ a methodology referred to as "jobs-to-be-done" (Anthony et al., 2008; Christensen, et. al., 2007; Anthony and Sinfield, 2007; Sinfield, 2005). The jobs-to-be-done approach places attention on the primary problem that individuals are trying to address, rather than focusing on the current solutions they are using. In effect, the jobs-tobe-done approach separates the discussion of the problem from the discussion of solutions. Ultimately, this separation highlights opportunities to more appropriately address needs, and sheds light on challenges that may go unaddressed today or are currently addressed by what are termed "compensating behaviors" - when an individual has created a potentially functional although less than perfect solution to a problem, because no readily available commercial solution appears [to them] to exist. In the words of Ted Levitt, a famous Harvard marketing professor of a generation ago; "People don't buy $1 / 4$ " drills, they hire a solution to create a $1 / 4$ " hole". What Levitt was really saying is that if there were a better way to make the hole, someone would readily give up the drill. Building on this analogy, to focus the technology adoption process put forward in this study, it is recommended that determination of INDOT "needs" be rooted in a periodic "jobs to be done" analysis that can complement the existing focus group need gathering model.

To make this analysis efficient and practical, as part of this project the PI has developed the basis for a deep analysis of the "jobs" that INDOT personnel are trying "to get done" day to day (actual implementation of this analysis approach is demonstrated in Section III of this report). As is common practice, this analysis took the form of a series of "job surveys" targeted toward the various functional areas of INDOT. To date, over 360 core "jobs" have been identified that are believed to be generally 
important to various members of the INDOT organization for which technology (broadly defined) may offer new useful solutions. These jobs have been derived from brainstorming and extensive interviews and vetting with INDOT personnel. As an organizing scheme is ultimately required to link jobs to potential technological solutions, jobs have been grouped into functional areas (e.g., materials management, contract administration). For each of these areas, a short on-line survey was created to assess the "importance" of each of the defined "jobs", as well as the level of "satisfaction" relevant INDOT personnel have with currently available solutions for these jobs. A snapshot of an example survey is provided in Figure I-5 (Note that the full set of surveys is provided in Appendix C). It is critical that these surveys have managerial support and be delivered to INDOT personnel through internal channels. The surveys must also be targeted to personnel who focus on the specific functional areas of interest.

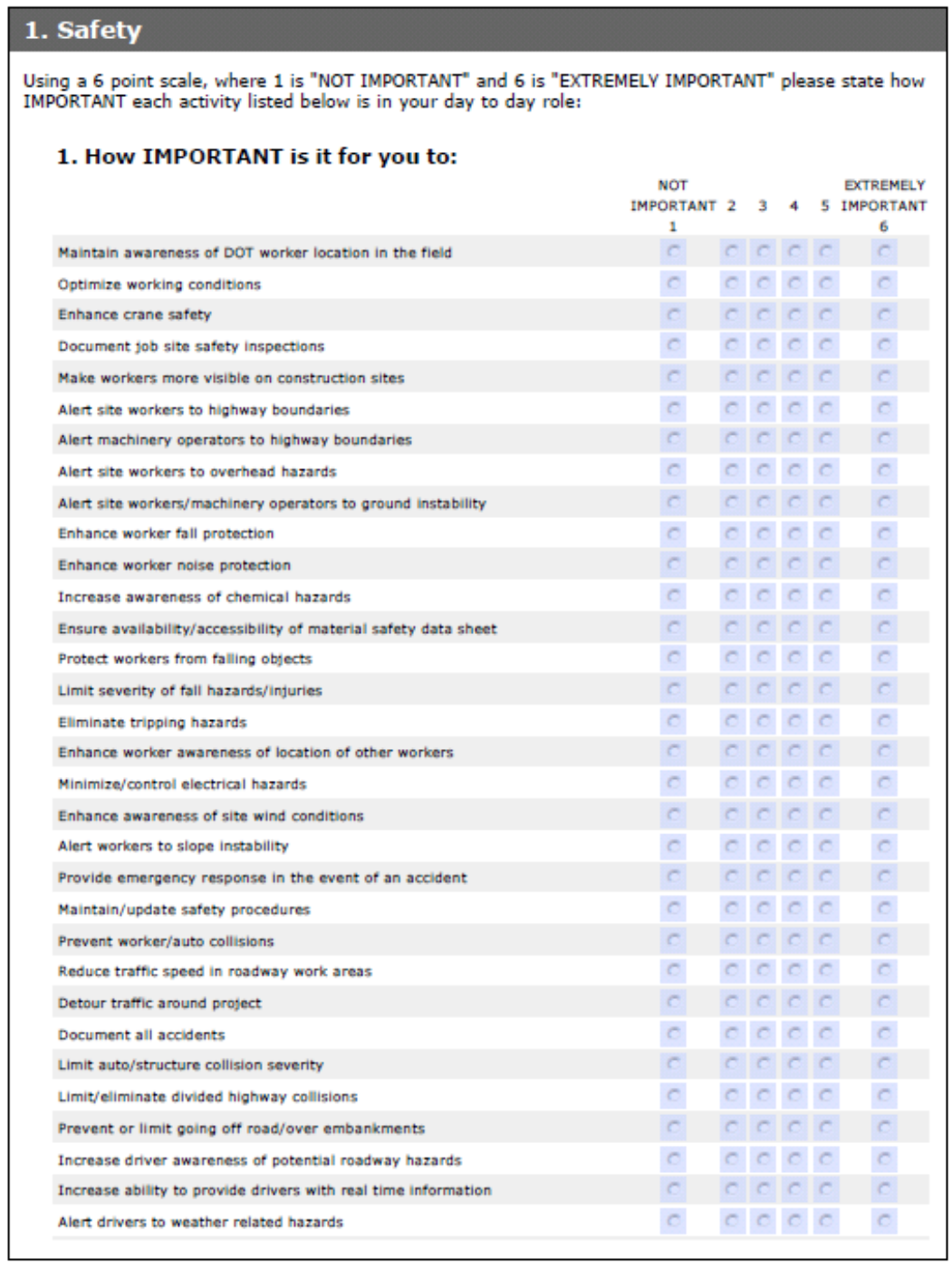

Figure I-5: Snapshot of "job" survey on safety.

Ultimately, all of the jobs assessed through these surveys can be placed on an $x$-y graph mapping their importance and dis-satisfaction scores. Jobs that are highly important AND unsatisfied can then drive prioritization of efforts to search for relevant solutions. (Typically, important but well satisfied jobs benefit only minimally from new advances, and are thus less valuable to pursue). 
Once established, prioritized jobs provide a lasting, strategic view of the true needs of an organization and can be very valuable in driving future searches for relevant solutions and in prioritizing the amount of resource dedicated to examine unsolicited promotions of technologies (e.g., from vendors). The jobs identified for INDOT are likely to be quite similar to those developed for virtually any other DOT (within the US), and thus there is great accrued value from performing the analysis as thoroughly as possible at the outset. The baseline surveys established through this work can be built upon and evolve over time. It is recommended that the jobs surveys be updated and repeated annually to ensure appropriate focus for on-going technology adoption efforts. Ultimately, if INDOT personnel observe that the surveys drive action (in the form of new solution adoption), incentive to complete the surveys will increase and the results will become increasingly beneficial.

\subsection{Identifying relevant, ready-to-use solutions}

Effective identification of means to address priority needs requires awareness of available technologies that could satisfy DOT jobs-to-be-done. These "solutions" must be identified within and beyond the transportation sector. Due to the historical focus of transportation-related technology transfer on research end products (i.e., situations in which the technological solution is prescribed), little attention has been given to the massive challenge of methodically finding "off-the-shelf" technologies of potential relevance to DOT operations.

One notable exception to the traditional research-based solution identification activity pertains to the activities of the AASHTO Technology Implementation Group (TIG). As excerpted from TIG's website (http://tig.transportation.org/), the role of the organization is as follows:

“AASHTO's Technology Implementation Group - or TIG - scans the horizon for outstanding advancements in transportation technology and invests time and money to accelerate their adoption by agencies nationwide.

Each year, TIG selects a highly valuable, but largely unrecognized procedure, process, software, device, or other innovation that has been adopted by at least one agency, is market ready and is available for use by other interested agencies.

Guided by the vision of "a culture where rapid advancement and implementation of high payoff, innovative technologies is the expectation of the transportation community," TIG's objective is to share information with AASHTO member agencies, local agencies, and their industry partners to improve the Nation's transportation system."

TIG's achievements have indeed been very valuable for the transportation community having championed the widespread adoption of technologies such as cable median barriers, thermal imaging of commercial vehicles, and GPS. However, the group maintains an exceptionally narrow focus (choosing to pursue only a handful of technologies each year) and relies on expert input (Standing Committee on Research (SCOR) and the Research Advisory Committee (RAC)) to guide selection of its priority technologies, which are typically truly state-of-the-art. In the context of the work herein, it is desirable to mimic the effective targeting of relevant, user ready technologies performed by the TIG, but on a broader scale, spanning technologies of both greater and lesser significance. Once again, the search for solutions employed outside the transportation context may broaden the arguably narrow solutionseeking perspective currently employed by DOTs.

The notion of "horizon scanning" (Stevens et al., 1999) is of particular value and should involve investigation within and beyond the transportation sector. This practice is well developed and has been employed in multiple contexts involving complex needs (e.g., the National Horizon Scanning Centre in 
England has employed horizon scanning processes in the Euro-scan collaboration pursued to identify and share healthcare practices among six participating countries) (Stevens et al., 1999). Historically, technologies that have enabled new levels of performance, and even discontinuous or disruptive change, have often come from outside of the affected industry (e.g., hydraulics as a disruptor of cable excavation equipment, electronic word processing as a disruptor of mechanical typewriters, fiber optics as a discontinuous performance improvement to cable telephony) (Christensen, 1997). The sheer breadth of this challenge combined with the reality of the limited resources available for horizon monitoring within a public organization like INDOT demands efficiency in any process intended for this purpose.

When considering horizon scanning for relevant technologies, much can be learned from the processes that companies use to track emerging technologies. Technology scanning is a routine aspect of corporate operations and tends to fall into two major areas of activity: 1) finding technologies that could enhance the capability of an organization, and 2) finding technologies that could undermine the capability of an organization (referred to by some as the pursuit of competency-enhancing and competency-destroying innovations (Tushman and Anderson, 1986; Anderson and Tushman, 1990)). Much of the attention dedicated to the latter topic is driven by corporate concerns about obsolescence and the sustainability of long term competitive advantage. To this end, the identification of a "threat" technology can be complicated by the fact that the purveyor of that technology may not want to be discovered until well established. Further, the potential for a technology to progress and address a given need over its lifecycle may be unclear. The task of identifying a competency enhancing technology, on the other hand, is notably easier given that those who have the technology typically want to be found a case that more closely represents the situation here.

Nonetheless, technologies that may be relevant to the "jobs" of interest can come from many avenues. One of the most important steps in a technology search, therefore, is to define the scope of the search. McKee et al. (undated) discuss a phase of "scoping and preparation" that should precede any organized, on-going search activity. Similarly, Anthony and Sinfield (2006), call out the need for "goals \& bounds" that will focus a pursuit of innovative solutions and delineate the nature of solutions that are desirable, discussable, and unthinkable to the organization conducting the search. The intent of these pre-search phases is to ensure that only technologies that have legitimate potential to be adopted are explored, thus saving time and enhancing the overall efficiency of the process. Different criteria are used by different authors to define the scope of a technology search, but in the context of the INDOT related search, the authors of this report believe the following criteria are most helpful:

- Does the technology address an important, unsatisfied job?

- Is the technology commercially available or exist in a ready to use form?

- Is the cost of the technology justified by the nature of the need addressed?

- Is the technology currently used in the target circumstance (e.g., in DOT contexts)?

- Can the technology vendor be supported through tax payer dollars?

- Is the technology vendor capable of servicing an organization of INDOT's scale?

- Do resources with required skills for implementation of the technology exist within INDOT?

- Is the new technology compatible with existing systems and practices?

Even after defining scoping criteria (which should be routinely revisited throughout a search exercise and incorporated in search tools and processes as described below), the challenge of actually finding relevant technologies remains. This is a point where a shift from an "emerging technology" mindset to one rooted in the principles of "open innovation" can be helpful (Montara et al., 2009). While a search for emerging technology might encompass scans of research developments, public announcements of theoretical possibilities, analysis of corporate, government, academic, or venture capital investments 
and reviews of patent filings, for the goals of this effort, it is desirable to find commercially available and/or ready to use technologies that can be adopted and employed in the near term. Here, a different set of avenues exist to gain awareness - avenues that are the mainstay of open innovation processes.

On this front, several major corporations have made concerted efforts to embrace open innovation methods. IBM has run on-line "innovation jams" with as many as 150,000 participants from more than 100 countries to gain awareness of new ideas, and Eli Lilly created a focused unit, called InnoCentive, to obtain input from the global scientific community (Sewell, 2010). Further, Procter \& Gamble represents one of the greatest advocates of employing open innovation concepts to bolster its capabilities. In 2006, then CEO A.G. Lafley declared that the company needed to shift its mindset from "not invented here" to "proudly found elsewhere" (Huston and Sakkab, 2006). This mandate led to a systematic shift in the company's approach to technology awareness and utilization that offers several key insights for INDOT. Most importantly, an efficient on-going horizon scanning process founded on open innovation principles should involve targeted outreach to gain awareness of potential solutions as well as effective means to manage in-bound (solicited and unsolicited) technology leads.

With regard to outreach, the challenge again has two aspects: one element of the effort is focused on in-industry awareness and the second is focused on observation of relevant developments outside the transportation sector. Arguably, INDOT, and DOT's in general, already possess many successful approaches to understand what is happening within the transportation industry. Effective and successful programs include NCHRP's Peer Exchange Program (Harder, 2001), Product Demonstration Showcases (e.g., as run by the LTAP Programs (http://www.pdshowcase.org/home) ), FHWA's Priority, Market-Ready Technologies and Innovations initiative, and the International Highway Technology Scanning Program carried out by the FHWA in cooperation with the AASHTO and NCHRP (USDOT FHWA, 2008). All of these programs provide the opportunity to enhance technology awareness and exchange information. The key challenge with these programs, however, is that they typically involve participation by a wide range of individuals that do not necessarily have formal links to each other within a DOT. Thus there is little means to centralize the knowledge gained by participants.

Companies skilled in technology scanning combat this problem by designating specific resources (people, and small budgets) for the sole purpose of maintaining technology awareness. P\&G, for example, maintains a crew of 75 global "innovation scouts" (McGregor, 2007). Wyeth Consumer Health runs a Scientific Landscape Team. Similarly, Unilever, Frito-Lay, Eastman Chemical, and Johnson \& Johnson's Ethicon Endo-Surgery Unit have "technology scouting" teams (Paap, 2009). These teams centralize responsibility for the scanning function. This ensures that all insights are given equivalent attention, and creates a locus of information for technology adoption decision making. In this context, it is recommended that INDOT dedicate a small pool of partial FTE resources as the core of a technology scouting team. This point provides a direct avenue to combat one of the key challenges of technology transfer and adoption reported by Harder and Benke (2005), which is the fact that the transportation sector generally lacks "transfer agents" - i.e., those who have a cumulative knowledge of available solutions and a simultaneous awareness of what is needed by end-users. As envisioned, members of this scouting team would participate in the array of already existing knowledge sharing activities outlined above, have a responsibility to synthesize insights gained to maintain INDOT's state of awareness, and be well informed on the results of the end-user jobs analysis defined earlier.

When considering the potential of technologies outside the transportation sector, efforts can be guided by a process sometimes called "backward scanning" (McKee et al., undated), which focuses on outlining individuals, organizations, or industries that may share challenges similar to those of the entity conducting the technology scan. Further, this scan can be focused on groups that are deemed to be 
early-adopters of technologies that are likely relevant to INDOT operations (e.g., NGO's, municipal services, military) (McKee et al., undated). As discussed by Sinfield in the article "A Structured Approach to Technology Assessment" (Sinfield, 2005) this process can be rooted in the foundational jobs obtained directly from end users. Effectively, end users that share the same fundamental jobs-to-be-done are likely to seek mutually relevant solutions. This "synergy of need" is of course circumstance specific. Thus, while those constructing concrete roadways are likely to share "jobs" with those building concrete residences, those interested in night-time safety may include the military and municipal services such as fire and police in addition to personnel involved in night construction. With this in mind, the technology scouting team described above could potentially be comprised of representatives from the various functional units of INDOT and these individuals should, to the extent possible, attend additional trade shows, expositions, or conferences outside the transportation sector. Definition of the exact venues to attend could be driven by an understanding of which INDOT jobs are indeed important and unsatisfied, as well as a focused, low-cost, web-based examination of the activities of professional/commercial societies in the potentially pertinent fields of interest.

Finally, management of in-bound leads on new potentially relevant technologies has historically been challenging for DOT's. Harder and Benke (2005) points out that, when dealing with technology vendors, there is often a misunderstanding of receiver needs, inappropriately presented technology, and significant time is spent on technology that is not suitable for the environment in which DOT's operate. These challenges point to the fact that efficient in-sourcing of technologies requires that those with solutions understand those who have challenges to be addressed. An industry leading mechanism to facilitate desired interactions with technology vendors efficiently and at low cost is exemplified by Procter \& Gamble's “Connect \& Develop" program (Huston and Sakkab, 2006). This program makes use of a web portal that clearly outlines the specific needs of P\&G (on a "job" by "job" basis) and provides a formal set of criteria that must be addressed by responsive solutions. The portal is centralized and is reviewed with screening criteria in mind to rapidly define next steps for each inbound idea. It is recommended that a similar portal type structure be developed for INDOT so INDOT can proactively and cost effectively solicit solutions to its important and unsatisfied jobs. The priority of jobs to be done, as defined by users, will serve to streamline this process and will also limit the number of irrelevant enquiries.

Overall, in all of the technology monitoring efforts outlined above it is critical to build on the scoping exercise that focuses the search by bringing in the insights of those who "know where to look". To this end, Robert (1999) calls attention to the formation of sentinel groups that have keen awareness of new and potentially relevant developments. While the notion of creating an advisory board for specific initiatives is commonplace in the transportation arena - for example, INDOT's Strategic Research Planning Focus Groups, CalTrans Research and Technology Advisory Panel (RTAP), the FHWA's Research \& Technology Leadership Team, or TIG's Standing Committee on Research (SCOR) and the Research Advisory Committee (RAC) - the keys to long term success are to centralize the function of collecting advisory board counsel for the specific mission of proven/ready to use technology adoption, and to populate these guidance committee's with individuals that have perspectives beyond the transportation sector.

\subsection{Linking INDOT's needs and solutions}

Once deeply rooted needs (here, important and unsatisfied jobs to be done) are identified at scale, and sources of potentially relevant technological solutions are clear, the next challenge is to efficiently link these needs to potential solutions. The problem of linking needs and technologies is also multifaceted. Part of the challenge relates to accurately defining the need as discussed in 5.1 above, preferably in the context of a job-to-be-done. Another part of the problem is tied to casting a broad net to find 
technologies that may be relevant to the needs, as described in Section 5.2. Finally, the last aspects of the problem relate to making the user (one with the need) and the vendor (one with the solution) aware of their mutual potential, and assessing the degree to which the technology can actually satisfy the need within associated constraints.

This last aspect of the problem actually has two sides as well. First, the DOT must accurately track those technologies about which it is aware. Second, the DOT must have an efficient means to manage inbound leads on new potentially relevant technologies.

This latter challenge calls for an effective means to index information, improved search tools, and a more robust system of transfer agents that can effectively connect technologies and users. Currently, in the transportation sector, insight into available solutions is documented in multiple databases (again with a focus on research-derived end products), such as FHWA's Database of Priorities, Market-Ready Technologies, and Innovations, the FIATECH catalog of Emerging Construction Technologies, the Research and Innovative Technology Administration database, or the Transportation Research Information Services (TRIS) bibliographic database. These databases, while extremely valuable, are quite disparate in their topical coverage and do little to provide insight into the wealth of commercially available/ready to use technologies on the market, especially in other industries. In response, Harder and Benke (2005) point to the benefits that would be gained from a national archive similar to the National Agricultural Library or the National Library of Medicine. The notion of a "national" database would indeed go a long way toward reducing the complexity of searching multiple disparate sources, again by centralizing technology content. Ultimately, however, the key enabler for any connection oriented tool is the indexing scheme used to archive the data, as a database is only as useful as one's ability to navigate it!

To enable a rapid ability to identify potentially relevant solutions for important and unsatisfied jobs, it is therefore recommended that INDOT develop a jobs-to-be-done based technology database similar to the databases used by consumer oriented companies to link consumer jobs and solution characteristics in market research initiatives. This database would archive all encountered DOTrelevant technological solutions according to the INDOT related jobs-to-be-done that they could address. With refinement, this archival mechanism could yield a robust framework for content management and dramatically streamline the recording and retrieval of job and technology information. Further, since the majority of DOTs carry out similar tasks (by transportation mode), the jobs-based archival system would have national value.

As envisioned, this database of DOT jobs and related technologies would be maintained and updated by the technology scouting team. It could be queried by any DOT personnel and thus would facilitate operations driven technology adoption. Any individuals not associated with the scouting team could also add content to the database. For example, they could add a newly observed technology and its potential use, or a new use for a previously archived technology. Any additions to the database would be required to include brief justification of the rationale for its classification under a given job and functional area - a description that would allow those searching for a solution to use their judgment as to the actual relevance of the technology for their challenge. Further, the technology would have to be labeled to define its alignment with the technology scoping criteria outlined in Section 5.2. Ultimately, it would also be desirable to label any archived technology with a "readiness level" tied to any specific jobrelated application (e.g., modeled after the robust technology readiness level system developed by NASA). This readiness level evaluation would provide a first tier screen with a focus primarily on whether or not to explore the job-solution combination, rather than an absolute in-depth review of the solution's ability to address the specific job at hand within desired specifications. 
Once a conceptually viable short list of technological alternatives is identified for any given important and unsatisfied job to be done, it will be critical to rapidly cull the list down to one or two possibilities that have the greatest potential to address the job at hand based on job-specific requirements. These short-listed options will then become the focus of a multi-phase championing, evaluation, and implementation effort described in subsequent sections of this report.

\subsection{Championing New Technologies}

Job-to-be-done and solution combinations that have merit should be championed through the remainder of the technology adoption process by individuals that are in supervisory roles and deeply understand the significance of the job-to-be-done and the potential merits of the proposed solution. The value of "champions" as drivers of change has been noted as a key success factor in researchderived technology transfer, as well as a host of other situations involving change management (e.g., disruptive innovation, Anthony et al, 2008; business building, Thompson, 2005) and is no less valuable in the transportation context.

The champion for any given concept can be identified by any number of means - self-selection based on personal passion in rectifying a given problem, selection by a technology scout or member of an operational unit that seeks support, or at the request of senior leadership who believe the individual's skills are best aligned to champion the target idea. The champion will help architect the evaluation and implementation plans for the targeted technology. The champion is thus a point of continuity in the process and retains awareness of the catalyst for the adoption of any given technology as well as any changes to the nature of that technological solution that are deemed necessary as a result of testing and piloting efforts. Ultimately, the champion may be deemed an expert on the technology's effectiveness if adopted.

\subsection{Evaluating New Technologies}

Although approximately $75 \%$ of state DOTs have an organized evaluation program (NCHRP, 2004), evaluation can often be a bottleneck to overall technology adoption and several challenges are apparent in this process phase:

- Defining and conducting evaluation tests can be a slow endeavor that can reduce technology adoption momentum and lead to subsequently poor implementation

- Evaluation requests and/or activities for specific technologies or vendors are often redundant within and/or across states

- DOTs can be overwhelmed by evaluation requests from outside vendors

- There is commonly a shortage of time, funds, and staff for trials

- Although some states do have product evaluation lists, the lists rarely convey actual evaluation test results, and instead simply state that a technology has been "evaluated" leaving considerable confusion as to the merits of a technology for a specific application

- Evaluations are frequently requested and often performed for technologies that do not actually address pressing needs of DOTs

- The breadth of "needed" technologies leads to significant challenges in finding available expertise to conduct proper evaluations

State-based evaluation programs are of course bolstered by federal efforts to maintain evaluation databases (e.g., AASHTO's National Transportation Product Evaluation Program (NTPEP), The Highway Innovation Technology Evaluation Center (HITEC), AASHTO's Lead State Program on the Strategic Highway Research Program (SHRP), AASHTO's Product Evaluation List (PEL)). However, even these programs may be less effective than one would hope. While many query these databases in the hope that they may find a pertinent solution to a job they may face, few individuals actually take the time to 
enter data into these systems. Further, as mentioned earlier, national programs may not focus on technologies that are necessarily relevant to the specific circumstances of a given state. In addition, PELs do not "push" findings to users, so instead users must rely on clever use of search terms to find evaluation information that may pertain to their needs. Finally, even when a relevant evaluation is identified in a federal or other state database, few states will actually accept the evaluation or recommendation, often leading to a "reevaluation" in the state's specific application setting. The sum of these challenges leaves considerable room for improvement in current evaluation practices.

As a starting point, it is recommended as part of the best-of-breed process that all evaluation efforts within INDOT be centralized to better manage evaluation requests and avoid unnecessary redundancy. Centralization of this activity can also enable management of a small pool of funds for trial. This pool can best be utilized by ensuring that, before any evaluation effort proceeds, it is clear that the solution to be investigated actually addresses a priority "need" as identified through the process outlined in Section 5.1 - this will prevent unnecessary evaluations from taking place. Further, to better manage the breadth and complexity of evaluation activities, "evaluation" should be made part of the official responsibilities of select representatives in key functional areas. While an ad-hoc, partial FTE commitment, this approach will ensure that appropriate expertise is involved in an evaluation and will also help uphold the need to fully document and record the findings of the evaluation so they can be located and used by those within and outside the DOT. Finally, it is recommended that the output of evaluations be standardized in a format that captures not only the outcome of the evaluation activity but also the performance results observed in the trial. This will enhance the potential to make decisions on the applicability of any given solution for future applications.

Beyond these recommendations, there is also opportunity to simplify evaluation procedures (and thus reduce their overall cost and time) to focus more specifically on "what has to be true" for a solution to be effective in its intended application. While this may seem obvious, it is clear that evaluation tests in the transportation sector often take the form of "full-scale" trials, many of which involve multiple variables and considerable complexity. This approach increases the resources required for trials and thereby limits the number of new solutions that can be investigated within a prescribed budget.

An alternate approach may be found in the way uncertainty is managed by organizations that attempt to pursue new forms of innovation within existing companies or try to pioneer the creation of new organizations as entrepreneurs. Parallels between these sectors and the challenge of transportation technology evaluation are numerous: the actual effectiveness of a solution may be unknown until applied in the exact context under consideration, the propensity for adoption by end users is always an estimate until proven, predictions of the financial implications of the initiative are inevitably uncertain, and the talent required to navigate these uncertainties is unique and rare.

To address exactly these types of challenges, intrapreneurs and entrepreneurs have adopted a technique called Discovery Driven Planning (DDP), which was framed for its value in assumption management by McGrath and MacMillan (1995). In this technique, effort is expended to define "what one would have to believe" for a given concept to be a success (rather than assess its alignment with an exhaustive set of "selection criteria"). Before doing any tests, these assumptions are reviewed and prioritized. First, the assumptions are assessed to determine the consequences if they are wrong. For example, failure for one assumption to be true could mean a new technology is completely ineffective, while failure of another assumption could mean that moderate modification to procedures is required to enhance its value. Second, the assumptions are assessed based on the likely cost to test the assumption. Ultimately, following a DDP approach leads to a rank-ordering of assumptions and related tests, with the most critical assumption that can be tested for the least amount of cost and time at the top of the list. This list than becomes an action plan that is used to guide activity in the subsequent 
phase of the process outlined below (i.e., assumption testing). Some assumptions will tie to the ability of a technology to meet requisite specifications. Other assumptions will relate to potential cost avoidance, improved safety, or enhanced efficiency. Still other assumptions will stem from the "usability" of a new technology and the likelihood that personnel possess the skills required to employ the technology. Over multiple rapid iterations of the process, it is likely that several tranches of assumptions will be identified for new DOT-related technologies that will make assumption identification increasingly efficient.

Incorporation of DDP principles into an overall assumption analysis process is put forward in great detail by Anthony et al. (2008) and is sometimes referred to as "emergent strategy", as the decision to proceed with any given concept takes shape as assumptions are ultimately addressed. The philosophy behind this approach is that one should pursue a new concept with a deep understanding that there is a high likelihood of failure, and thus expenditures and effort should be treated with caution and directed toward failing the idea fast - if this is not possible, confidence will grow in the idea and it becomes increasingly straightforward to justify further investment in the concept. Another key aspect of this process is that it encourages objectivity and problem solving in the consideration of a new idea, rather than simple "evaluation".

The DDP approach is in notable contrast to existing programs within the transportation arena that place a strong emphasis on evaluation criteria. For example, ASSHTO's TIG initiative requires technology advocates to assess a technology's state of development, payoff potential, and market readiness (http://tig.transportation.org/). Similarly, FHWA's Priority, Market-Ready Technologies and Innovations initiative asks technology supporters if a new technology supports agency priorities, including strategic goals, fulfills a user need, is likely to be implemented, is developed to a point of being truly market ready, and if the expertise to support deployment of the technology exists within the DOT. While all extremely valid questions, questions of this type do not force analytics, and affirmative answers (which advocates are highly likely to provide) can inevitably include embedded assumptions. Instead, it can be more valuable to make the assumptions prominent and define what can be done to "prove" the assumption. For example, what would one need to believe for a technology to be "truly market ready" and how could one prove this? Similarly, how could one demonstrate that skills actually exist to make use of a new technology? The difference between traditional evaluation and assumption analysis is subtle, but very powerful, and tends to ensure well-founded decision-making.

The concept of pursuing "trials" with new technologies is not new to DOT's. Multiple programs such as AASHTO's National Transportation Product Evaluation Program (Goddard, 2007) and IDOT's Experimental Feature Program (IDOT, 2009), and SHRP's Lead State initiative (TRB, 1999), have made use of trials to evaluate new technologies. However, these trials or pilots typically test multiple unknowns simultaneously and often at considerable expense. The key difference between these traditional testing strategies (often referred to as "deliberate strategy") and DDP/emergent strategy is that early assumptions' tests are intended to be quite small, and to the extent possible, only one assumption is tested at a time until a point at which confidence justifies a larger scale test (that would be more in-tune with the traditional pilot project). Effectively, DDP calls for a "series" rather than "parallel" analysis of assumptions. The rationale for this piecemeal analysis has been conveyed visually by Anthony et al. (2008) using a figure like that shown in Figure I-6 below. 


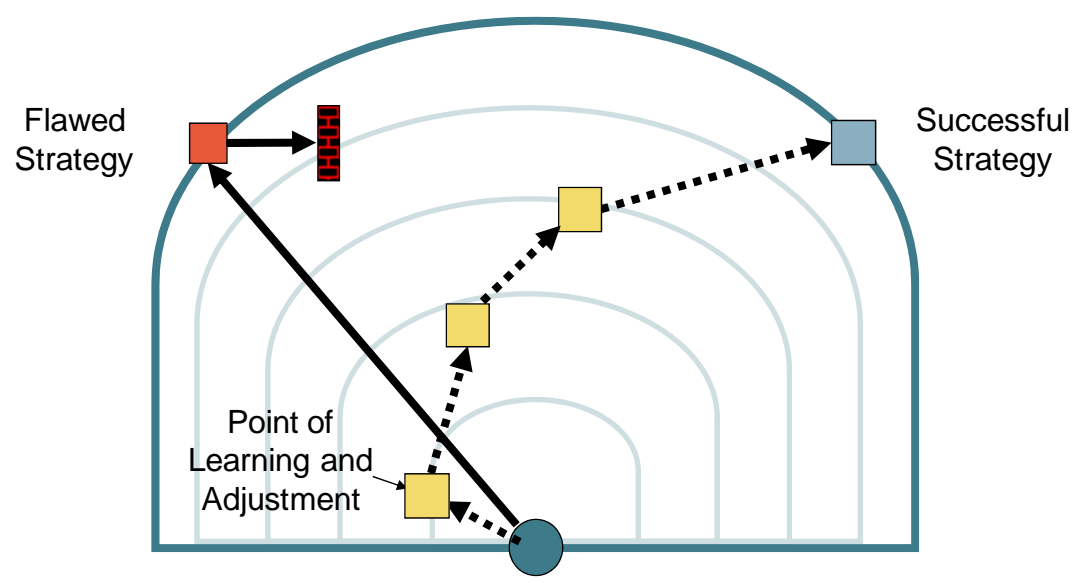

Figure I-6: Conceptual comparison of deliberate and emergent strategy (adapted from Anthony et al., 2008).

When a new idea is under consideration there are a multitude of ways that it can be pursued represented by the arch-like horizon in Figure I-6. Often, organizations "leap" in a select direction in an attempt to demonstrate rapid progress, only to find out this particular execution of the concept was flawed. By this time, those involved with the "trial" have expended their financial and social capital, limiting their ability to redirect, and ultimately leading to failure of the concept. Instead, an emergent approach calls for smaller steps involving a series of low-risk experiments that help "find" the right path.

This separation of underlying assumptions and low-risk testing enable rapid learning, responsive modification, and enhance the chances of successful long-term adoption. Numerous fields have found that they traditionally attempt to test too many assumptions simultaneously, unnecessarily increasing the risk and cost of tests, and enhancing the likelihood of a negative result (e.g., Wunker and Sinfield, 2009).

In summary, it is suggested that the proposed evaluation process follows a DDP approach, as shown in Figure 1-7. Key to this evaluation process are the previously discussed champions and the governance structure - to be described in latter sections of this report. 


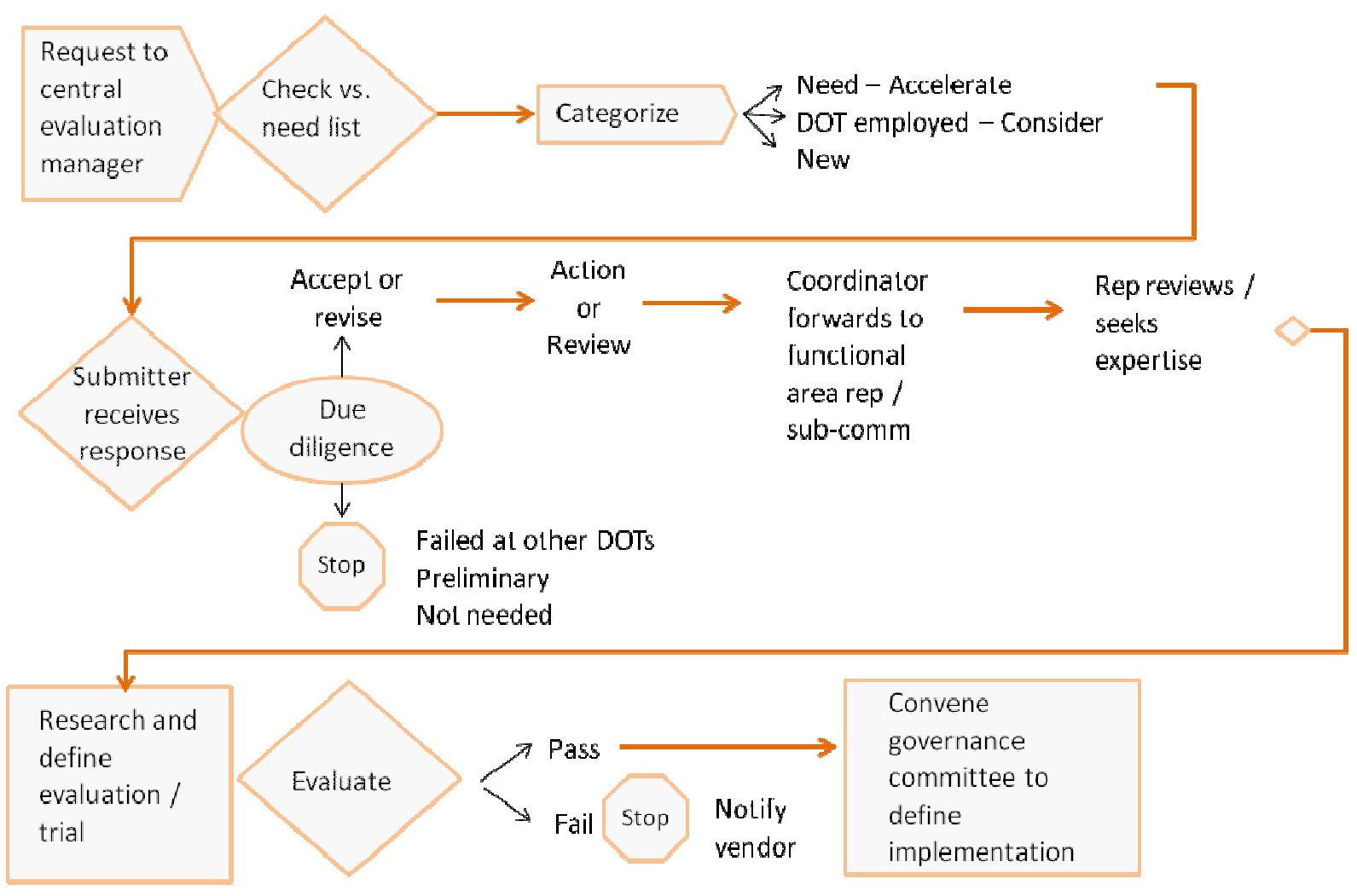

Figure 1-7: Overview of the recommended evaluation process

\subsection{Facilitating staged implementation}

Broad implementation of a new technology is reflected by successful adoption across a large portion of relevant DOT personnel. Just as with evaluation, achieving widespread implementation has its challenges. At a high level, three primary issues appear to limit success in implementation efforts:

- It is generally difficult to identify or engage an "owner" for a new technology adoption effort

- In most DOTs there is a lack of a systematic means to enable operating unit "pull" that will increase confidence in new solutions and encourage adoption

- Awareness of new technologies tends to be limited despite formal announcement channels

It is proposed here, that the first of these challenges can be addressed through the establishment of "champions" for a new technology (as described in Section 5.2). These champions should be involved in evaluation as well as awareness building aspects of implementation.

Addressing the second challenge, related to operating unit "pull", centers on creation of demand among users and development of their willingness to try the new technology. Such adoption behaviors can perhaps be best enabled by reflecting on the body of work that has shaped technology adoption/diffusion theory. Everett Rogers, author of the pivotal work "Diffusion of Innovations" (Rogers, 1962), has over time outlined two key frameworks that could be embraced to enhance technology adoption and successful implementation within INDOT. The first is referred to as the Innovation Decision Process theory and states that adopters of a technology progress through five stages in the diffusion process. Carr (1999) summarized this theory as follows: "First, they must learn about the innovation (knowledge); second, they must be persuaded of the value of the innovation (persuasion); they then must decide to adopt it (decision); the innovation must then be implemented 
(implementation); and finally, the decision must be reaffirmed or rejected (confirmation)." This process parallels very closely the purchase funnel traditionally used in marketing, a point revisited later.

The second framework is referred to as the Perceived Attributes theory and could be highly valuable in prioritizing potential technological solutions to priority jobs. This theory states that five key attributes are critical when encouraging adoption of a technology and were again summarized by Carr (1999): that it can be tried out (trialability), that results can be observed (observability), that it has an advantage over other innovations or the present circumstance (relative advantage), that it is not overly complex to learn or use (complexity), that it fits in or is compatible with the circumstances into which it will be adopted (compatibility).

In the early 90's these foundational frameworks were scrutinized by Geoffrey Moore, who authored "Crossing the Chasm". In this book, Moore substantiated what has become known as the technology adoption lifecycle (see Figure I-8) and indicated that a key obstacle to broad adoption of a technology (a transition from visionaries to pragmatists), requires successful crossing of the "chasm" between early adopters and the early majority. Moore defined the early adopters as visionaries that were extremely acceptant customers who value the potential of an idea and are willing to experiment with it to garner its benefits. In contrast, the early majority represents pragmatists that must see proven benefits from an offering and tend to have a small set of confidants that they judge as credible sources of that proof.

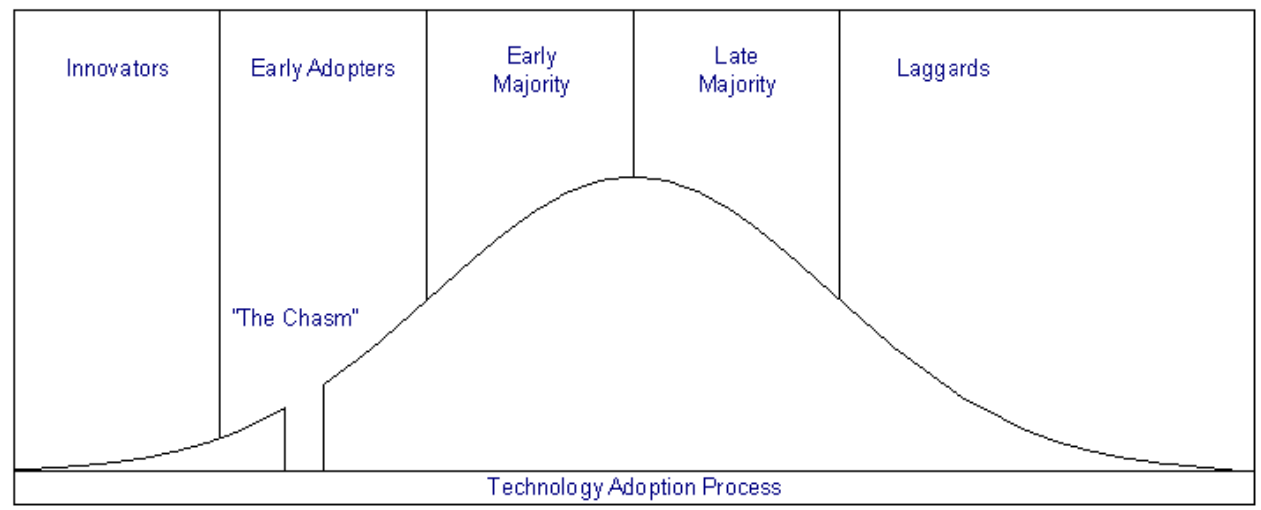

Figure 1-8: The Technology Adoption Lifecycle (after Moore, 1991).

Continuing this line of logic, Wilson et al. (1996), draw on an analysis of adoption of networked learning models in educational contexts, and point to several principles that appear to facilitate this crossing and are likely transferable to any technology adoption situation:

- Enable "first time success"

- Facilitate on-going "peer" support

- Align incentives to encourage natural adoption rather than a top-down mandate

Translated into the context of technology adoption for INDOT, one can see several valuable lessons. First, there is a need when considering any technology to identify visionary early adopters that are flexible and willing to deal with the inherent imperfections of that technology as a starting point for implementation. Second, these early adopters should be peers of the broader majority whose opinions will be valued. Further, effort must be placed on developing some of these early adopters into advocates who will communicate the more pragmatic benefits of a new solution and spur a "bottom-up" interest in the new technology, while at the same time helping the "top" of the organization rationally justify further investment. 
Thus, when planning evaluation tests and early pilots of a new technology, the technology champion should seek to identify users that are credible to the broader organization, amenable to a "less than perfect" initial experience, and extrovert in their willingness and tendency to communicate their perceptions and learning from early technology trials. While SHRP's Lead State program certainly encompasses some of these characteristics, it is important to consider these traits even in the early evaluation of a new technology when the outcomes of its use are relatively small scale. Also, the characteristics defined here are as indicative of the nature of the people that should be involved in the process, as the culture of their institutions.

Ultimately, rollout to the broader population of technology users requires a comprehensive strategy encompassing the following:

- Identification and characterization of the target user

- Coordination with marketing efforts to expand the base of actual users

- A robust training program for use of the technology that includes self-guided material if possible, as well as instructor led content for more complex technologies

- A user friendly means to evaluate and document the effectiveness of the technology in practice

- Recommended staging of the role out (e.g., by geography or unit)

- An estimate of requisite costs as a function of time for the roll-out and key milestones that would justify continued investment

Finally, to encourage awareness of new technologies and their merits, it is recommended here that marketing efforts be embedded throughout the overall technology adoption process, rather than simply be treated as a "phase" of process. The merits, and necessity, of effective marketing to encourage technology adoption are widely discussed in the transportation sector and the majority of reports on technology transfer listed in Section 2.0 make some reference to the value of sound marketing. Most recently, as part of the Technology Transfer Toolbox initiative, Harder (2004) put forward an in-depth discussion of the merits of a Marketing Plan Module that could help stakeholders throughout the transportation sector better convey the merits and value of new technologies. The components of an effective marketing plan are also well documented and can be found in references from texts to DOT training materials. Among the most robust overviews of an effective marketing plan in the transportation context stems from effort by the Technology Deployment Work Group, a partnership between FHWA, Indiana Division; INDOT; Purdue University; and JTRP (Harder and Benke, 2005). This group indicated that a marketing plan should include the following components:

- Needs assessment

- Project and technology description

- Technology analysis

- Technology background, profile, and analysis

- Description of current practice in Indiana

- Market profile and segments

- Technology support

- Cost-benefit evaluation

- Suggested funding sources

- Short- and long-term goals and objectives for implementation

- Recommended implementation strategies and requirements

- Action items

- Partners, personnel, task responsibilities

- Success measures 
While this structural approach to the description of a marketing plan is extremely valuable, there are at least two key components to a marketing program that could be enhanced to bolster technology adoption efforts. First, although represented as a "stage" in the overarching technology adoption process, as mentioned above "marketing," in its broadest sense, should actually be a continuous aspect of the process. Second, there is really no "one size fits all" marketing plan that can be used to convey the merits of a technology to encourage adoption. These points are inherently connected and explored in greater detail below.

The creation of a marketing program is rooted in what is sometimes called a "purchase funnel" (Court et al., 2009) (see Figure I-10) (a variant of the technology adoption curve discussed earlier).

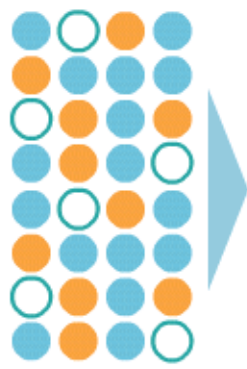

Awareness

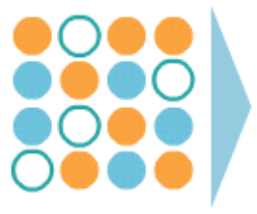

Familiarity

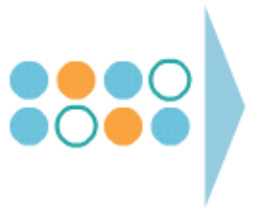

Consideration

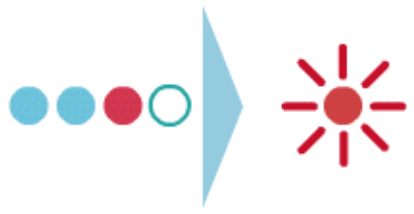

Purchase
Loyalty

Figure I-10: The traditional consumer purchase funnel (reproduced from Court et al., 2009).

The funnel reflects the fact that any potential consumer (here a potential "adopter"), goes through several stages of perspective when investigating a new offering (here a new technology). At first they must become aware that the offering exists. Then they must gain some understanding of its value (what it is, how it performs). If interesting, the offering may enter the consumer's consideration set and the consumer may "convert" (i.e., purchase) to use of the offering. If the consumer experience is positive after adoption the consumer will become loyal to the offering and could potentially be called about later for repeat purchase and advocacy (to gain the interest of others and broaden adoption). While developed in the context of consumer products, this same model has significant implications on the marketing of a new technology within a DOT. At each stage of the funnel, a different type of marketing is required - the nature of the audience, the key messages that must be conveyed, their format, the best vehicles to communicate these messages, and the decisions that must be influenced are all different. Marketing content, if you will, should vary based on audience and intent.

There is also an additional axis to the marketing equation which is represented by the "state of readiness" of the technologies being explored in the technology adoption process. The further back a technology is in the overall process, the fewer true facts are available to make a case for its adoption and the more qualitative criteria are important. Also, the earlier in the process the more focused the audience (e.g., an advisory board vs. all operations personnel) to whom communication is directed.

With these concepts in mind, Table I-3 outlines a potential means to structure marketing efforts based on key stakeholders and important marketing content by process stage. To the extent possible marketing information should be carried out using simple, inexpensive web-based tools like e-mail alerts and communities of practice that enable individuals to sign-up for information on their specific areas of interest, thus improving targeting of marketing messages and ensuring that awareness is developed in a rapid and cost-effective manner. Potential templates for these internal marketing documents are presented in Appendix D. 


\begin{tabular}{|c|c|c|c|c|c|}
\hline \multirow{2}{*}{ Stakeholders } & \multirow{2}{*}{$\begin{array}{l}\text { Linking jobs } \\
\text { \& solutions } \\
\text { Technology } \\
\text { Scouts }\end{array}$} & \multirow{2}{*}{$\begin{array}{c}\begin{array}{c}\text { Identifying } \\
\text { champions }\end{array} \\
\begin{array}{c}\text { Technology Board } \\
\text { Champions }\end{array}\end{array}$} & \multicolumn{2}{|c|}{ Evaluation } & \multirow{3}{*}{$\begin{array}{c}\begin{array}{c}\text { Solution } \\
\text { Implementation }\end{array} \\
\text { INDOT Supervisors } \\
\text { Other DOTs } \\
\text { Federal Agencies }\end{array}$} \\
\hline & & & $\begin{array}{c}\text { Technology Board } \\
\text { Champions } \\
\text { Vendors }\end{array}$ & $\begin{array}{c}\text { Technology Board } \\
\text { Champions } \\
\text { Vendors }\end{array}$ & \\
\hline & & & & & \\
\hline Awareness & 1,2 & 1,2 & $1,2,3$ & $1,2,3,4,6$ & $1,2,3,4,6$ \\
\hline Familiarity & 1,2 & 1,2 & $1,2,3$ & $1,2,3,4,6$ & $1,2,3,4,6$ \\
\hline Consideration & $1,2,3 a, b$ & $1,2,3 a, b$ & $1,2,3$ & $1,2,3,4,6$ & $1-9$ \\
\hline Conversion & $1,2,3 a, b$ & $1,2,3 a, b$ & $1,2,3,4,6$ & $1,2,3,4,6$ & $1-9$ \\
\hline Loyalty & & & & & $1,2,8,9$ \\
\hline
\end{tabular}

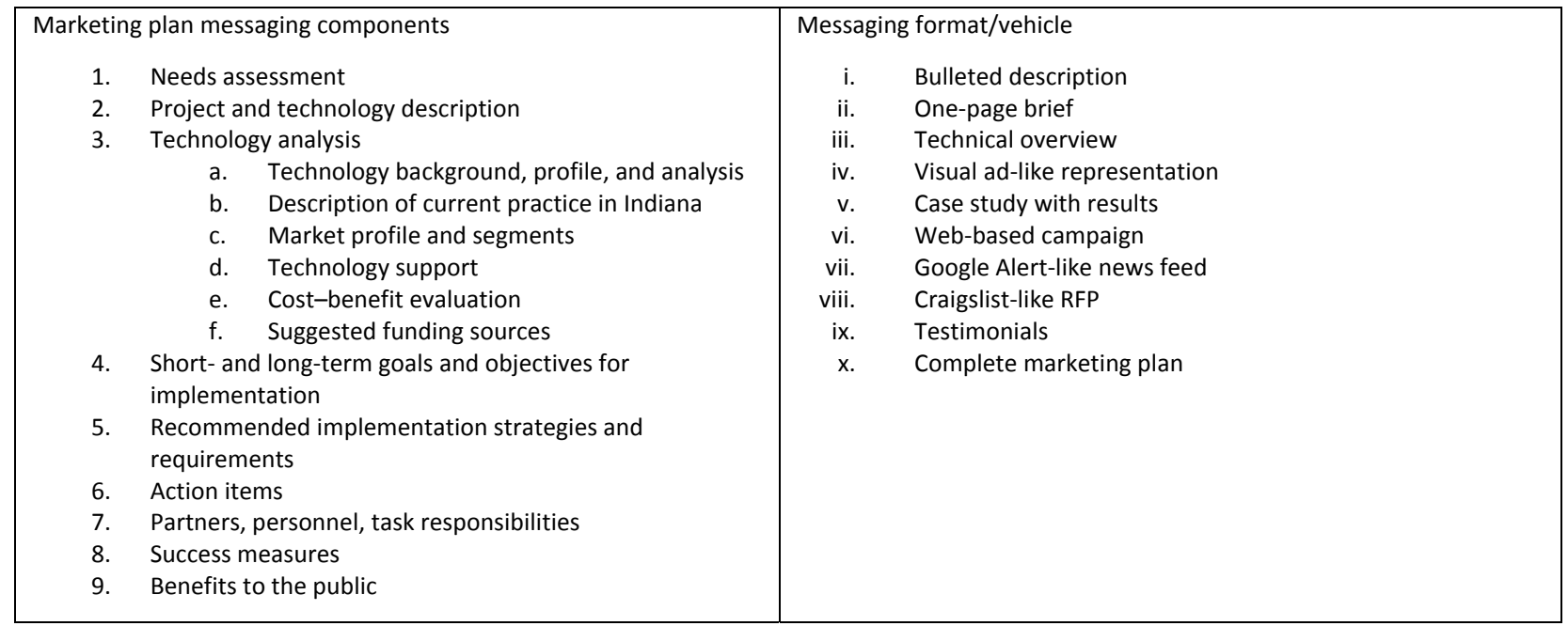

Table I-3: Marketing program structure as a function of technology adoption process stage and intent.

In summary, to the extent possible, the information included in marketing efforts should only be the minimum necessary to guide decision-making. Incorporation of additional information, or premature analyses, only increases the cost of the effort and conveys greater certainty than it truly exists or discourages users who may feel that there are too many unknowns to continue pursuit of the idea.

Overall, the discussion outlined above is oriented toward marketing efforts internal to the transportation community, and specifically DOT personnel, involved in the technology adoption process. External communication and marketing (i.e., to the public) should likely be left to true marketing professionals. At this level, INDOT resources should be focused on synthesizing information that professional marketers will need to develop effective marketing materials for a publicly visible initiative. 


\subsection{SUMMARY OF TECHNOLOGY ADOPTION CHALLENGES AND RECOMMENDATIONS}

A summary of the key challenges and related recommendations for a best-of-breed technology adoption process is provided below in Figure I-10 a-d.

\section{Key challenges}

Research driven processes call attention to needs that are unlikely to have

Leadership-based input can miss important

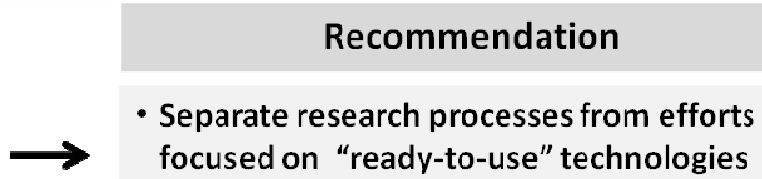

\}
- Field ANNUAL survey personnel to assess importance of activities and satisfaction with available solutions
National need identification, while valuable, lacks state-specific context day-to-day needs of general personnel

Figure I-10a: Recommended process improvement for Need Identification.

\section{Key challenges}

Historical bias toward transfer of research by-products vs. commercial/ ready-to-use technologies

A generally introspective view of technological options steeped in transportation sector experience

A need to better index information and enable better "finding tools"

Lack of transfer agents to link technologies and users

\section{Recommendation}

- Separate research processes from efforts focused on "ready-to-use" technologies
- Launch a user-friendly web community to manage outbound needs and inbound solutions (as well as "technology scouts")

Figure I-10b: Recommended process improvement for Solution Identification. 


\section{Key challenges}

Slow processes lose momentum leading to poor implementation

Evaluations for technologies are often redundant within/across states

Evaluation requests permeate DOTs

Shortage of time and funds for trials

Many evaluation lists simply state "evaluated" w/o commentary

While federal evaluation databases are used to some extent, few enter data due to time constraints

Evaluations are frequently requested for unneeded technologies

Breadth of "needed" technologies leads to significant expertise challenges for evaluation

\section{Recommendation}

- Centralize contact, process, and findings from evaluation activities

- Simplify trials to focus on "what has to be true"

- Dedicate small pool of funds to trial

- Formulate template to capture evaluation results

- Create dedicated resource for trial / evaluation management

- Screen evaluation need by "job" priority, and potential impact

- Make "evaluation" part of the job description for representatives of key functional areas (ad hoc, partial FTE)

Figure I-10c: Recommended process improvement for Evaluation.

\section{Key challenges}

Owner of need is either difficult to identify or hard to engage

A lack of systematic means to enable operating unit "pull"

Awareness of new technologies tends to be limited despite announcement

\section{Recommendation}

- Identify "champion" at evaluation stage and involve in implementation / word-of-mouth awareness building

- Involve mid- and base-personnel in need identification and solution vetting to build buy-in

- Leverage multiple low-cost messaging vehicles to enhance awareness and adoption

Figure I-10d: Recommended process improvement for Implementation. 


\section{SECTION II: GOVERNING AND SUPPORTING INDOT'S BEST-OF-BREED PROCESS}

As stated throughout this report, the process of adopting new technologies shares many of the challenges that are encountered when any organization tries to pursue innovation. From a structural perspective, Anthony et al. (2008) call attention to several organizational constructs that have proven successful in managing these challenges and facilitating the pursuit of innovation, and are thus likely transferable to the technology adoption process discussed herein. In this context, it is clear that orchestrating the overall technology adoption process requires careful governance by a guidance or advisory group, isolation and protection of resources (human and financial), as well as the involvement of people with unique skills who can fulfill expert content roles.

Figure II-1, depicts the proposed governance structure to oversee INDOT's process to adopt ready-touse technologies, which adopts these principles and, as envisioned, would operate independent of the more traditional research-based process.
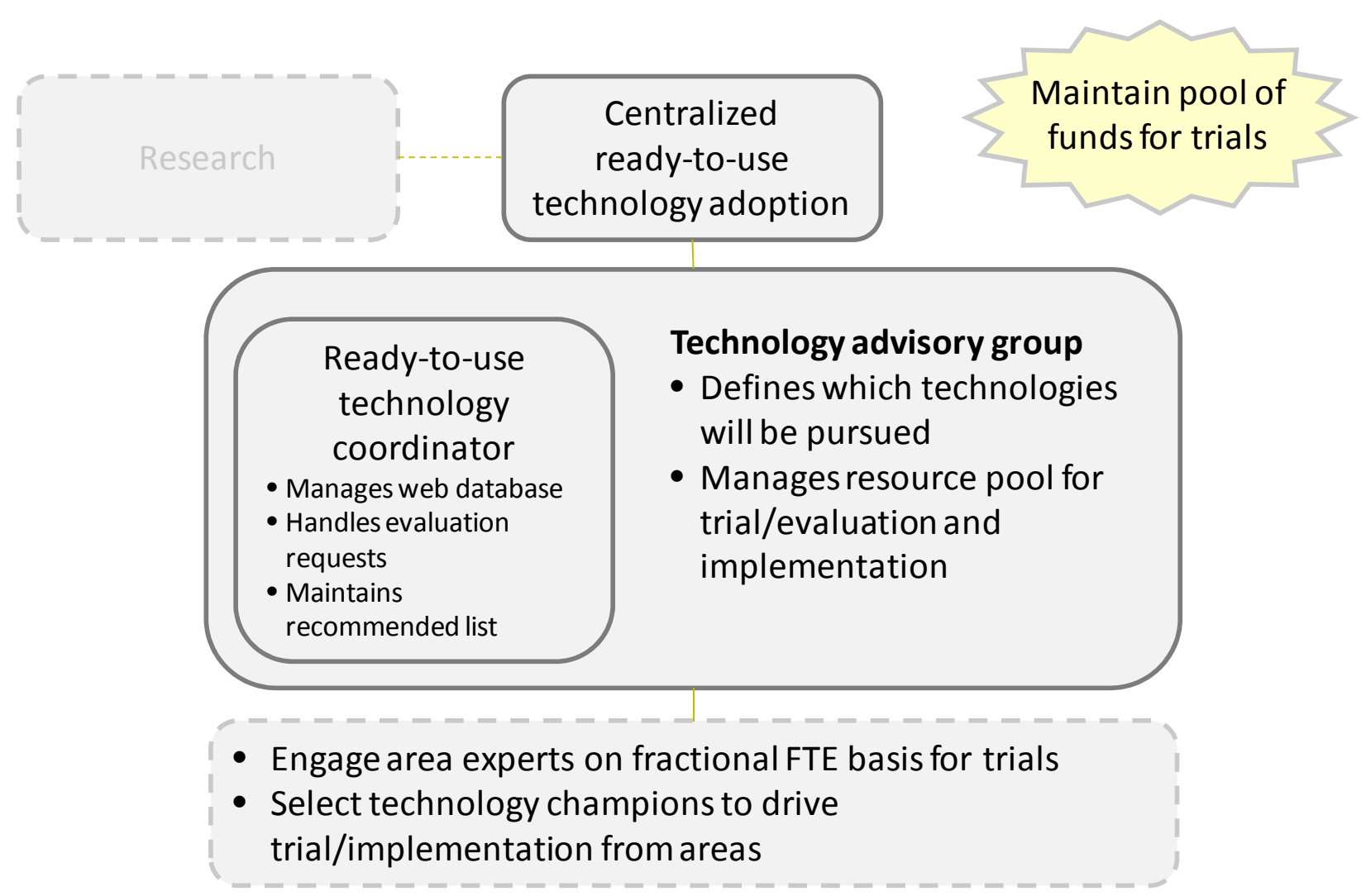

Figure II-1: Proposed governance structure to support the technology adoption process of INDOT.

Specifically, a "Technology Advisory Group" composed of a diverse (e.g., function, geography), but small set of individuals, is needed to shepherd technologies through the overall adoption process. The group would have two primary responsibilities:

- Decision-making - The group would define the most relevant technologies to drive through the process

- Resourcing - Decisions would also be made about funding and human resource support for approved evaluations tests and pilot efforts 
A key member of this group would be the "Ready-to-use Technology Coordinator", who would serve as a centralized contact to manage the web database employed to record needs and new technologies, handle and filter evaluation requests (and thereby prevent redundant or unnecessary tests), and ensure that evaluation findings and recommendations are thorough, actionable, and up to date.

The efforts of this group would be complemented by area experts that could be engaged on a fractional FTE basis to ensure proper performance of evaluation tests - as mentioned earlier this role should be called out as a formal responsibility for these individuals. Further, input from the technology champions (Section 1-5.4) and technology scouts (Section 1-5.2) would help inform the activities of the Advisory Group.

Overall it is important to isolate resources for this organizational unit to ensure that its mission can be achieved. These resources include funds to support personnel that periodically take on the role of technology scouts, dedicate time to evaluation of new technologies, champion new technologies and serve as members of decision making, advisory, and training groups that facilitate the overall process. From a monetary perspective, resources are required to carry-out evaluation activities, marketing initiatives, and post-implementation evaluation and monitoring necessary to ensure that true operational advances result from newly adopted technologies.

Finally, from a human resource perspective, the individuals that carryout technology scouting, assumption testing, and general oversight of the technology adoption process must have a mindset and the skills to manage the uncertainty and dynamic nature of the process. Dyer et al. (2008) recently carried out a study of innovative entrepreneurs and demonstrated that they tend to differ from operationally oriented personnel (e.g., successful managers) in four behavioral patterns (1) questioning; (2) observing; (3) experimenting; and (4) idea networking. These traits are deemed to be extremely valuable in the pursuit of innovation and are also likely the characteristics needed to navigate the technology adoption process outlined herein. To this end, it is recommended that individuals participating roles described above display strong spikes in these areas. 


\section{SECTION III: TECHNOLOGIES OF INTEREST FOR INDOT}

\subsection{INDOT'S JOBS-TO-BE-DONE}

To initiate the best-of-breed technology adoption process, the PI and his research team performed an analysis to identify "jobs" believed to be generally important to various members of the INDOT organization for which technology (broadly defined) may offer new useful solutions. An extensive list of 363 tasks and activities was developed through discussions with leaders in each of the functional areas of the INDOT organization. These tasks were then prioritized by requesting input via focus group and survey on two key questions:

1. How IMPORTANT is this task in your day to day role?

2. How SATISFIED are you with available methods, tools, or technologies that help you perform this task?

Responses to these questions were grouped based on the organizing scheme used to manage research needs focus groups carried out from 2/4/10 to 2/12/10 which highlighted the following areas:
A. Transportation Planning, Finance, and Policy
B. Program Engineering and Pavement
C. Design and Production
D. Construction and Contracts
E. Traffic Safety and Management
F. Maintenance and Operations

In total, 38 individuals recognized as leaders in their respective functional areas provided input on the task prioritization. Figure III-1 presents average ratings given to each of the 363 tasks and activities studied in the form of a plot of importance ( $1=$ low importance to $6=$ high importance) versus dissatisfaction ( $1=$ low dissatisfaction to $6=$ high dissatisfaction). Jobs that are highly important AND unsatisfied drive our prioritization of efforts to search for relevant technologies. (Typically, important but well satisfied jobs benefit only minimally from new advances, and are thus less valuable to pursue). Note that Figure III-1 is not intended to call out individual tasks, but instead to illustrate the broad distribution of results among the tasks assessed. This spread is a positive and reassuring result as it demonstrates that respondents observed significant differences between the tasks and were therefore likely providing valid input. (The full set of job survey results are presented in Appendix E).

Tasks were ranked by priority according to their respective Importance-Satisfaction (I-S) Factor. The I-S factor is defined as the distance of the task from the point of highest importance and highest dissatisfaction when mapped in Figure III-1 (the upper right corner). The lower the I-S factor the higher the priority. I-S factors less than 2 are considered high priority, 2 to 3 are considered medium priority, and those above 3 are low priority. Tasks falling on the same arc of distance from the high importance, high dissatisfaction coordinate $(6,6)$ are ranked at a secondary level in order of overall importance. The top 30 out of 363 tasks are shown in Table III-1. 


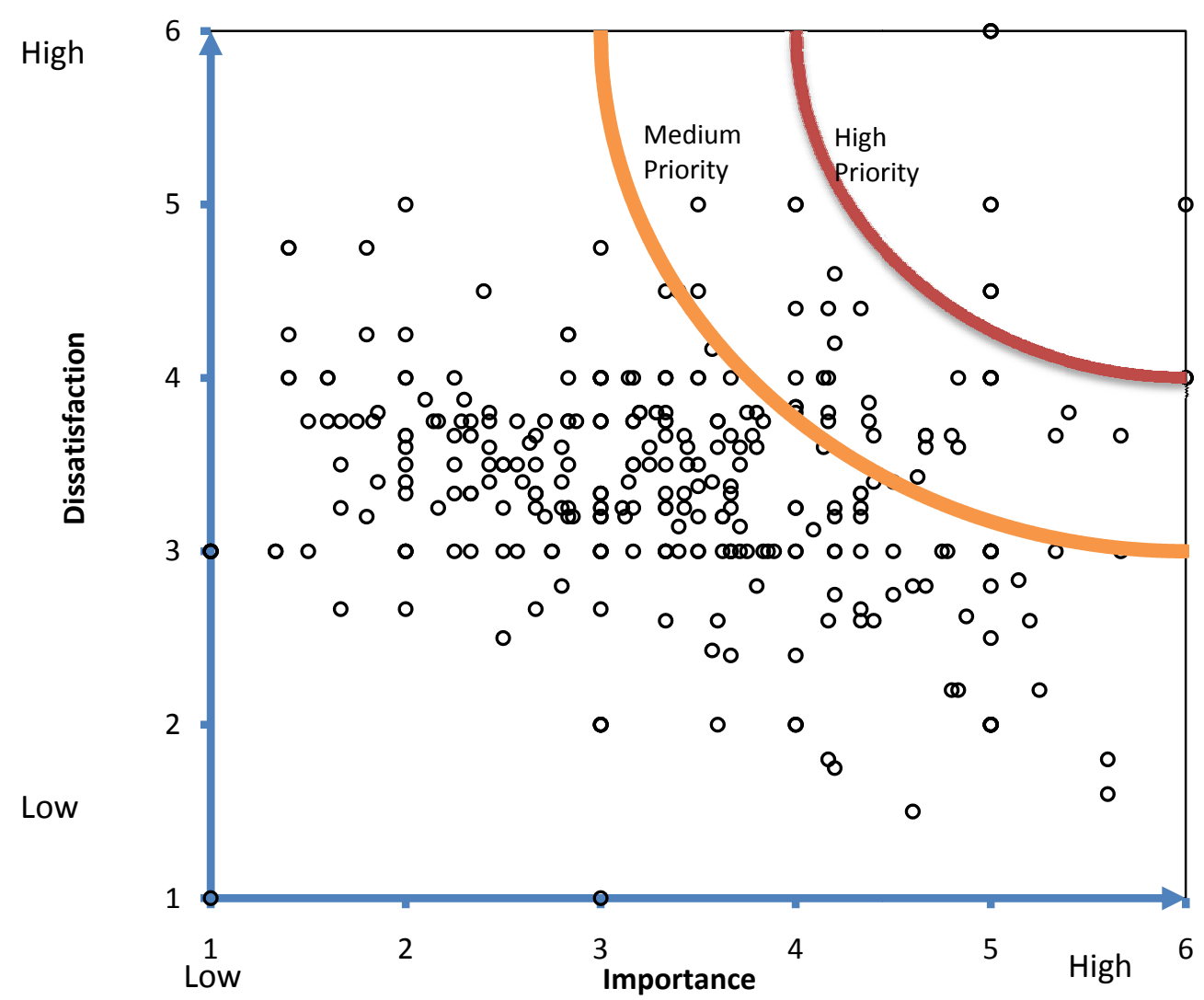

Figure III-1: Relationship between task importance and dissatisfaction for all 363 evaluated tasks.

\begin{tabular}{|c|c|c|c|c|c|}
\hline Rank & I-S & Task & Rank & I-S & Task \\
\hline 1 & 1.0 & Design erosion control systems & 16 & 2.2 & Create mix designs for pavements \\
\hline 2 & 1.0 & Design water removal/control sys. & 17 & 2.2 & Design drill shafts \\
\hline 3 & 1.0 & Perform seismic design & 18 & 2.2 & Design earthwork \\
\hline 4 & 1.0 & Remediate land slides & 19 & 2.2 & Design sheet piles \\
\hline 5 & 1.4 & Design lateral earth support struct. & 20 & 2.2 & Examine soil stratigraphy \\
\hline 6 & 1.4 & Design pavement sub-grades & 21 & 2.2 & Monitor bridge long-term deflections \\
\hline 7 & 1.4 & Design reinforced embankments & 22 & 2.3 & Evaluate box beam post-tensioning \\
\hline 8 & 1.8 & $\begin{array}{l}\text { Limit auto/structure collision } \\
\text { severity }\end{array}$ & 23 & 2.3 & Protect bridges from steel corrosion \\
\hline 9 & 1.8 & $\begin{array}{l}\text { Limit/eliminate divided highway } \\
\text { collisions }\end{array}$ & 24 & 2.3 & $\begin{array}{l}\text { Enhance visibility of roadway markings } \\
\text { in rain/fog/snow }\end{array}$ \\
\hline 10 & 1.8 & $\begin{array}{l}\text { Prevent or limit going off road/over } \\
\text { embankments }\end{array}$ & 25 & 2.3 & Ensuring visibility of roadway signage \\
\hline 11 & 2.0 & Automate laboratory soil test & 26 & 2.4 & $\begin{array}{l}\text { Properly place signage (e.g., traffic } \\
\text { lights, stop signs, speed limits) }\end{array}$ \\
\hline 12 & 2.0 & $\begin{array}{l}\text { Compare test results to design } \\
\text { specifications }\end{array}$ & 27 & 2.4 & $\begin{array}{l}\text { Obtain data on roadway utilization and } \\
\text { traffic congestion }\end{array}$ \\
\hline 13 & 2.0 & Design foundations & 28 & 2.4 & $\begin{array}{l}\text { Increase driver awareness of potential } \\
\text { roadway hazards }\end{array}$ \\
\hline 14 & 2.0 & Specify soil testing programs & 29 & 2.5 & $\begin{array}{l}\text { Monitor corrosion of steel in reinforced } \\
\text { concrete }\end{array}$ \\
\hline 15 & 2.2 & Conduct drilling for soil profiling & 30 & 2.6 & Monitor joints in bridges \\
\hline
\end{tabular}

Table III-1: Top 30 Priority Tasks/Activities that could Benefit from Improved Technologies/Solutions 
Beyond the aggregate data, high priority and medium priority tasks in need of better suited technological solutions were also examined by functional area. Tables III-2a-e below provide areaspecific summaries that include all tasks with an I-S factor of less than or equal to 3 (medium to high priority). The "\% importance" ( $100 \%$ being maximum) represents the importance that respondents on average place on a particular task, while the "\% satisfaction" is the level of satisfaction respondents on average place on their ability to address the task with currently available solutions $(100 \%$ is again the maximum).

\section{Transportation Planning, Finance, and Policy}

\begin{tabular}{|c|c|c|c|c|c|}
\hline Task & \% Importance & $\begin{array}{l}\text { \# of Responses } \\
\text { to Importance }\end{array}$ & \% Satisfaction & $\begin{array}{l}\text { \# of Responses } \\
\text { to Satisfaction }\end{array}$ & I-S \\
\hline $\begin{array}{l}\text { Obtain data on roadway } \\
\text { utilization and traffic congestion }\end{array}$ & 86.7 & 3 & 46.7 & 3 & 2.4 \\
\hline $\begin{array}{l}\text { Manage databases and } \\
\text { documents }\end{array}$ & 60.0 & 5 & 32.0 & 5 & 2.6 \\
\hline $\begin{array}{l}\text { Review sub-contracted design } \\
\text { works }\end{array}$ & 73.3 & 6 & 46.7 & 6 & 2.7 \\
\hline Regulate worker hours & 68.0 & 5 & 46.7 & 3 & 2.8 \\
\hline Estimate project costs & 72.5 & 8 & 51.4 & 7 & 2.9 \\
\hline $\begin{array}{l}\text { Identify potential delays in } \\
\text { projects }\end{array}$ & 60.0 & 10 & 43.3 & 6 & 3.0 \\
\hline
\end{tabular}

Table III-2a: Transportation Planning, Finance and Policy Summary

\section{Pavement Engineering}

High Priority

\begin{tabular}{|c|c|c|c|c|c|}
\hline Task & \% Importance & $\begin{array}{l}\text { \# of Responses } \\
\text { to Importance }\end{array}$ & $\begin{array}{c}\% \\
\text { Satisfaction }\end{array}$ & $\begin{array}{l}\text { \# of Responses } \\
\text { to Satisfaction }\end{array}$ & I-S \\
\hline Design pavement sub-grade & 80.0 & 1 & 20.0 & 1 & 1.4 \\
\hline \multicolumn{6}{|l|}{ Medium Priority } \\
\hline Task & $\%$ Importance & $\begin{array}{l}\text { \# of Responses } \\
\text { to Importance }\end{array}$ & \% Satisfaction & $\begin{array}{l}\text { \# of Responses } \\
\text { to Satisfaction }\end{array}$ & I-S \\
\hline Create mix designs for pavements & 80.0 & 1 & 40.0 & 1 & 2.2 \\
\hline Budget a roadway project & 76.7 & 6 & 48.0 & 5 & 2.7 \\
\hline Investigate pavement failures & 73.3 & 6 & 48.0 & 5 & 2.8 \\
\hline
\end{tabular}

Table III-2b: Pavement Engineering Summary 


\section{Design and Production}

High Priority

\begin{tabular}{|c|c|c|c|c|c|}
\hline Task & $\begin{array}{c}\% \\
\text { Importance }\end{array}$ & $\begin{array}{l}\text { \# of Responses } \\
\text { to Importance }\end{array}$ & $\begin{array}{c}\% \\
\text { Satisfaction }\end{array}$ & $\begin{array}{l}\text { \# of Responses } \\
\text { to Satisfaction }\end{array}$ & I-S \\
\hline Design erosion control systems & 80.0 & 1 & 0.0 & 1 & 1.0 \\
\hline $\begin{array}{l}\text { Design water removal and } \\
\text { control systems }\end{array}$ & 80.0 & 1 & 0.0 & 1 & 1.0 \\
\hline Perform seismic design & 100.0 & 1 & 20.0 & 1 & 1.0 \\
\hline Remediate land slides & 80.0 & 1 & 0.0 & 1 & 1.0 \\
\hline $\begin{array}{l}\text { Design lateral earth support } \\
\text { structures }\end{array}$ & 80.0 & 1 & 20.0 & 1 & 1.4 \\
\hline Design reinforced embankments & 80.0 & 1 & 20.0 & 1 & 1.4 \\
\hline \multicolumn{6}{|l|}{ Medium Priority } \\
\hline Task & \% Importance & $\begin{array}{l}\text { \# of Responses } \\
\text { to Importance }\end{array}$ & $\begin{array}{c}\% \\
\text { Satisfaction }\end{array}$ & $\begin{array}{l}\text { \# of Responses } \\
\text { to Satisfaction }\end{array}$ & I-S \\
\hline Automate laboratory soil test & 100.0 & 1 & 40.0 & 1 & 2.0 \\
\hline $\begin{array}{l}\text { Compare test results to design } \\
\text { specifications }\end{array}$ & 100.0 & 1 & 40.0 & 1 & 2.0 \\
\hline Design foundations & 100.0 & 1 & 40.0 & 1 & 2.0 \\
\hline Specify soil testing programs & 100.0 & 1 & 40.0 & 1 & 2.0 \\
\hline Conduct drilling for soil profiling & 80.0 & 1 & 40.0 & 1 & 2.2 \\
\hline Design earthwork & 80.0 & 1 & 40.0 & 1 & 2.2 \\
\hline Examine soil stratigraphy & 80.0 & 1 & 40.0 & 1 & 2.2 \\
\hline $\begin{array}{l}\text { Monitor bridge long-term } \\
\text { deflections }\end{array}$ & 80.0 & 1 & 40.0 & 2 & 2.2 \\
\hline Design drill shafts & 60.0 & 1 & 20.0 & 1 & 2.2 \\
\hline Design sheet piles & 60.0 & 1 & 20.0 & 1 & 2.2 \\
\hline $\begin{array}{l}\text { Protect bridges from steel } \\
\text { corrosion }\end{array}$ & 88.0 & 5 & 44.0 & 5 & 2.3 \\
\hline $\begin{array}{l}\text { Evaluate box beam post- } \\
\text { tensioning }\end{array}$ & 64.0 & 5 & 28.0 & 5 & 2.3 \\
\hline $\begin{array}{l}\text { Monitor corrosion of steel } \\
\text { reinforced concrete }\end{array}$ & 64.0 & 5 & 36.0 & 5 & 2.6 \\
\hline Monitor joints in bridges & 60.0 & 5 & 32.0 & 5 & 2.6 \\
\hline $\begin{array}{l}\text { Check/validate project } \\
\text { compliance with codes }\end{array}$ & 67.5 & 8 & 45.0 & 4 & 2.8 \\
\hline Design storm drains & 67.5 & 8 & 42.9 & 7 & 2.7 \\
\hline Ensure proper roadway runoff & 70.0 & 8 & 52.0 & 5 & 3.0 \\
\hline $\begin{array}{l}\text { Monitor corrosion of steel } \\
\text { structures }\end{array}$ & 60.0 & 5 & 44.0 & 5 & 3.0 \\
\hline
\end{tabular}

Table III-2c: Design and Production Summary 


\section{Traffic Safety and Management}

\begin{tabular}{|c|c|c|c|c|c|}
\hline Task & $\%$ Importance & $\begin{array}{l}\text { \# of Responses } \\
\text { to Importance }\end{array}$ & \% Satisfaction & $\begin{array}{l}\text { \# of Responses } \\
\text { to Satisfaction }\end{array}$ & I-S \\
\hline $\begin{array}{l}\text { Limit auto/structure collision } \\
\text { severity }\end{array}$ & 80.0 & 2 & 30.0 & 2 & 1.8 \\
\hline $\begin{array}{l}\text { Limit/eliminate divided highway } \\
\text { collisions }\end{array}$ & 80.0 & 2 & 30.0 & 2 & 1.8 \\
\hline $\begin{array}{l}\text { Prevent or limit going off } \\
\text { road/over embankments }\end{array}$ & 80.0 & 2 & 30.0 & 2 & 1.8 \\
\hline \multicolumn{6}{|l|}{ Medium Priority } \\
\hline Task & \% Importance & $\begin{array}{l}\text { \# of Responses } \\
\text { to Importance }\end{array}$ & \% Satisfaction & $\begin{array}{l}\text { \# of Responses } \\
\text { to Satisfaction }\end{array}$ & I-S \\
\hline $\begin{array}{l}\text { Ensuring visibility of roadway } \\
\text { signage }\end{array}$ & 76.7 & 6 & 40.0 & 5 & 2.3 \\
\hline $\begin{array}{l}\text { Enhance visibility of roadway } \\
\text { markings in rain/fog/snow }\end{array}$ & 66.7 & 6 & 32.0 & 5 & 2.3 \\
\hline $\begin{array}{l}\text { Properly place signage (e.g., } \\
\text { traffic lights, stop signs, speed } \\
\text { limits) }\end{array}$ & 93.3 & 3 & 46.7 & 3 & 2.4 \\
\hline $\begin{array}{l}\text { Increase drivers awareness of } \\
\text { potential roadway hazards }\end{array}$ & 63.3 & 6 & 32.0 & 5 & 2.4 \\
\hline Manage lighting needs & 73.3 & 3 & 46.7 & 3 & 2.7 \\
\hline $\begin{array}{l}\text { Provide emergency response in } \\
\text { the event of an accident }\end{array}$ & 63.3 & 6 & 40.0 & 4 & 2.7 \\
\hline $\begin{array}{l}\text { Alert drivers to weather related } \\
\text { hazards }\end{array}$ & 50.0 & 2 & 20.0 & 2 & 2.7 \\
\hline Document all accidents & 63.3 & 6 & 44.0 & 5 & 2.9 \\
\hline $\begin{array}{l}\text { Increase roadway visibility } \\
\text { through lighting }\end{array}$ & 63.3 & 6 & 45.0 & 4 & 2.9 \\
\hline $\begin{array}{l}\text { Reduce traffic speed in roadway } \\
\text { work areas }\end{array}$ & 50 & 6 & 30.0 & 4 & 2.9 \\
\hline
\end{tabular}

Table III-2d: Traffic and Safety Management Summary

\section{Maintenance and Operations}

Medium Priority

\begin{tabular}{lccccc}
\hline \multicolumn{1}{c}{ Task } & \% Importance & $\begin{array}{c}\text { \# of Responses } \\
\text { to Importance }\end{array}$ & \% Satisfaction & $\begin{array}{c}\text { \# of Responses } \\
\text { to Satisfaction }\end{array}$ & I-S \\
\hline Repair and maintain bridge deck & 62.9 & 7 & 40.0 & 5 & 2.7 \\
& 60.0 & 8 & 40.0 & 5 & 2.8 \\
$\begin{array}{l}\text { Communicate with } \\
\text { drivers/personnel in the field }\end{array}$ & & & & & \\
\hline
\end{tabular}

Table III-2e: Maintenance and Operations Summary 


\subsection{HIGH-POTENTIAL SOLUTIONS FOR INDOT NEEDS}

In order to identify means to address the priority needs expressed in the INDOT jobs survey, the PI and his research team carried out a technology scan by examining state and federal technology databases and conducting a survey of state DOTs to garner their recommendations on novel technologies. A multitude of resources were examined in the database scan to identify relevant solutions to address INDOT's priority jobs, including the following:

- FHWA/FHWA Database of Priorities, Market-Ready Technologies, and Innovations

- AASHTO's Technology Implementation Group

- $\quad$ State DOT PELS

- Technology Transfer News of the NYDOT

- The FIATECH catalog of Emerging Construction Technologies

- The Caltrans Division of Research and Innovation monthly news outlet

In addition, the same 18 states that provided input into the overarching technology adoption process were also queried to understand both technologies that they believe could address INDOTs priorities as well as any technologies that INDOT may simply want to consider based on their positive experiences. The results of this technology scan fall into four main categories as depicted in the Venn diagram of Figure III-2. More specifically, these "solutions" were classified as either DOT recommended solutions that align with INDOT priorities, DOT recommended solutions that do not align with INDOT priorities, novel technologies yet to be evaluated in DOT settings that align with INDOT priorities, novel technologies yet to be evaluated in DOT settings that do not align with INDOT priorities. The first three of these categories are described below.

Figure III-2: Technologies targeted through the best-of-breed technology adoption process 
Table III-7 presents DOT recommended solutions that align with INDOT's priority needs. These solutions have been tested in a variety of DOT setting across the U.S. (as indicated by the state associated with the recommendation), and thus, as proposed in the evaluation process previously discussed, should be considered for a accelerated adoption.

\begin{tabular}{|l|l|}
\hline INDOT Priority Task/Activity (“job") & DOT Recommended Solution(s) \\
\hline Design erosion control systems & $\begin{array}{l}\text { 1) Soil retention blanket and seeding (TX) } \\
\text { 2) Flexible channel liner (TX) } \\
\text { 3) Hydraulic mulch (SC) } \\
\text { 4) Inlet filter design (SC) }\end{array}$ \\
\hline Design water removal and control systems & 1) Edge drains (OK) \\
\hline Perform seismic design & 1) Displacement based design methodology (SC) \\
\hline Remediate land slides & 1) Borehole shear test (IA) \\
\hline Design lateral earth support structures & 1) MSE walls (OK) \\
\hline Design pavement sub-grades & $\begin{array}{l}\text { 1) Improved design method (IA) } \\
\text { 2) Geocell (KS) } \\
\text { 3) Cement treated sub-grades (OK, FL) } \\
\text { 4) Draincrete (FL) }\end{array}$ \\
\hline Limit auto/structure collision severity & 1) Rumble strips (KS, OK) \\
\hline Limit/eliminate divided highway collisions & $\begin{array}{l}\text { 1) High tension cables (IA, ME, SC, OR, OK) } \\
\text { 2) Rumble strips (ME, KS, OR, OK) } \\
\text { 3) Raised rib marking (SC) }\end{array}$ \\
\hline Prevent or limit going off road/over \\
embankments & $\begin{array}{l}\text { 1) Rumble strips (ME, KS, OK) } \\
\text { 2) Raised rib marking (SC) }\end{array}$ \\
\hline
\end{tabular}

Table III-3: DOT recommended solutions that align with INDOT priorities

Similarly, Table III-4 presents novel technologies that are yet to be evaluated in DOT settings. The technologies described in such a table. Parallel to the lessons learned in the corporate market setting, it is recommended that INDOT explores these technological solutions and fosters a shift to a "proudly found elsewhere" mindset. 


\begin{tabular}{|l|}
\hline \multicolumn{1}{|c|}{ AASHTO TIG Technologies } \\
\hline Surface resistivity test \\
\hline Linear referencing system \\
\hline USLIMITS \\
\hline Web-based comment collection \\
\hline High-definition 3d surveying \\
\hline $\begin{array}{l}\text { Slope stabilization using recycled plastic } \\
\text { reinforcement }\end{array}$ \\
\hline Low profile barrier systems \\
\hline Embedded data collector \\
\hline $\begin{array}{l}\text { Notch wedge joint maker - the safety edge - } \\
\text { shoulder wedge maker }\end{array}$ \\
\hline Balsi beam - a work zone protection device \\
\hline Design build traffic signal projects \\
\hline
\end{tabular}

\begin{tabular}{|c|}
\hline FHWA Technologies \\
\hline Construction Project Management \\
\hline $\begin{array}{l}\text { Accelerated construction technology } \\
\text { transfer (ACTT) }\end{array}$ \\
\hline $\begin{array}{l}\text { Construction analysis for pavement } \\
\text { rehabilitation strategies (CA4PRS) }\end{array}$ \\
\hline Finance \\
\hline Asset management guide \\
\hline Geotechnical and Hydraulics \\
\hline Continuous flight auger (CFA) piles \\
\hline Expanded polystyrene (EPS) geofoam \\
\hline Operations \\
\hline 511 Traveler information \\
\hline ACS-Lite \\
\hline DYNA SMART -P \\
\hline ITS Deployment analysis system (IDAS) \\
\hline Pavements \\
\hline Air void analyzer (AVA) \\
\hline Pavement smoothness methodologies \\
\hline Planning \\
\hline $\begin{array}{l}\text { Highway economic requirements system } \\
\text { (HERS-ST) }\end{array}$ \\
\hline Improved decision making using GIS \\
\hline $\begin{array}{l}\text { Transportation, economics and land use } \\
\text { system (TELUS) }\end{array}$ \\
\hline Structures \\
\hline Bridge and tunnel security \\
\hline Fiber-reinforced polymer (FRP) \\
\hline LFRD and rating of structures \\
\hline $\begin{array}{l}\text { Prefabricated bridge elements and systems } \\
\text { (PFBES) }\end{array}$ \\
\hline Safety and Design \\
\hline PEDSAFE \\
\hline Road safety audits \\
\hline USLIMITS \\
\hline
\end{tabular}

Table III-4: Novel technologies yet to be evaluated in DOT settings

Table 9 presents some of the technologies recommended by other DOTs that were identified throughout this effort. The circumstance/context specific needs of INDOT make many of these solutions less relevant with respect to INDOT's high priority needs. While these technologies are currently lower priority for INDOT, the list should be revisited in subsequent assessments of INDOT's jobs-to-be-done as they may address challenges and needs of the organization that emerge over time.

Interestingly, the lack of alignment between the technologies on the federal organization lists, the broader set of technologies recommended directly by state DOTs, and the expressed needs of INDOT, highlights the importance of understanding INDOT specific needs on a regular basis. 


\begin{tabular}{|c|c|}
\hline State & Recommended Technologies \\
\hline Alaska & $\begin{array}{l}\text { 1) Mechanistic-empirical pavement design program } \\
\text { 2) CADD } \\
\text { 3) Lidar } \\
\text { 4) GPS and machine control technologies } \\
\text { 5) Falling weight deflectometer and pavement management system } \\
\text { 6) AASHTOware } \\
\text { 7) RFID } \\
\text { 8) Construction manager at risk contracting } \\
\text { 9) Warm mix asphalt } \\
\text { 10)Ground penetrating radar }\end{array}$ \\
\hline Iowa & $\begin{array}{l}\text { 1) Advanced compaction control for soils } \\
\text { 2) Hot-mix asphalt } \\
\text { 3) Structural health monitoring }\end{array}$ \\
\hline Maine & $\begin{array}{l}\text { 1) Ground penetrating radar } \\
\text { 2) High tension cable barrier systems } \\
\text { 3) Prefab bridge construction } \\
\text { 4) Snow plow truck ground speed control and material metering systems } \\
\text { 5) Automated flagger assistance devices } \\
\text { 6) Over height vehicle bridge detection systems } \\
\text { 7) Plant mix RAP (a } 100 \% \text { recycled HMA base material) }\end{array}$ \\
\hline Kansas & $\begin{array}{l}\text { 1) Multi-layer polymer bridge deck overlays } \\
\text { 2) Boil test (determining permeability of concrete) }\end{array}$ \\
\hline Kansas & $\begin{array}{l}\text { 1) Turbidity limits and siltation ponds to control erosion } \\
\text { 2) Electronic documents } \\
\text { 3) Bridge management and pavement management systems } \\
\text { 4) Alternative pavements } \\
\text { 5) Super-pave methodology }\end{array}$ \\
\hline Oregon & $\begin{array}{l}\text { 1) MEPDG, } \\
\text { 2) Trenchless technology } \\
\text { 3) Bridge strengthening and repair using CFRP }\end{array}$ \\
\hline New York & $\begin{array}{l}\text { 1) Stake-less construction technology } \\
\text { 2) High speed weigh in motion } \\
\text { 3) } 5.9 \mathrm{GHz} \text { transponder technology } \\
\text { 4) Strain gauge ropes for landslide monitoring } \\
\text { 5) Real time traffic information systems } \\
\end{array}$ \\
\hline Tennessee & $\begin{array}{l}\text { 1) Latest design methodologies from the AASHTO Guide Specification For LRFD } \\
\text { 2) Seismic Bridge Design } \\
\text { 3) SAP2000 }\end{array}$ \\
\hline Oklahoma & $\begin{array}{l}\text { 1) Salt and sand truck tracking and monitoring } \\
\text { 2) Cable barrier systems }\end{array}$ \\
\hline Florida & $\begin{array}{l}\text { 1) Low-profile barriers--new end treatment recently added } \\
\text { 2) Embedded data collectors that monitor pile driving } \\
\text { 3) Rock scour erosion devices } \\
\text { 4) Vertical and horizontal in-situ permeameters }\end{array}$ \\
\hline South Carolina & 1) Dispersive wave technology and ground penetrating radar for scour assessment \\
\hline
\end{tabular}

$\mathrm{GA}, \mathrm{LL}, \mathrm{MD}, \mathrm{MT}$, and TX provided no response

Table III-5: DOT recommended solutions that do not align with INDOT's priorities 


\section{BENEFITS OF STUDY AND RECOMMENDATIONS FOR USE OF FINDINGS}

This study has provided a recommended process to guide INDOT's approach to identify, evaluate, and adopt new, proven technologies that can enhance INDOT's ability to perform its mission. This process, which encompasses need identification, solution identification, solution evaluation and staged solution implementation, incorporates several new tools which each have specific benefits as follows:

- Identify needs: A new means of assessing INDOT needs has been developed that relies upon a first-hand survey of end-user "jobs-to-be-done". In this effort, this new tool has helped to identify over 360 "jobs" that are carried out by INDOT personnel on a routine basis. This initial list will serve as a foundation for on-going efforts to assess future INDOT needs and the survey mechanism provides a long-term strategic view that can help focus INDOT's technology adoption priorities. In addition, the "jobs" identified through this work are likely highly relevant to any US DOT.

- Identify solutions: The proposed best-of-breed technology adoption process incorporates a recommendation for a web-based mechanism to track INDOT needs and potential solutions that is based on leading systems intended to address similar issues in the commercial sector. This system could provide a streamlined means to manage internal and external technology ideas and link them to INDOT needs in a cost effective manner.

- Identify champions: The recommendation for technology-specific champions will provide idea "ownership" in the technology adoption process and help overcome several traditionally encountered barriers in this process.

- Evaluate solutions: Centralization of the proposed evaluation process will drive efficiencies in evaluation efforts across INDOT eliminating redundant efforts, and ensuring consistency in evaluation reporting that can drive effective decision making.

- Facilitate staged implementation: The proposed staged implementation process employs a unique assumption driven approach to evaluation that optimizes resources for evaluation and also includes a tiered marketing approach to build awareness and encourage broad adoption of technologies that emerge successfully from evaluation and pilot activities.

Beyond the benefits provided by recommended the best-of-breed technology adoption process, this project has also put forward an efficient organizational construct to manage the process using limited resources. Finally, by implementing the first stages of the recommended process this effort has also called attention to a series of INDOT specific needs and associated high-potential technology-based solutions that if pursued could directly enhance efficiency, cost effectiveness, and/or safety of INDOT operations. Overall, the results of this work provide the foundation for a capability in technology awareness and adoption that will benefit INDOT operations for many years to come. 


\section{REFERENCES}

Anderson, P., and Tushman, M. (1990). "Technological discontinuities and dominant designs: A cyclical model of technological change," Admin. Sci. Quart. 35(4), 604-633.

Anthony, S. D., and Sinfield, J.V. (2007). "Product for Hire: Master the Innovation Lifecycle with a Jobsto-be-Done Perspective of Markets", Marketing Management, March/April, pp.19-24.

Anthony, S.D., Johnson, M.W., Sinfield, J.V., Altman, E.J. (2008), The Innovator's Guide to Growth Putting Disruptive Innovation to Work, Harvard Business Press, 299 p.

California Department of Transportation (Caltran), (2005). "Deployment Services Business Plan". Prepared by Caltran Division of Research and Innovation (DRI) Deployment Research Branch.

California Department of Transportation (Caltran). (2007). "California Transportation Research and Technology Advisory Panel (RTAP)". http://www.dot.ca.gov/newtech/rtap/index.htm.

Carr Jr., V.H. (1999) "Technology adoption and diffusion". US AirForce, Air University Center for Strategy and Technology.

Christensen, C.M., Anthony, S.D., Berstell, G., and Nitterhouse, D., (2007). "Finding the Right Job for Your Product," Sloan Management Review, pp. 2-11, Spring.

Christensen, C.M.. (1997). The Innovator's Dilemma: When New Technologies Cause Great Firms to Fail, Harvard Business Press, 1997, 256 p.

Connecticut Department of Transportation (ConnDOT) (2004) American Association of State Highway and Transportation Officials (AASHTO) Research Implementation and Performance Measures Workshop, July 18. http://www.ct.gov/dot/cwp/view.asp?a=1617\&Q=284844\&PM=1.

Court, D., Elsinga, D., Mulder, S., and Vetvik, O. J., (2009) “The Consumer Decision Journey," The McKinesy Quarterly, June.

Dyer, J.H., Gregersen, H.B., and Christensen, C. (2008). "Entrepreneur behanviors, opportunity recognition, and the origins of innovative ventures," Strategic Entrepreneurship Journal, 2, 317-338.

Elston, D., Huft, D., Harder, B.T., Curtis, J., Evans, M.R., Jenks, C.W., et al. (2009). "Transportation Research Program Administration in Europe and Asia: FHWA-PL-09-015". Office of International Programs Federal Highway Administration U.S Department of Transportation, American Association of State Highway and Transportation Officials.

Goddard, J. (2007). "An Industry Perspective of the AASHTO National Transportation Product Evaluation Program". AASHTO's National Transportation Product Evaluation Program. http://www.Itrc.Isu.edu/tec_07/presentations/Industry\%20Perspective\%20of\%20AASHTO\%20Natio nal\%20Transportation\%20Product\%20Evaluation\%20Program.pdf.

Harder, B.T. (2001). "Peer Exchange: A Value-Added Program Management Tool”. National Cooperative Highway Research Program (NCHRP) Project No.20-7/Task 125.

Harder, B.T. (2004). "Technology Transfer Toolbox Scoping Study, Final Report". Prepared for Federal Highway Administration, Office of Professional Development and Office of Research, Development, and Technology and Transportation Research Board, Technology Transfer Committee.

Harder, B.T. and Benke, R. (2005). "NCHRP Synthesis 355: Transportation Technology Transfer: Success, Challenges, and Needs". Transportation Research Board (TRB). 
Huston, L. and Sakkab, N. (2006). "P\&G's New Innovation Model". Review of "Connect and Develop: Inside Procter \& Gamble's New Model for Innovation. Harvard Business Review, Vol. 84, No. 3. http://hbswk.hbs.edu/archive/5258.html.

Illinois Department of Transportation. (2009). "Bureau of Materials and Physical Research: Physical Research Experimental Features".

lowa Department of Transportation. (2007). "Best Practices in Technology Transfer Research Peer exchange". www.iowadot.gov/research/peer_exchange.htm .

Lall, S. (2001). "National Strategies for Technology Adoption in the Industrial sector: Lessons of Recent Experience in the Developing Regions". Background Paper for Human Development Report, United Nations Development Programme (UNDP).

McGrath, R.G., and MacMillan, I. C., (1995) "Discovery Driven Planning”, Harvard Business Review, JulyAug.

McGregor, J. (2007) "P\&G Asks: What's the Big Idea?" BusinessWeekonline Most Innovative Companies. http://www.businessweek.com/print/innovate/content/may2007/id20070504_282528.htm.

McKee, C., Nolan, P., and Boghani, A.B. (undated) "Scanning and Evaluating Emerging Technologies", Monitor Innovation.

Miller, J.S. (2003). "Evaluating New Transportation Technologies with Tiered Criteria: Rail Case Study Approach". Transportation Research Record (TRR) 1838, 03-2403, 64.

Moore, G. (1991) Crossing the Chasm: Marketing and Selling High-Tech Products to Mainstream Customers, Harper Business Press.

Mortara, L., Napp, J., Slacik, I., and Minshall, T. (2009). "How to Implement Open Innovation: Lessons from Studying Large Multinational Companies". Center for Technology Management, University of Cambridge Institute for Manufacturing.

National Cooperative Highway Research Program (NCHRP) (2000). "Systems Approach to Evaluating Innovations for Integration Into Highway Practice", Report 442, Transportation Research Board and Worcester Polytechnic Institute, $131 \mathrm{p}$.

National Cooperative Highway Research Program (NCHRP) (2004). State Product Evaluation Programs, A Synthesis of Highway Practice, Synthesis 328, Transportation Research Board.

National Cooperative Highway Research Program (NCHRP) Panel Member Survey, (2008). "A Summary of Results, ratings and Comments from Panel Members on NCHRP Project from 2001 through 2006 NCHRR 20-44G"http://onlinepubs.trb.org/onlinepubs/archive/NotesDocs/NCHRPSurveyResults.pdf.

Nicholas, C. and Wilcox, C. (2000). "The Northwest Transportation Technology Exposition". Public Roads Magazine, 63, 3.

Paap, J. (2009). “Metrics for technology Scouting: Recent Workshop Demonstrates Growing Need to Measure Success", The Management Roundtable.

Rogers, E. (1962). Diffusion of Innovations, Glencoe: Free Press.

Schmitt, R.P., E.A. Beimborn, and M.J. Mullroy, Technology Transfer Primer, FHWA-TS-84-226, University of Wisconsin, Milwaukee, July 1985.

Sewell, D. (2010). "P\&G open to outside ideas, but no kitty Swiffers." http://wtop.com/?nid=111\&sid=1853624. 
Sinfield, J., Anthony, S. "Constraining Innovation: How Developing and Continually Refining Your Organization's Goals and Bounds Can Help Guide Growth", Strategy \& Innovation, November December, Vol. 4, No. 6, p. 1, 6-9, 2006.

Sinfield, J.V. (2005). "A Structured Approach to Technology Assessment", Strategy \& Innovation, September - October, Vol. 3, No. 5, pp. 1, 10-13.

Stevens, A., Mine, R., Lilford, R. and Gabby, J. (1999). "Keeping Pace with New Technologies: Systems Needed to Identify and Evaluate Them". British Medical Journal (BMJ), 314, 1.

Thompson, D. (2005). Blueprint to a Billion: 7 Essentials to Achieve Exponential Growth, Wiley, 288p.

Toole, J.S. (2003). "Technology Transfer Toolbox, Concept for Phased Development". Federal Highway Administration.

Transportation Pooled Fund Program (TPF) (2005). "Transfer Technology Toolbox: A Research Implementation How-To Guide". http://www.pooledfund.org/documents/solicitations/974.pdf.

Transportation Research Board,(TRB) (1999). "Managing Technology Transfer: A Strategy for the Federal Highway Administration Research and Technology Coordinating Committee-Special Report 256". http://www.nap.edu/catalog/11380.html National Academy of Sciences.

Tushman M, Anderson P. (1986). Technological Discontinuities and Organizational Environments. Administrative Science Quarterly 31: 439-465.

U.S Department of Transportation Federal Highway Administration, (FWHA). (2008). "International Programs: Programs Overview"

Wallace, C.E., J.A. Anderson, and E.M. Wilson (1998) "Transportation Technology Transfer: A Primer on the State-of- the-Practice," Transportation Research Circular 488, Transportation Research Board, National Research Council, Washington, D.C., May 1998 [Online]. Available: http://Gulliver.trb.org/publications/circulars/circ488/circ4 88_index.pdf.

Wilson, B., Ryder, M., McCahan, J., \& Sherry, L. (1996). Cultural assimilation of the Internet: A case study. In M. Simonson (Ed.), Selected papers from the annual meeting. Washington D. C.: Association for Educational Communications and Technology.

Wisconsin Department of Transportation (WisDOT), (2007). "State DOT Strategies to Maximize Research Implementation". Prepared for Research and Communication Services Section, Bureau of Business Services, Prepared by CTC \& Associates LLC and WisDOT Research \& Library Unit.

Wunker, S. and Sinfield, J. (2009). "Early Market Testing Can Benefit Health Care," BusinessWeek Online, November 18, 2009

Zirlin, J. (2009). "Bringing Innovations to Market". Public Roads Magazine, 72, 4. http://www.tfhrc.gov/pubrds/09janfeb/04.htm . 


\section{Appendix A}

\section{DOT Survey Participants}




\begin{tabular}{|c|c|}
\hline Alaska & $\begin{array}{l}\text { James Sweeney, P.E. Research Engineer. Statewide (Alaska) Research Section. } \\
\text { Angela Parsons, P.E. Tech Eng I/Architect I. Statewide (Alaska) Research Section. }\end{array}$ \\
\hline California & $\begin{array}{l}\text { Tori Kanzler. Branch Chief. Research Program Development Branch. Division of } \\
\text { Research and Innovation. }\end{array}$ \\
\hline Florida & $\begin{array}{l}\text { J. Darryll Dockstader. Research Center Manager. Florida Department of } \\
\text { Transportation. }\end{array}$ \\
\hline Georgia & Rick Deaver. Chief of Research and Development. GDOT \\
\hline Illinois & $\begin{array}{l}\text { Joseph W. Vespa, PE. Engineer of Technical and Product Studies. Bureau of Materials } \\
\text { and Physical Research. Illinois Department of Transportation. } \\
\text { Amy M. Schutzbach, P.E. Engineer of Physical Research. Bureau of Materials and } \\
\text { Physical Research. Illinois Department of Transportation. } \\
\text { Patty Broers. Research Coordination Manager. Bureau of Materials and Physical } \\
\text { Research. Illinois Department of Transportation. }\end{array}$ \\
\hline lowa & $\begin{array}{l}\text { Mary M. Starr. Research \& Technology Bureau. } \\
\text { Mark J. Dunn, P.E. Operations Research Engineer. Research and Technology Bureau. } \\
\text { lowa Department of Transportation }\end{array}$ \\
\hline Kansas & $\begin{array}{l}\text { Rick Kreider. Chief of Bureau of Materials and Research. Kansas Department of } \\
\text { Transportation. } \\
\text { Jim L. Kowach. Chief of Design. Kansas Department of Transportation. }\end{array}$ \\
\hline Maine & $\begin{array}{l}\text { Dale Peabody. Transportation Research Division. Office of Safety, Training \& Research. } \\
\text { Maine DOT. }\end{array}$ \\
\hline Maryland & $\begin{array}{l}\text { Allison R. Hardt. Chief, Research Division. Maryland State Highway Administration. } \\
\text { Office of Policy and Research. }\end{array}$ \\
\hline Montana & Sue Sillick, Manager of Research Programs. Montana Department of Transportation. \\
\hline New York & Gary Frederick. Director, Research and Development. NYS Dept. of Transportation. \\
\hline North Carolina & Mustan Kadibhai, P.E. Research Engineer. NCDOT Research \& Development Unit. \\
\hline Ohio & $\begin{array}{l}\text { Vicky Fout. Implementation Program Manager. Office of Research and Development. } \\
\text { Ohio Department of Transportation. }\end{array}$ \\
\hline Oklahoma & $\begin{array}{l}\text { Chris Westlund P.E. Engineering Services Branch. Planning and Research Division. } \\
\text { Oklahoma Department of Transportation }\end{array}$ \\
\hline Oregon & Barnie Jones. Research Manager. ODOT. \\
\hline South Dakota & Virginia Ripley \\
\hline Tennessee & Tim Huff. CE Manager I. Tennessee DOT Structures. \\
\hline Texas & C. Richardson. Public Information Coordinator. TxDOT - Research Office. \\
\hline
\end{tabular}




\section{Appendix B}

\section{State-specific Approaches to Technology Adoption}

(Based on survey and/or phone interviews) 


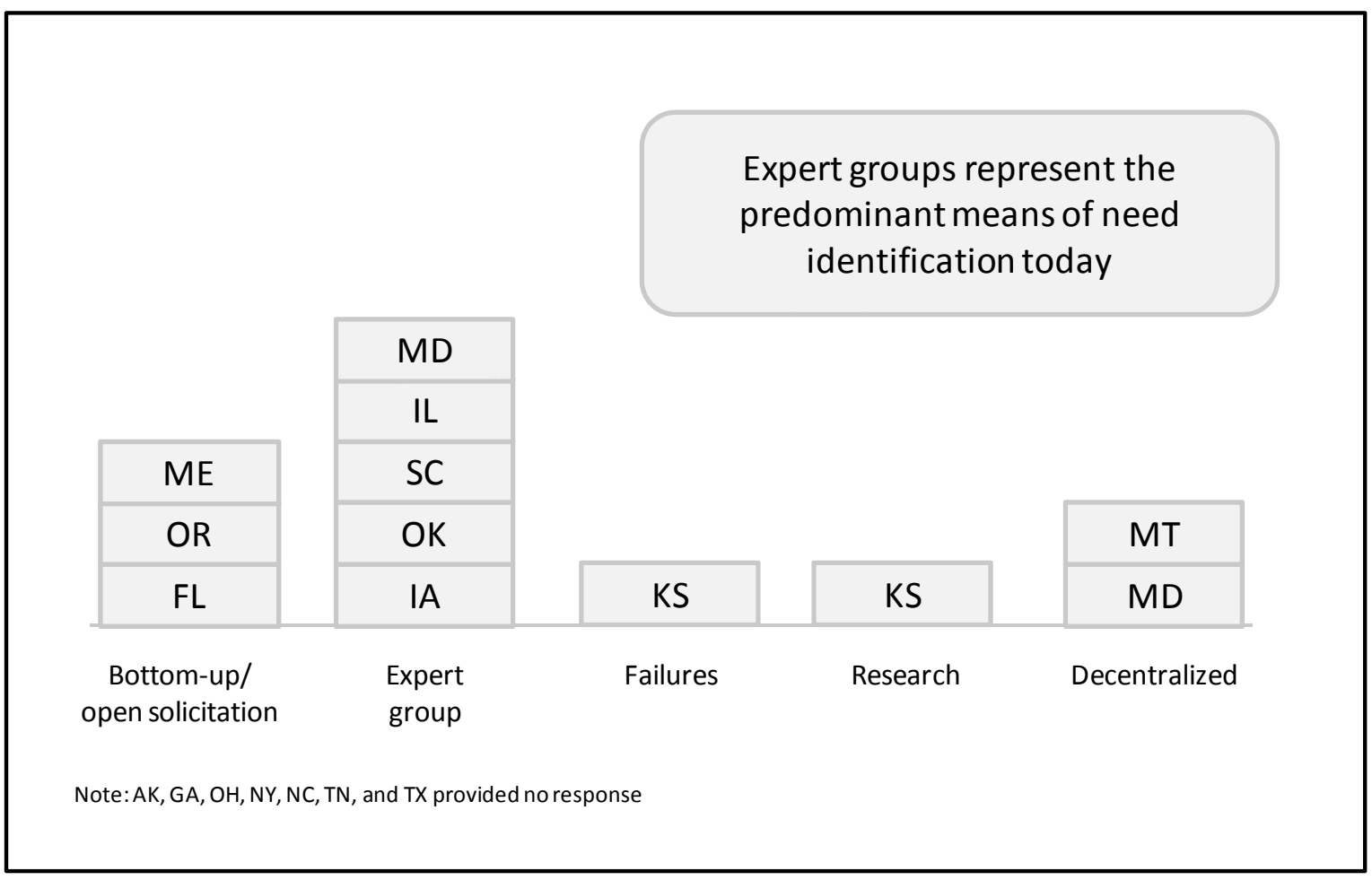

Figure B-1: State-specific approaches to need identification.

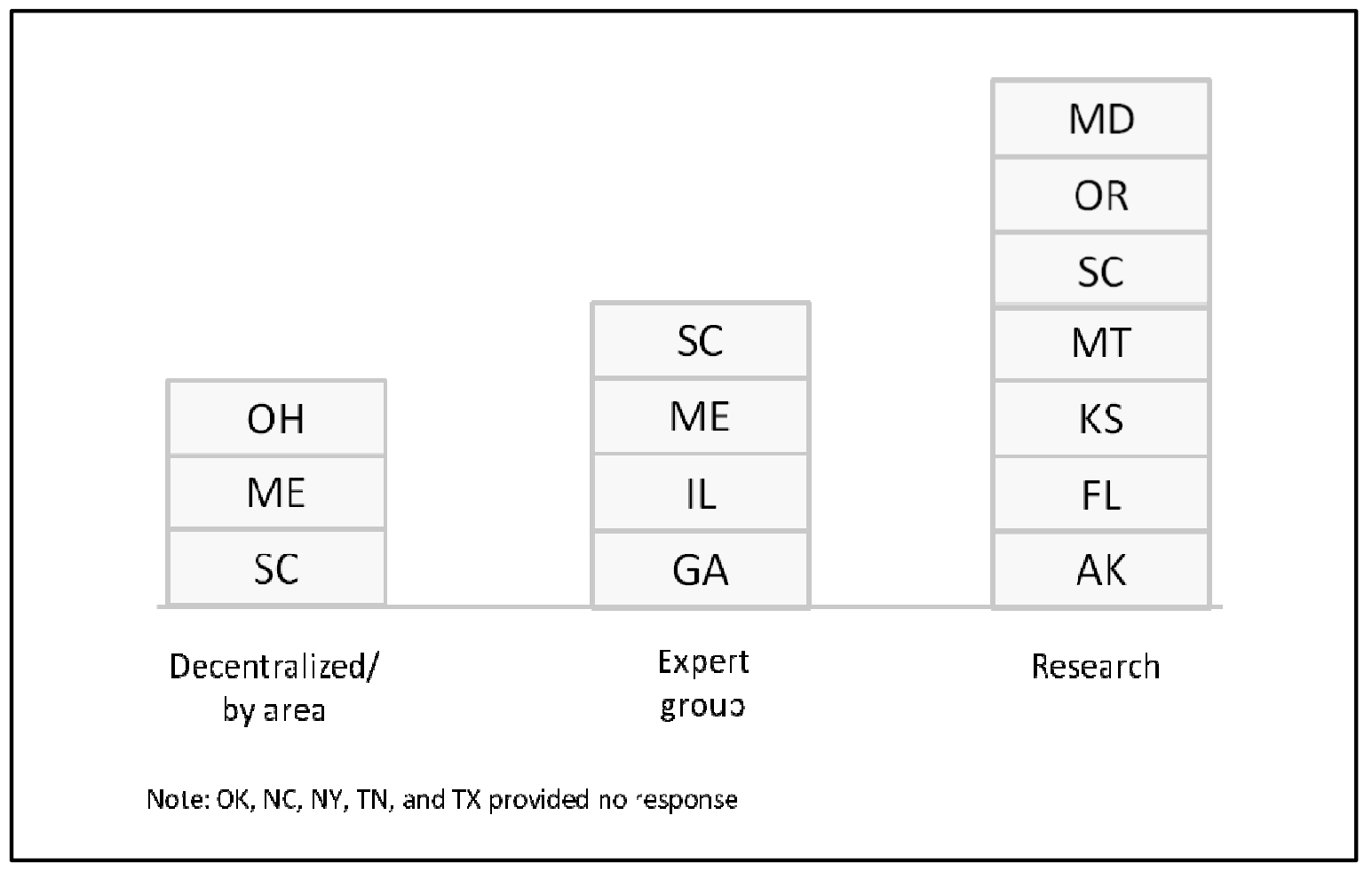

Figure B-2: State-specific approaches to solution identification. 


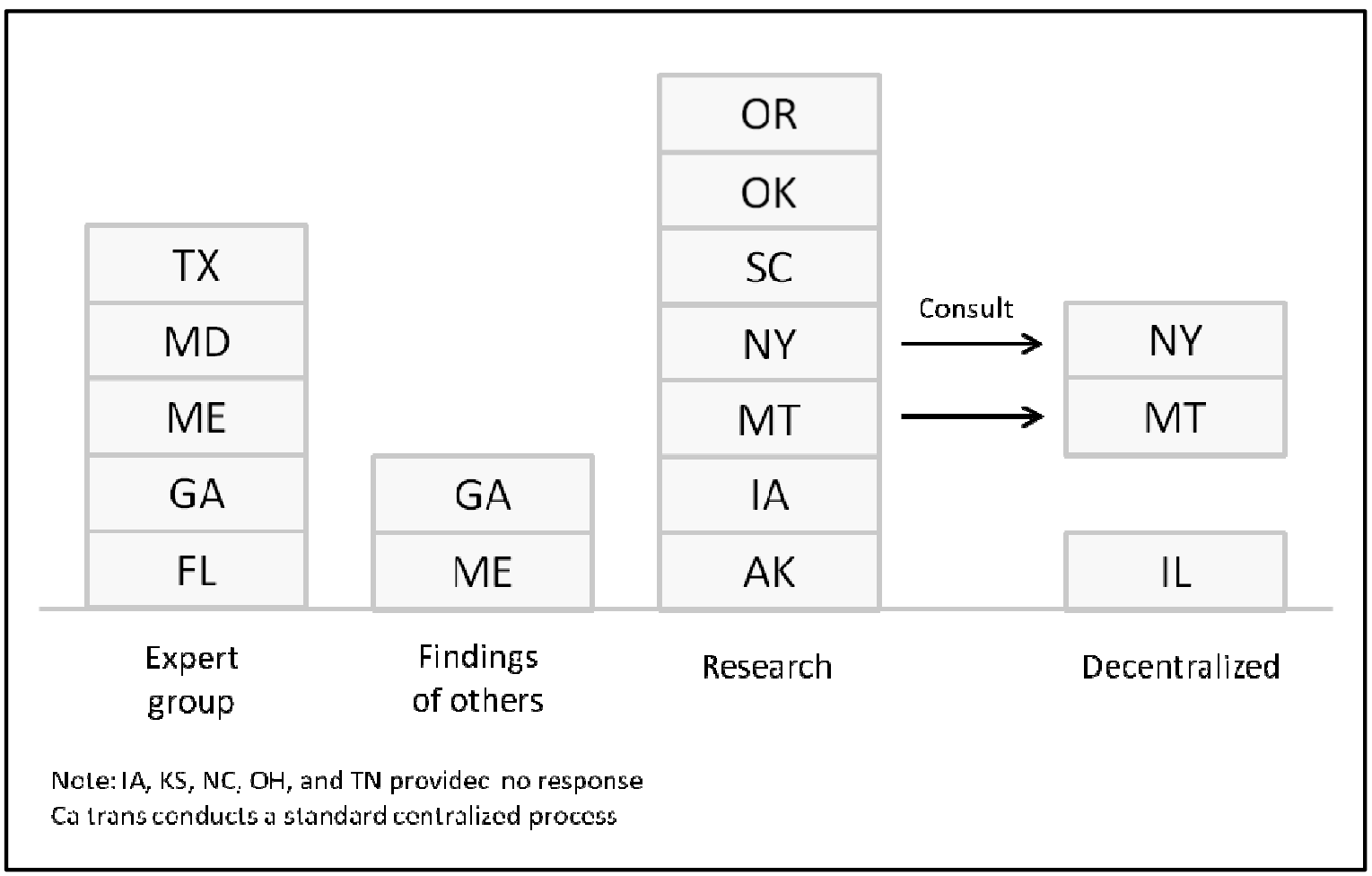

Figure B-3: State-specific approaches to testing and evaluation.

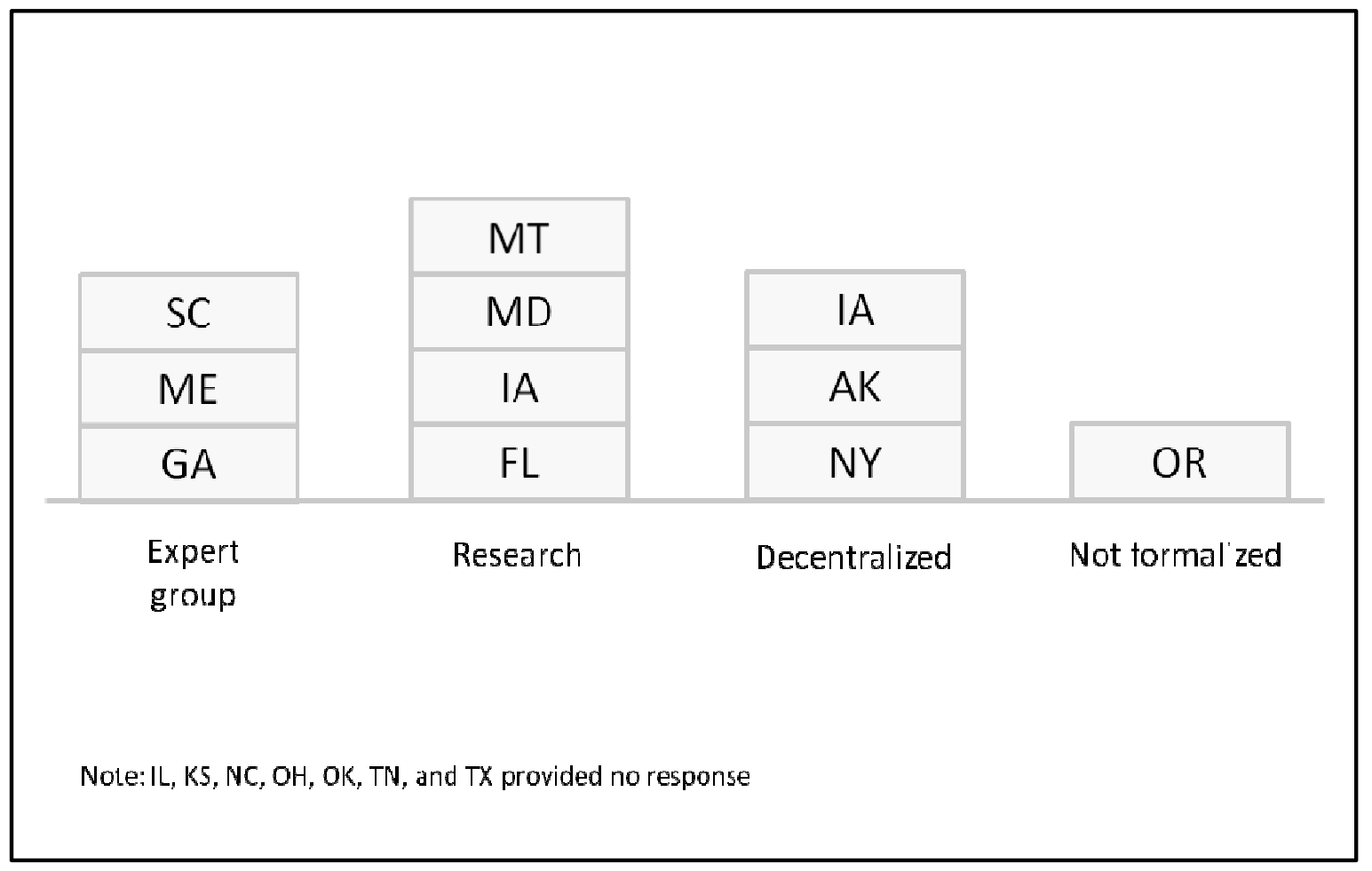

Figure B-4: State-specific approaches to implementation. 


\section{Appendix C}

Job Surveys Employed for INDOT Need Identification 


\section{Construction Management}

Using a 6 point scale, where 1 is "NOT IMPORTANT" and 6 is "EXTREMELY IMPORTANT" please state how IMPORTANT each activity listed below is in your day to day role:

\section{How I MPORTANT is it for you to:}

Manage project cash flow $\begin{array}{llllll}\text { IMPORTANT } & 2 & 3 & 4 & 5 & \text { IMPORTANT }\end{array}$

Assess financial risk

Manage contractor selection

Identify potential delays in projects

Review project plans (confirm that a project meets specifications and plans)

Manage capital (verifying contractor bonds/finances for project phases)

Acquire permits

Estimate earth-moving costs (earth-works)

Determine quantity take-offs for construction materials

Manage projects (define and identify critical path)

Coordinate (sub)contractors

Procure materials for projects in timely and efficient manner

Manage project spoils

Estimate project costs

Write or review change orders

Establish project contingencies

Maintain construction site safety

Ensure worker safety

Manage equipment security

Establish and maintain a site presence

Supervise work quality control

Perform quality control on site

Protect in-place construction

Regulate worker hours

Track deliveries to site

Set-up or maintain stage areas

Coordinate police safety support

Settle worker disputes

Ensure and supervise job safety

O

0

O

0

$\bigcirc$

0

0

0

0

0

0

0

0

0

0

0

0

0

0

0

0

0

0

0

0
$0 \bigcirc \bigcirc 0$ 0000 1000 OOO $0 \bigcirc \bigcirc 0$ 0000 0000 0000 0000 0000 0000 0000 $0 \bigcirc \bigcirc 0$ 0000 0000 0000 0000 0000 0000 0000 0000 $0 \bigcirc \bigcirc 0$ $0 \bigcirc \bigcirc 0$ 0000 0000 0000 0000 0000 1000 $\bigcirc^{6}$ 


\section{Construction Management}

Using a 6 point scale, where 1 is "NOT SATISFIED" and 6 is "EXTREMELY SATISFIED" please state how SATISFIED you are with available solutions for each activity listed below (Note that selection of EXTREMELY SATISFIED indicates that you are pleased with the current solution for the task and that you do not believe it needs to be changed or improved):

\section{How SATISFIED are you with available tools, methods or technologies to:}

$\begin{array}{llllll}\text { NOT } & & & & \text { EXTREMELY } \\ \text { SATISFIED } & 2 & 3 & 4 & 5 & \text { SATISFIED }\end{array}$

Manage project cash flow

Assess financial risk

Manage contractor selection

Identify potential delays in projects

Review project plans (confirm that a project meets specifications and plans)

Manage capital (verifying contractor bonds/finances for project phases)

Acquire permits

Estimate earth-moving costs (earth-works)

Determine quantity take-offs for construction materials

Manage projects (define and identify critical path)

Coordinate (sub) contractors

Procure materials for projects in timely and efficient manner

Manage project spoils

Estimate project costs

Write or review change orders

Establish project contingencies

Maintain construction site safety

Ensure worker safety

Manage equipment security

Establish and maintain a site presence

Supervise work quality control

Perform quality control on site

Protect in-place construction

Regulate worker hours

Track deliveries to site

Set-up or maintain stage areas

Coordinate police safety support

Settle worker disputes

Ensure and supervise job safety

0

O

$\bigcirc$

0

0

0

0

0

0

0

0

0

0

0

0

0

0

0

0

0

0

0

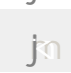

0

0

0

O
6

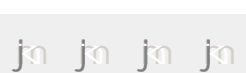

0000

0000

$0 \bigcirc \bigcirc 0$

0000

0000

0000

0000

0000

0000

0000

0000

0000

0000

0000

0000

0000

0000

0000

0000

0000

0000

0000

0000

0000

0000

0000

$0 \bigcirc 00$

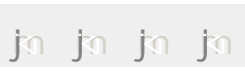

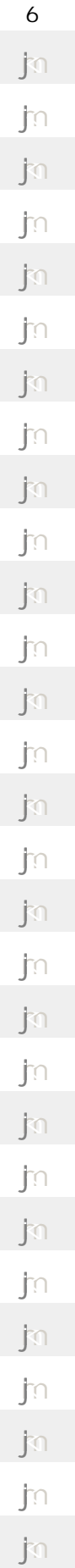


3. Please list any additional tasks that you believe are an I MPORTANT part of Construction Management. Please also include how SATI SFI ED you are with the existing solutions for these tasks. 


\section{Contract Administration}

Using a 6 point scale, where 1 is "NOT IMPORTANT" and 6 is "EXTREMELY IMPORTANT" please state how

IMPORTANT each activity listed below is in your day to day role:

\section{How I MPORTANT is it for you to:}

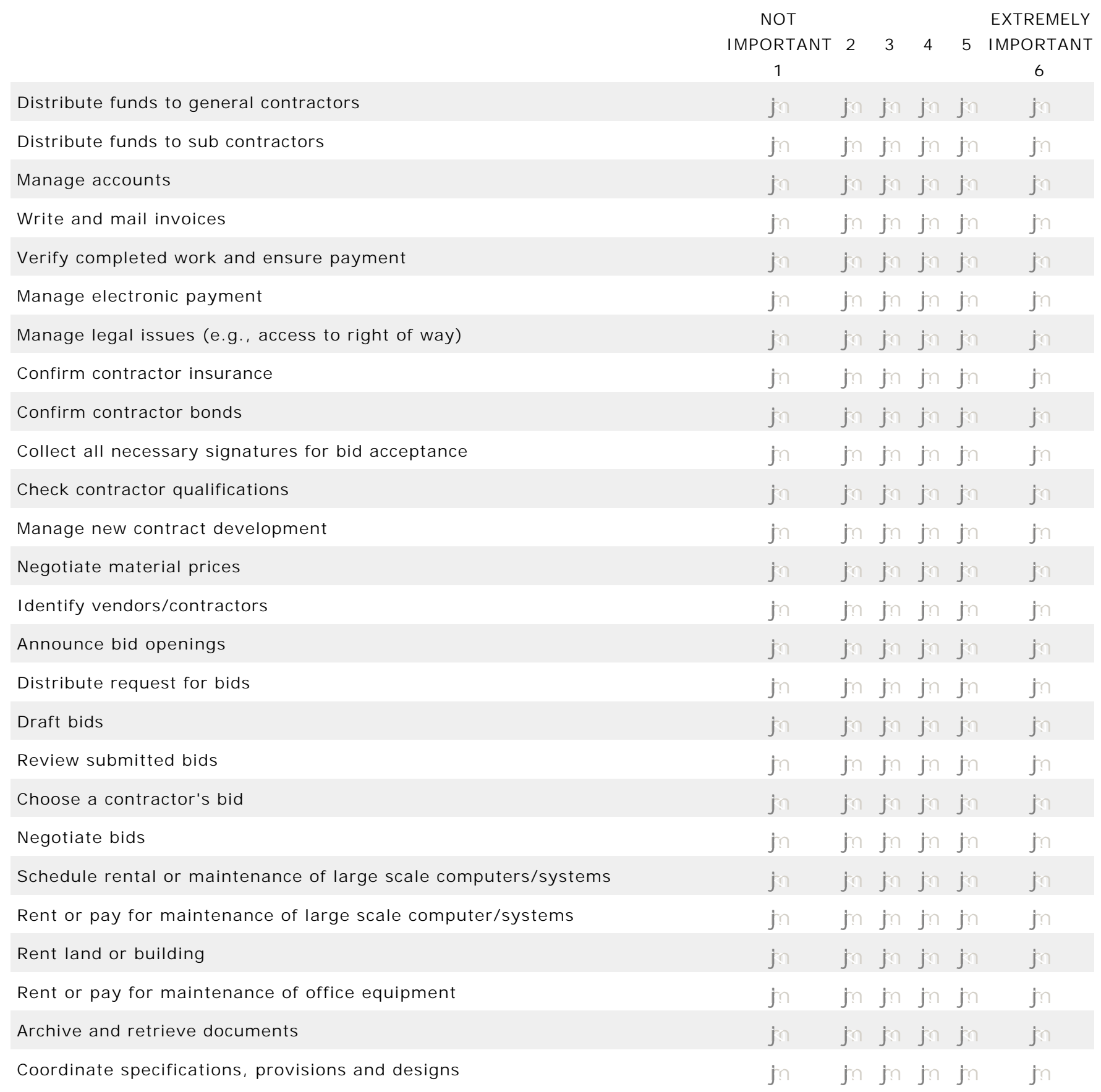




\section{Contract Administration}

Using a 6 point scale, where 1 is "NOT SATISFIED" and 6 is "EXTREMELY SATISFIED" please state how SATISFIED you are with available solutions for each activity listed below (Note that selection of EXTREMELY SATISFIED indicates that you are pleased with the current solution for the task and that you do not believe it needs to be changed or improved):

\section{How SATI SFI ED are you with available tools, methods or technologies to:}

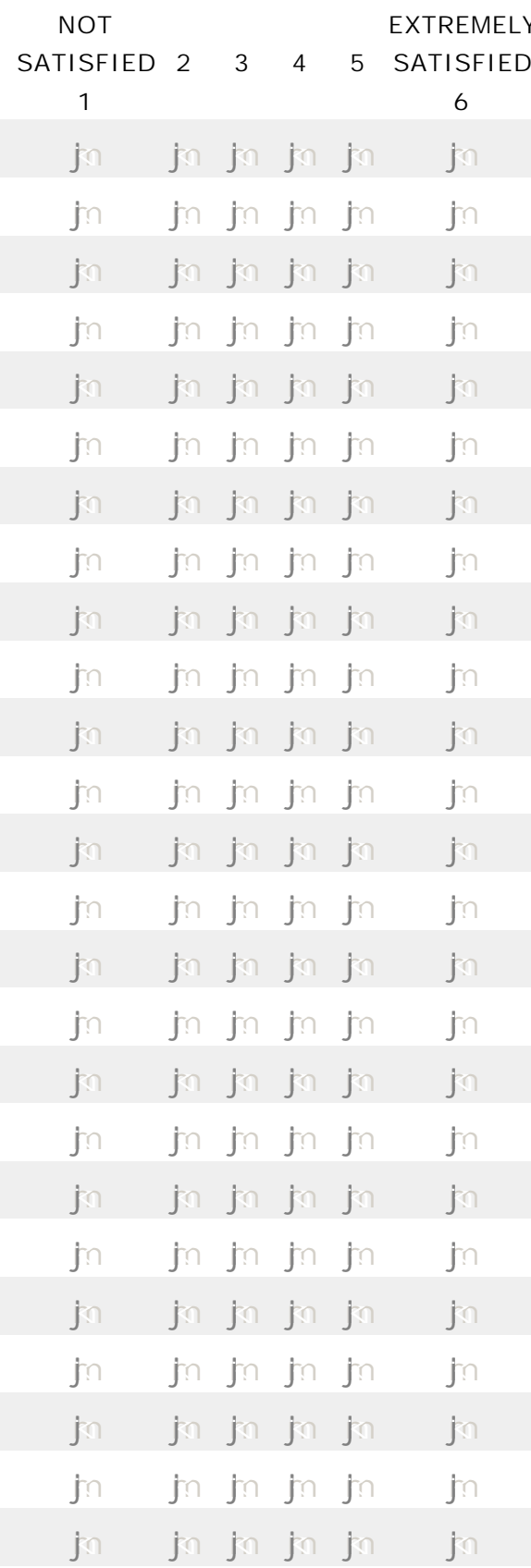

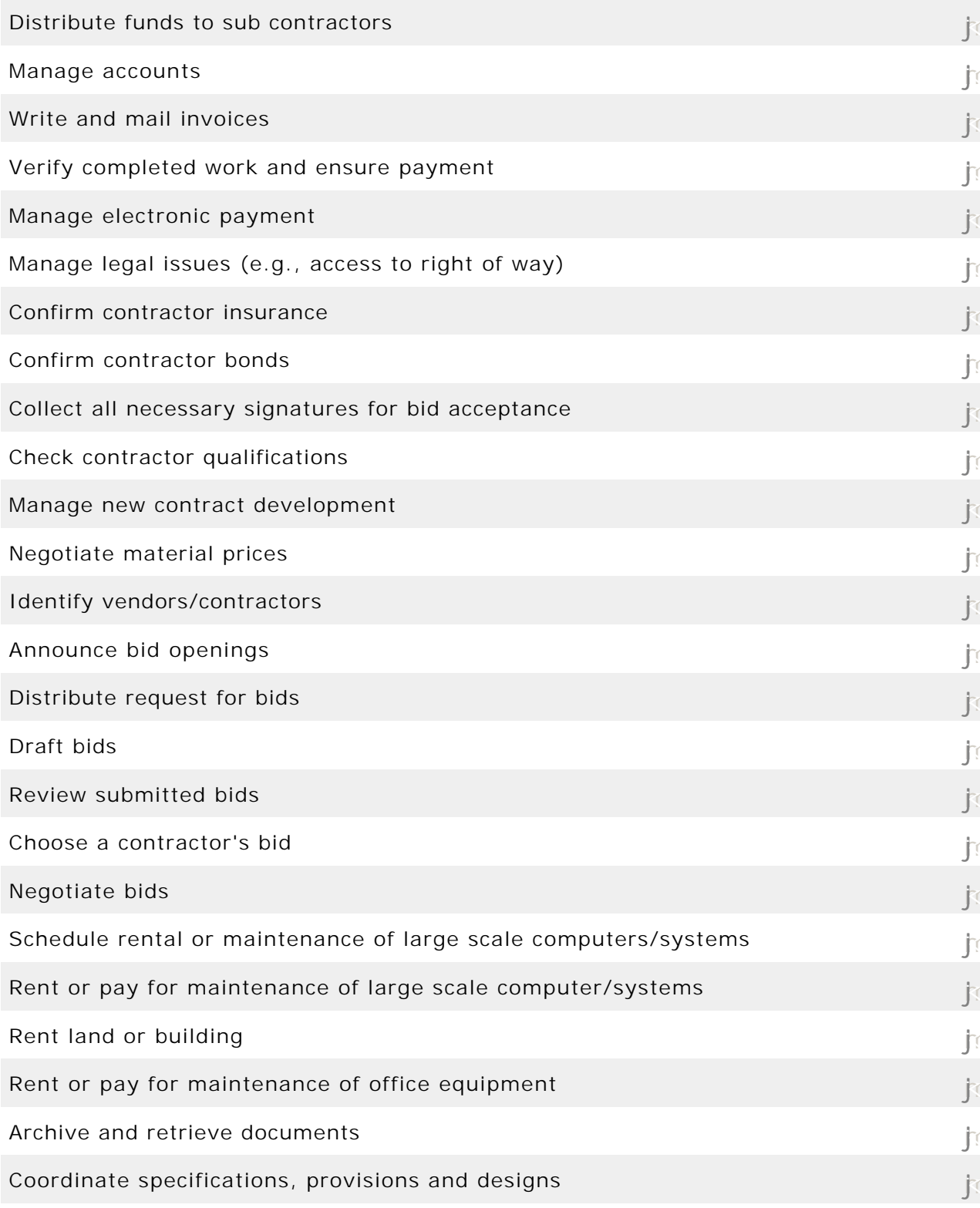

3. Please list any additional tasks that you believe are an I MPORTANT part of Contract Administration. Please also include how SATI SFI ED you are with the existing solutions for these tasks. 


\section{Geotechnical Engineering}

Using a 6 point scale, where 1 is "NOT IMPORTANT" and 6 is "EXTREMELY IMPORTANT" please state how

IMPORTANT each activity listed below is in your day to day role:

\section{How I MPORTANT is it for you to:}

NOT

EXTREMELY

$\begin{array}{llllll}\text { IMPORTANT } & 2 & 3 & 4 & 5 & \text { IMPORTANT }\end{array}$

Examine soil stratigraphy

1

Conduct drilling for soil profiling

00000

Determine site grade

Determine soil classification

0000

Determine particle size distribution of soils

Obtain soil samples

Define mineralogy of sampled soil

Determine site geology

Examine soil phase relations

Test soil Atterberg limits

Perform unconfined compression test on sampled soil

0000

00000

Perform Ko consildated triaxial test on sampled soil

Perform constant rate of strain test on sampled soil

Perform shear box test on soil

Perform resonant column test on soil

Obtain undisturbed soil samples

Perform in-site strength test on soil (e.g., SPT blow count)

Perform compaction test on sampled soil

Perform consolidation test on sampled soil

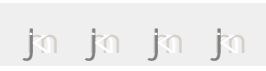

00000

Obtain Shelby tube soil samples

0000

Determine organic content of sampled soil

0000

Monitor landslides or slope stability

Investigate landslides (identify areas of potential rock fall)

0000

0000

Design retaining structures

Remediate land slides

Perform ground modification (e.g., grouting, dynamic compaction)

Perform ground retention (e.g., geo-grids, geo-textiles)

Design and install reinforced embankments

Design water removal and control systems

Design and install erosion control systems 


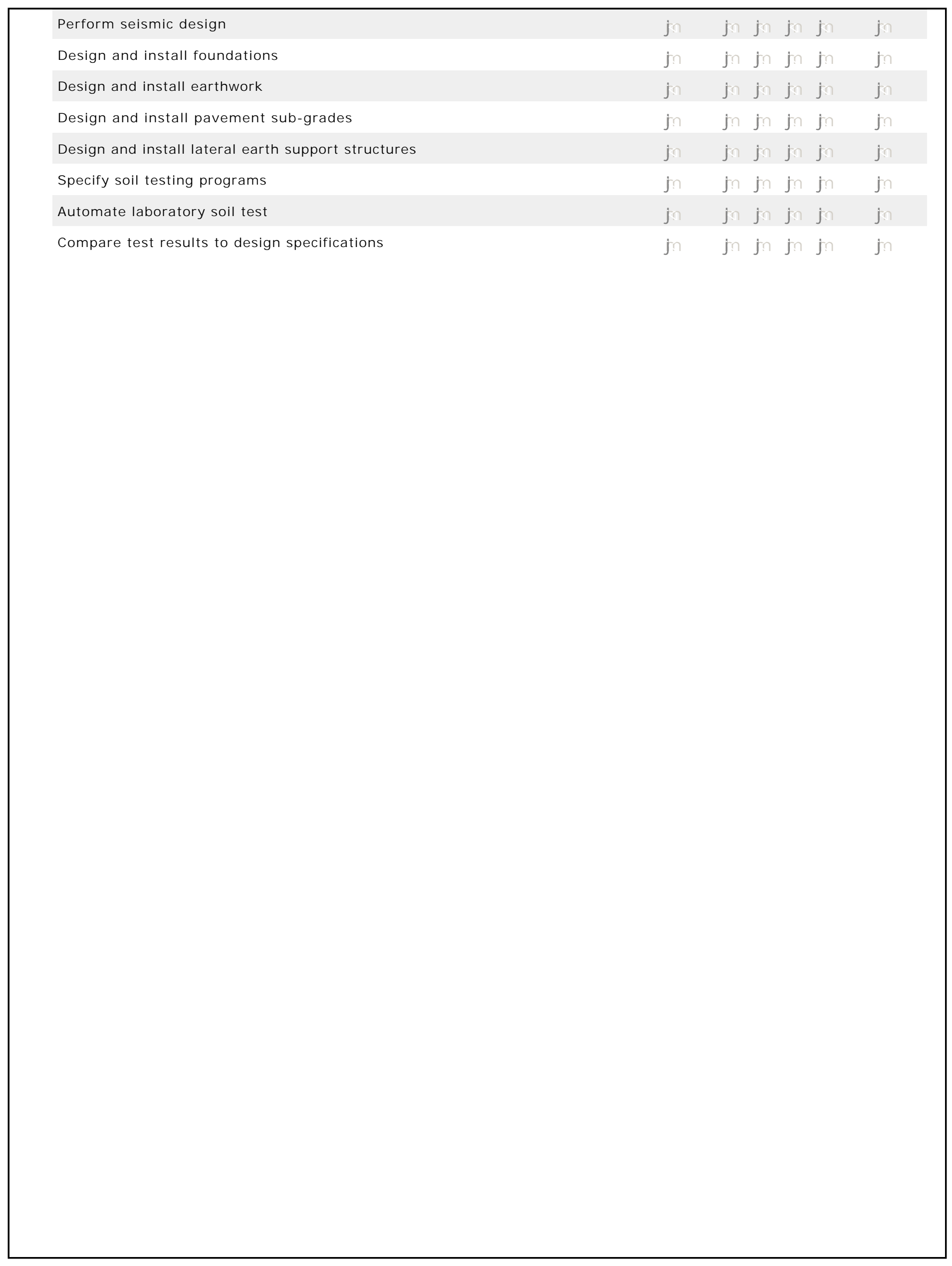




\section{Geotechnical Engineering}

Using a 6 point scale, where 1 is "NOT SATISFIED" and 6 is "EXTREMELY SATISFIED" please state how SATISFIED you are with available solutions for each activity listed below (Note that selection of EXTREMELY SATISFIED indicates that you are pleased with the current solution for the task and that you do not believe it needs to be changed or improved):

\section{How SATISFIED are you with available tools, methods or technologies to:}

$\begin{array}{llllll}\text { NOT } & & & & \text { EXTREMELY } \\ \text { SATISFIED } & 2 & 3 & 4 & 5 & \text { SATISFIED }\end{array}$

Examine soil stratigraphy 1

Conduct drilling for soil profiling

Determine site grade

Determine soil classification

Determine particle size distribution of soils

Obtain soil samples

Define mineralogy of sampled soil

Determine site geology

Examine soil phase relations

Test soil Atterberg limits

Perform unconfined compression test on sampled soil

Perform Ko consildated triaxial test on sampled soil

Perform constant rate of strain test on sampled soil

Perform shear box test on soil

Perform resonant column test on soil

Obtain undisturbed soil samples

Perform in-site strength test on soil (e.g., SPT blow count)

Perform compaction test on sampled soil

Perform consolidation test on sampled soil

Obtain Shelby tube soil samples

Determine organic content of sampled soil

Monitor landslides or slope stability

Investigate landslides (identify areas of potential rock fall)

Design retaining structures

Remediate land slides

Perform ground modification (e.g., grouting, dynamic compaction)

Perform ground retention (e.g., geo-grids, geo-textiles)

Design and install reinforced embankments

Design water removal and control systems

Design and install erosion control systems

Design and install drill shafts

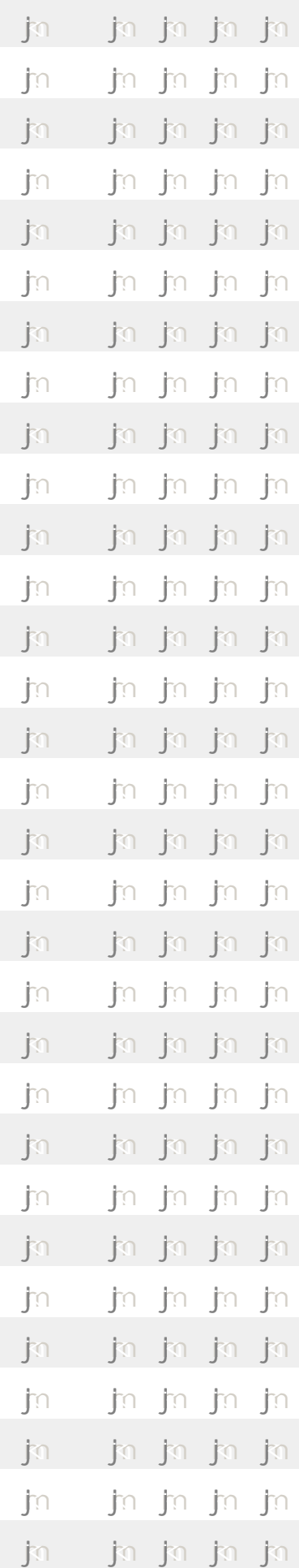




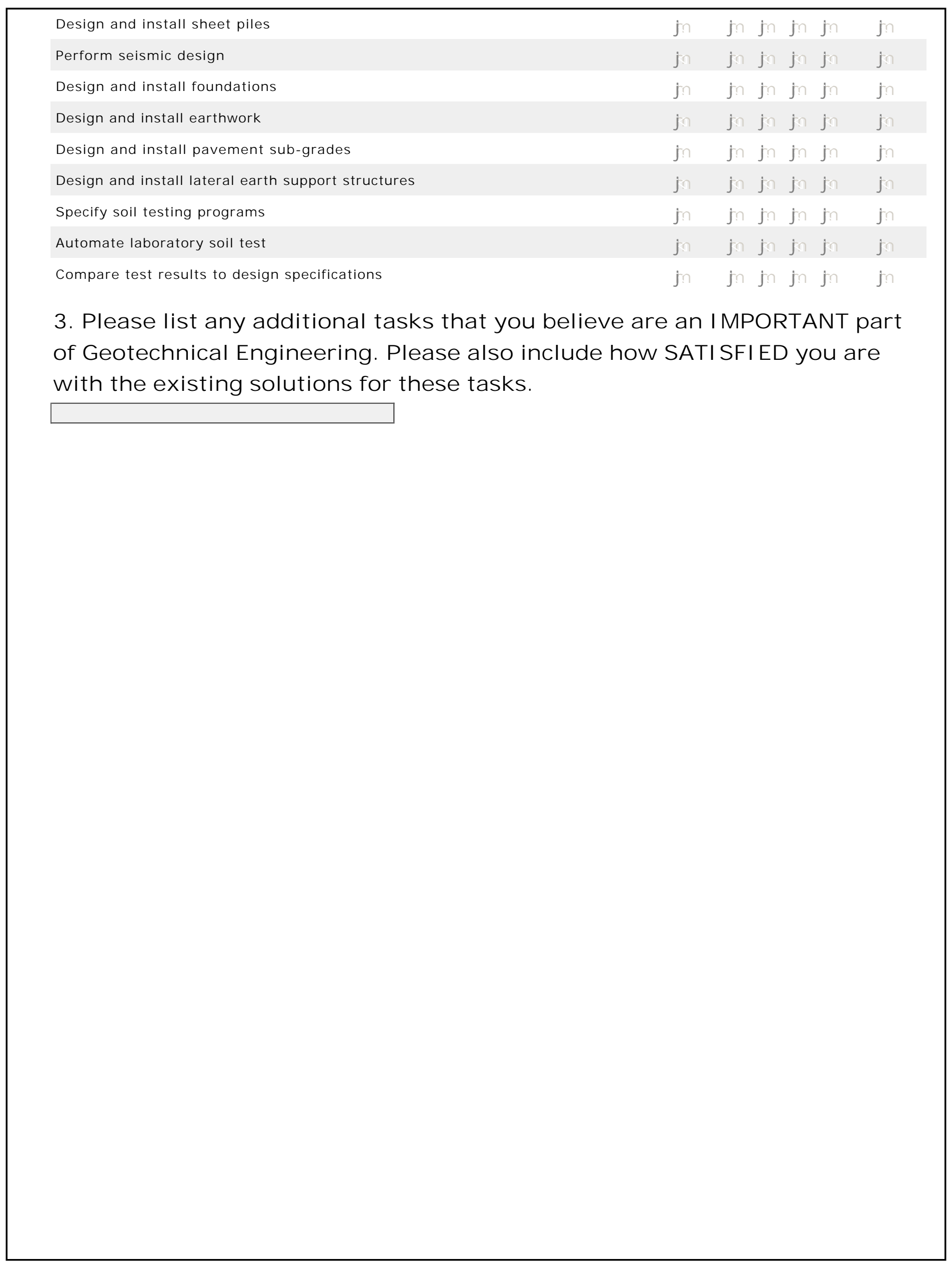




\section{Highway Operations "Maintenance and Repair"}

Using a 6 point scale, where 1 is "NOT IMPORTANT" and 6 is "EXTREMELY IMPORTANT" please state how

IMPORTANT each activity listed below is in your day to day role:

\section{How I MPORTANT is it for you to:}

Place/repair road signage

NOT

EXTREMELY

$\begin{array}{llllll}\text { IMPORTANT } & 2 & 3 & 4 & 5 & \text { IMPORTANT }\end{array}$

Place/repair signal lights

1

Place/repair guard rails

Install new bulbs in roadway light fixtures

Place/repair barricades

Install digital displays

Maintain road markings

Remove debris

Clear snow

Salt roads

Maintain landscaping

Maintain median

Clear roadways of accidents

Repair and maintain bridge deck

Prevent icing on bridges

Identify bridge-vehicle collision

Patch roadway cracks

Fill potholes

Plow

Deice

Repave roads

Remove trash from shoulders and roadsides

Design water removal and control

Repair/maintain bridge side rails

Prevent rust/corrosion of bridge steel members

Paint bridges

Place/repair bridge lighting

Clean bridge side rails

Maintain fleet vehicles

Manage storage of vehicles and equipment

Perform routine equipment maintenance

Order vehicle/equipment replacement parts

0

O

0

0

0

0

O

0

0

$\bigcirc$

0

0

0

0

0

0

0

0

0

0

0

0

0

0

0

0

0

0

0

0

0

0
0000

OOOO

$0 \bigcirc \bigcirc 0$

OOO

$0 \bigcirc \bigcirc 0$

0000

0000

$0 \bigcirc \bigcirc 0$

0000

0000

0000

0000

0000

$0 \bigcirc \bigcirc 0$

0000

0000

OOOO

0000

0000

0000

$0 \bigcirc \bigcirc 0$

OOOO

0000

0000

0000

$0 \bigcirc 00$

0000

0000

0000

$0 \bigcirc \bigcirc 0$

OOOO

1000
6

0

0

0

0

0

0

0

0

0

0

0

0

0

0

0

0

0

0

0

0

0

0

0

0 
Perform in field repairs of vehicles/machinery

$\bigcirc 00000$

Manage vehicle/equipment replacement and auction

00000

00000

Manage material inventory

00000

Order material

Manage receipt of materials

Excavate

Relocate excavated soil

Process materials

Compact soil

Drill hole for signage

Operate cranes

Rent and schedule crane rental

Assess site conditions for crane use

Train operators for safety/impact truck usage

Ensure awareness of road conditions by driving public

Secure worksite against trespassers

Monitor overheight/overweight vehicles

Warn traffic about vehicle overtilt risk

Employ warning systems to prevent accidents

Enable buddy systems for INDOT personnel during work activities

Prevent INDOT vehicles from rolling when unattended

Place roadway safety equipment (e.g. cones)

Analyze fuel cost for vehicle fleet

Track vehicle fleet

Communicate with drivers/personnel in the field

Transport tools and equipment

Monitor potable water

Prevent water damage on bridges

Manage traffic diversion

Train operators on safe use of equipment

Ensure proper equipment maintenance to enhance safety (e.g., brakes, tires)

0

O

O

O

O

O

O

O

0

0

0

$\bigcirc$

0

O

0

$\bigcirc$

0

0

0

0

O

0

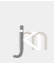

0

0

0

0
0000

0000

0000

0000

0000

0000

0000

0000

0000

0000

0000

0000

0000

0000

0000

0000

0000

0000

0000

0000

0000

0000

0000

OOO

0000

OOO

1000
0

0

0

0

0

0

0

0 


\section{Highway Operations "Maintenance and Repair"}

Using a 6 point scale, where 1 is "NOT SATISFIED" and 6 is "EXTREMELY SATISFIED" please state how SATISFIED you are with available solutions for each activity listed below (Note that selection of EXTREMELY SATISFIED indicates that you are pleased with the current solution for the task and that you do not believe it needs to be changed or improved):

\section{How SATISFIED are you with available tools, methods or technologies to:}

$\begin{array}{llllll}\text { NOT } & & & & \text { EXTREMELY } \\ \text { SATISFIED } & 2 & 3 & 4 & 5 & \text { SATISFIED }\end{array}$

Place/repair road signage

Place/repair signal lights

Place/repair guard rails

Install new bulbs in roadway light fixtures

Place/repair barricades

Install digital displays

Maintain road markings

Remove debris

Clear snow

Salt roads

Maintain landscaping

Maintain median

Clear roadways of accidents

Repair and maintain bridge deck

Prevent icing on bridges

Identify bridge-vehicle collision

Patch roadway cracks

Fill potholes

Plow

Deice

Repave roads

Remove trash from shoulders and roadsides

Design water removal and control

Repair/maintain bridge side rails

Prevent rust/corrosion of bridge steel members

Paint bridges

Place/repair bridge lighting

Clean bridge side rails

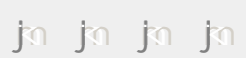

Maintain fleet vehicles 
Order vehicle/equipment replacement parts

O 000

00000

Perform in field repairs of vehicles/machinery

O

Manage vehicle/equipment replacement and auction

Manage material inventory

Order material

Manage receipt of materials

Excavate

Relocate excavated soil

Process materials

Compact soil

Drill hole for signage

Operate cranes

Rent and schedule crane rental

Assess site conditions for crane use

Train operators for safety/impact truck usage

Ensure awareness of road conditions by driving public

Secure worksite against trespassers

Monitor overheight/overweight vehicles

Warn traffic about vehicle overtilt risk

Employ warning systems to prevent accidents

Enable buddy systems for INDOT personnel during work activities

Prevent INDOT vehicles from rolling when unattended

Place roadway safety equipment (e.g. cones)

Analyze fuel cost for vehicle fleet

Track vehicle fleet

Communicate with drivers/personnel in the field

Transport tools and equipment

Monitor potable water

Prevent water damage on bridges

Manage traffic diversion

Train operators on safe use of equipment

Ensure proper equipment maintenance to enhance safety (e.g., brakes, tires)

\section{Please list any additional tasks that you believe are an I MPORTANT part of Highway Operations. Please also include how SATI SFI ED you are with the existing solutions for these tasks.}




\section{Hydraulics Engineering}

Using a 6 point scale, where 1 is "NOT IMPORTANT" and 6 is "EXTREMELY IMPORTANT" please state how IMPORTANT each activity listed below is in your day to day role:

\section{How I MPORTANT is it for you to:}

Estimate hydraulic gradient

Formulate ways to prevent erosion

Formulate ways to limit freeze thaw on embankments

$\begin{array}{llllll}\text { IMPORTANT } & 2 & 3 & 4 & 5 & \text { IMPORTANT }\end{array}$

Monitor overflow conditions at roadway crossings

Detect corroded pipes in the ground

Observe overflow to facilitate modeling

Monitor silt collection

Ensure proper roadway runoff

Monitor sub-soil and stormwater drainage

Model water flow in infrastructure systems

Design flow through bridge pilings

Assess bridge pier scour

Design culverts

Design storm drains

Design detention ponds

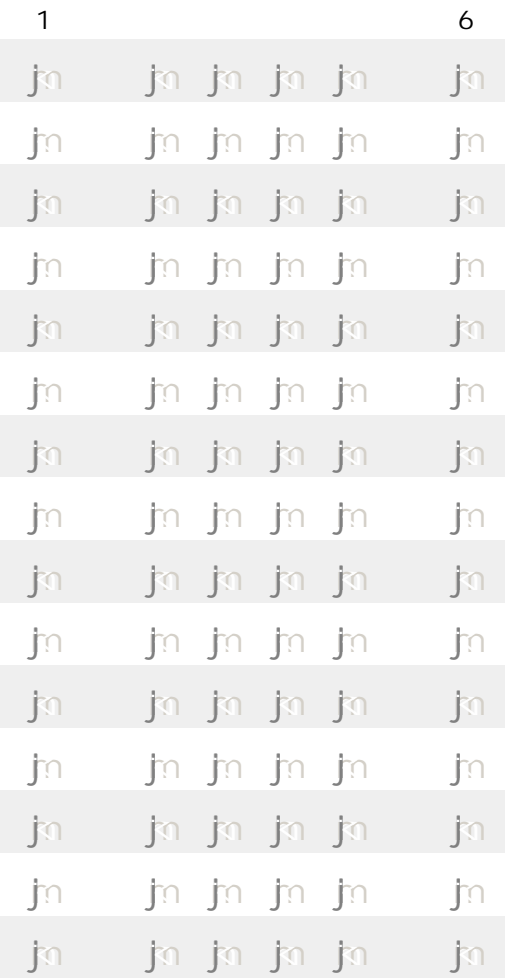




\title{
2. Hydraulics Engineering
}

Using a 6 point scale, where 1 is "NOT SATISFIED" and 6 is "EXTREMELY SATISFIED" please state how SATISFIED you are with available solutions for each activity listed below (Note that selection of EXTREMELY SATISFIED indicates that you are pleased with the current solution for the task and that you do not believe it needs to be changed or improved):

\section{How SATISFIED are you with available tools, methods or technologies to:}

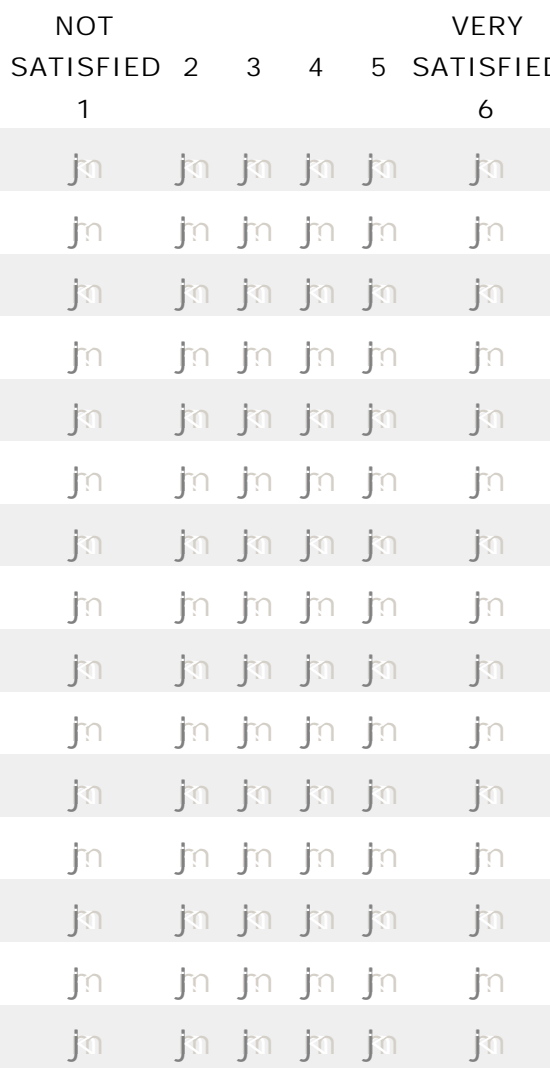

\begin{abstract}
Estimate hydraulic gradient
Monitor silt collection

Ensure proper roadway runoff

Assess bridge pier scour

Design culverts

Design storm drains

Design detention ponds
\end{abstract}

Formulate ways to prevent erosion

Formulate ways to limit freeze thaw on embankments

Monitor overflow conditions at roadway crossings

Detect corroded pipes in the ground

Observe overflow to facilitate modeling

Monitor sub-soil and stormwater drainage

Model water flow in infrastructure systems

Design flow through bridge pilings

3. Please list any additional tasks that you believe are an I MPORTANT part of Hydraulics Engineering. Please also include how SATISFIED you are with the existing solutions for these tasks. 


\section{Information Technology Systems}

Using a 6 point scale, please evaluate how IMPORTANT each activity is.

For instance:

1. Clean the floor.

How important is this task? NOT IMPORTANT or VERY IMPORTANT

\section{How important is it for you to:}

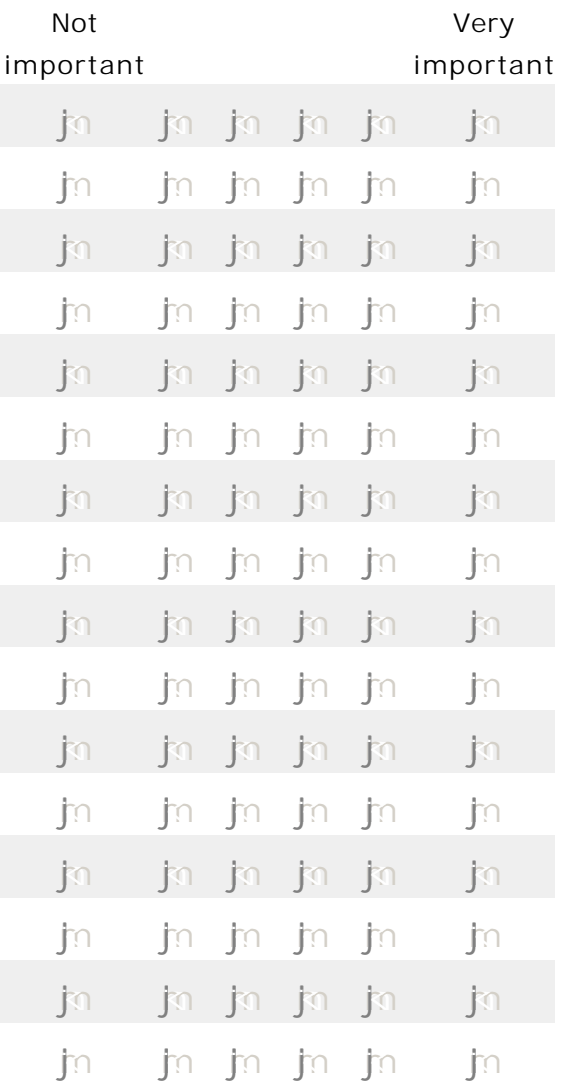

Harvest power supply remotely

Monitor traffic flow

Detect traffic at intersections

Apply Geographic Information System (GIS) technology

Apply Computer Aided Design (CAD) technology

Manage database and document

Ensure driver awareness of directions (sign post)

Provide real-time information to drivers

Communicate specific and sudden situations to drivers

Provide roadside assistance to the driving public

Provide medical care to the driving public

Communicate pending policy/legislative decisions to the driving public

Gather/give feedback on pending legislative policies

Ensure policy awareness for driving public

Apply graphical software to road designs

Maintain geographic information

portant portant 


\section{Information Technology Systems}

Using a 6 point scale, how SATISFIED you are with the available solutions for this task.

For instance:

1. Clean the floor.

How satisfied are you with the technologies, tools or methods available for this task? NOT SATISFIED or VERY SATISFIED

\section{How satisfied are you with available tools, methods or technologies to:}

\begin{tabular}{|c|c|c|}
\hline & $\begin{array}{c}\text { Not } \\
\text { satisfied }\end{array}$ & $\begin{array}{c}\text { Very } \\
\text { Satisfied }\end{array}$ \\
\hline \multicolumn{3}{|l|}{ Harvest power supply remotely } \\
\hline \multicolumn{3}{|l|}{ Monitor traffic flow } \\
\hline \multicolumn{3}{|l|}{ Detect traffic at intersections } \\
\hline \multicolumn{3}{|c|}{ Apply Geographic Information System (GIS) technology } \\
\hline \multicolumn{3}{|c|}{ Apply Computer Aided Design (CAD) technology } \\
\hline \multicolumn{3}{|l|}{ Manage database and document } \\
\hline \multicolumn{3}{|c|}{ Ensure driver awareness of directions (sign post) } \\
\hline \multicolumn{3}{|l|}{ Provide real-time information to drivers } \\
\hline \multicolumn{3}{|c|}{ Communicate specific and sudden situations to drivers } \\
\hline \multicolumn{3}{|c|}{ Provide roadside assistance to the driving public } \\
\hline \multicolumn{3}{|l|}{ Provide medical care to the driving public } \\
\hline \multicolumn{3}{|c|}{ Communicate pending policy/legislative decisions to the driving public } \\
\hline \multicolumn{3}{|c|}{ Gather/give feedback on pending legislative policies } \\
\hline \multicolumn{3}{|l|}{ Ensure policy awareness for driving public } \\
\hline Apply graphical software to road designs & & \\
\hline Maintain geographic information & & \\
\hline
\end{tabular}

3. Please list any additional jobs or tasks that you believe are an important part of I nformation Technology Systems. Please also include how satisfied you are with the existing solutions to the job. 


\section{Materials Management}

Using a 6 point scale, where 1 is "NOT IMPORTANT" and 6 is "EXTREMELY IMPORTANT" please state how IMPORTANT each activity listed below is in your day to day role:

\section{How I MPORTANT is it for you to:}

Create mix designs for pavements

$\begin{array}{llllll}\text { IMPORTANT } & 2 & 3 & 4 & 5 & \text { IMPORTANT }\end{array}$

Select aggregate type

Determine proper aggregate size

Perform quality testing on project materials

Test concrete slump

Test concrete compressive strength

Conduct Atterberg limit tests

Monitor deterioration of concrete infrastructure

Monitor cracking of concrete infrastructure

Monitor strength of concrete for infrastructure projects

Manage material stockpiles

Oversee aggregate transport within State

Manage aggregate storage within State

Ensure compliance with specifications for projects

Ensure use of proper aggregates

Oversee material testing

Oversee concrete pours

Assess proper use of aggregates in hot mix asphalt

Select proper ad-mixtures for concrete/asphalt designs

Monitor proper use of ad-mixtures during roadway installation

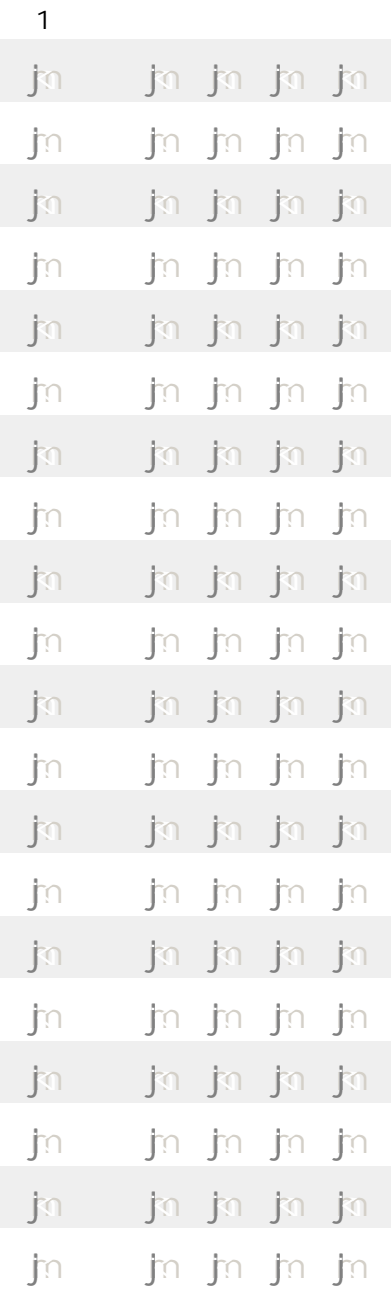

6

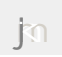

0

0

O

O

0

0

0

0

O

O

0

0

0

0

0

0

0

0

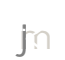




\section{Materials Management}

Using a 6 point scale, where 1 is "NOT SATISFIED" and 6 is "EXTREMELY SATISFIED" please state how SATISFIED you are with available solutions for each activity listed below (Note that selection of EXTREMELY SATISFIED indicates that you are pleased with the current solution for the task and that you do not believe it needs to be changed or improved):

\section{How satisfied are you with available tools, methods or technologies to:}

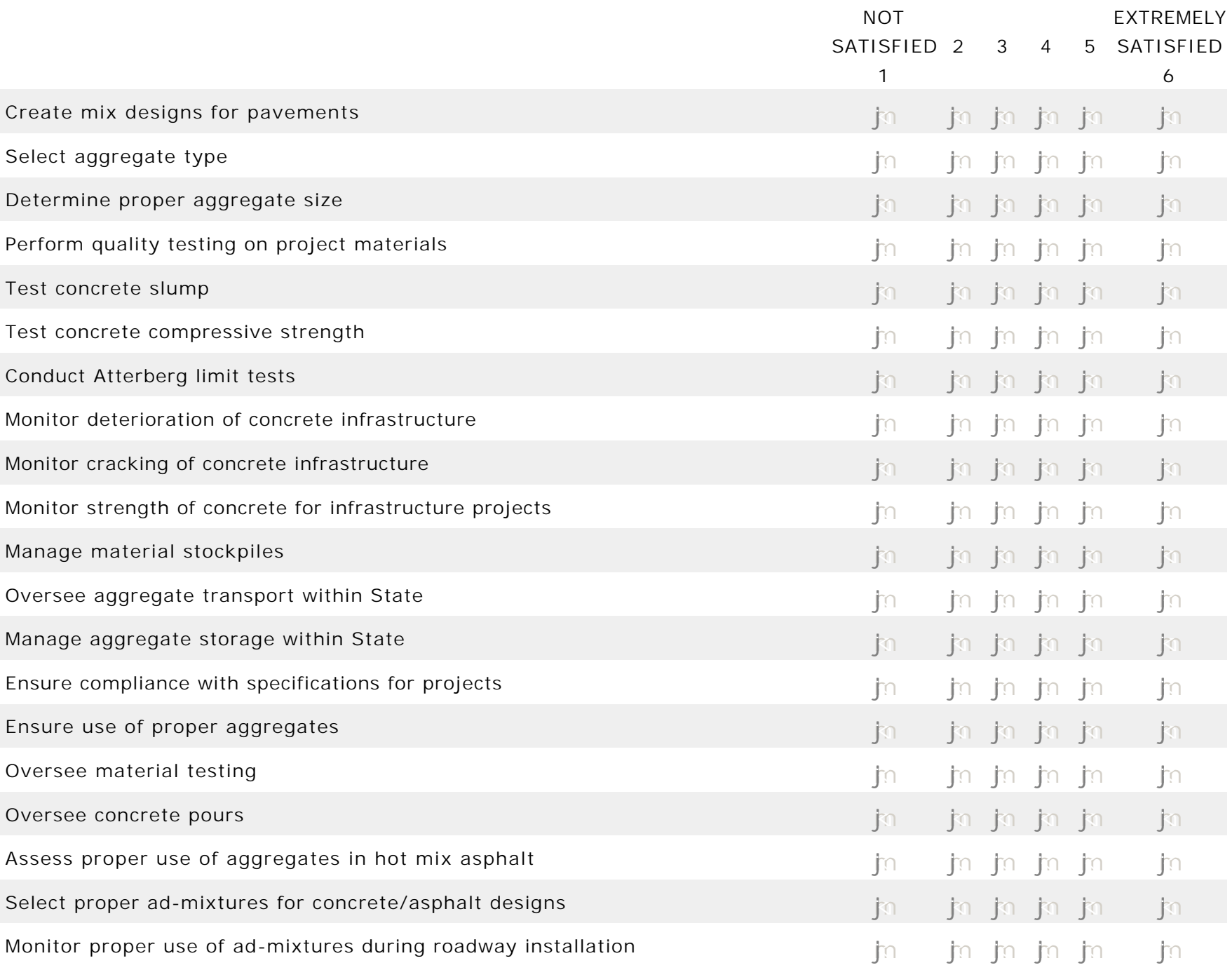

3. Please list any additional tasks that you believe are an I MPORTANT part of Materials Management. Please also include how SATI SFI ED you are with the existing solutions for these tasks. 


\section{Pavement Engineering}

Using a 6 point scale, where 1 is "NOT IMPORTANT" and 6 is "EXTREMELY IMPORTANT" please state how

IMPORTANT each activity listed below is in your day to day role:

\section{How I MPORTANT is it for you to:}

Plan a roadway project

Perform a preliminary roadway survey

$\begin{array}{llllll}\text { IMPORTANT } & 2 & 3 & 4 & 5 & \text { IMPORTANT }\end{array}$

Define roadway alignment

Scope a roadway project

Budget a roadway project

Design pavement cross sections

Prepare and approve pavement projects for contract letting

Monitor warranties for a project

Propose pavement structure-related specifications and special provisions

Investigate pavement failures

Select and specify projects for pavement maintenance and/or rehabilitation

Monitor pavement condition (e.g. roughness, friction)

Manage pavement condition

Design under-pavement drainage systems

Test placed materials for alignment with design specifications

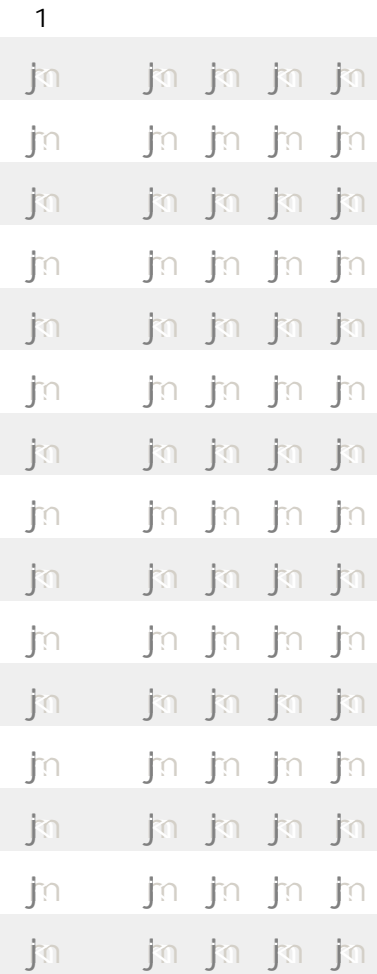




\title{
2. Pavement Engineering
}

Using a 6 point scale, where 1 is "NOT SATISFIED" and 6 is "EXTREMELY SATISFIED" please state how SATISFIED you are with available solutions for each activity listed below (Note that selection of EXTREMELY SATISFIED indicates that you are pleased with the current solution for the task and that you do not believe it needs to be changed or improved):

\section{How SATISFIED are you with available tools, methods or technologies to:}

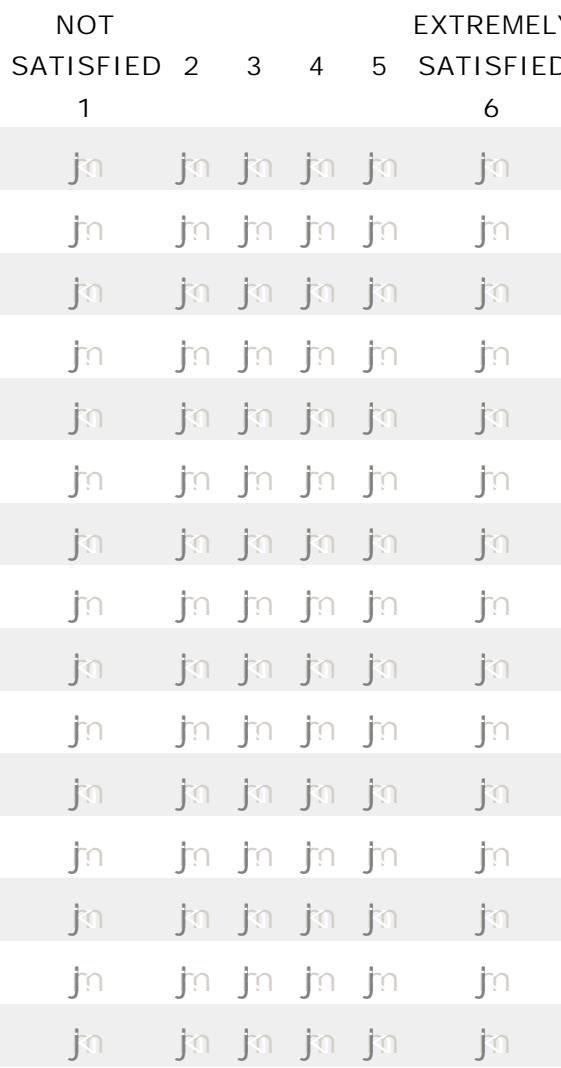

\begin{abstract}
Plan a roadway project
Perform a preliminary roadway survey

Define roadway alignment

Scope a roadway project

Budget a roadway project

Design pavement cross sections

Prepare and approve pavement projects for contract letting

Monitor warranties for a project

Propose pavement structure-related specifications and special provisions

Investigate pavement failures

Select and specify projects for pavement maintenance and/or rehabilitation

Monitor pavement condition (e.g. roughness, friction)

Manage pavement condition

Design under-pavement drainage systems

Test placed materials for alignment with design specifications
\end{abstract}

\section{Please list any additional tasks that you believe are an I MPORTANT part of Pavement Engineering. Please also include how SATI SFIED you are with the existing solutions for these tasks.}




\section{Safety}

Using a 6 point scale, where 1 is "NOT IMPORTANT" and 6 is "EXTREMELY IMPORTANT" please state how

IMPORTANT each activity listed below is in your day to day role:

\section{How I MPORTANT is it for you to:}

Maintain awareness of DOT worker location in the field $\begin{array}{llllll}\text { IMPORTANT } & 2 & 3 & 4 & 5 & \text { IMPORTANT }\end{array}$

\section{Optimize working conditions}

Enhance crane safety

Document job site safety inspections

Make workers more visible on construction sites

Alert site workers to highway boundaries

Alert machinery operators to highway boundaries

Alert site workers to overhead hazards

Alert site workers/machinery operators to ground instability

Enhance worker fall protection

Enhance worker noise protection

Increase awareness of chemical hazards

Ensure availability/accessibility of material safety data sheet

Protect workers from falling objects

Limit severity of fall hazards/injuries

Eliminate tripping hazards

Enhance worker awareness of location of other workers

Minimize/control electrical hazards

Enhance awareness of site wind conditions

Alert workers to slope instability

Provide emergency response in the event of an accident

Maintain/update safety procedures

Prevent worker/auto collisions

Reduce traffic speed in roadway work areas

Detour traffic around project

Document all accidents

Limit auto/structure collision severity

Limit/eliminate divided highway collisions

Prevent or limit going off road/over embankments

Increase driver awareness of potential roadway hazards

Increase ability to provide drivers with real time information

Alert drivers to weather related hazards

0

0

$\bigcirc$

0

0

0

0

0

0

0

0

0

0

0

0

0

0

0

0

0

0

0

0

0

0

0

0

0

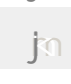

0

0

0
$0 \bigcirc \bigcirc 0$

$0 \bigcirc \bigcirc 0$ $0 \bigcirc \bigcirc 0$ 0000 $0 \bigcirc \bigcirc 0$ 0000 $0 \bigcirc \bigcirc 0$ $0 \bigcirc \bigcirc 0$ OOO $0 \bigcirc 00$ $0 \bigcirc 00$ $0 \bigcirc \bigcirc 0$ $0 \bigcirc 00$ $0 \bigcirc 00$ 0000 0000 $0 \bigcirc 00$ OOOO $0 \bigcirc 00$ OOO 0000 $0 \bigcirc \bigcirc 0$ $0 \bigcirc 00$ $0 \bigcirc 00$ OOOO $0 \bigcirc 00$ OOOO OOOO 0000 $0 \bigcirc 00$ $0 \bigcirc \bigcirc 0$ $0 \bigcirc \bigcirc 0$
6

0 


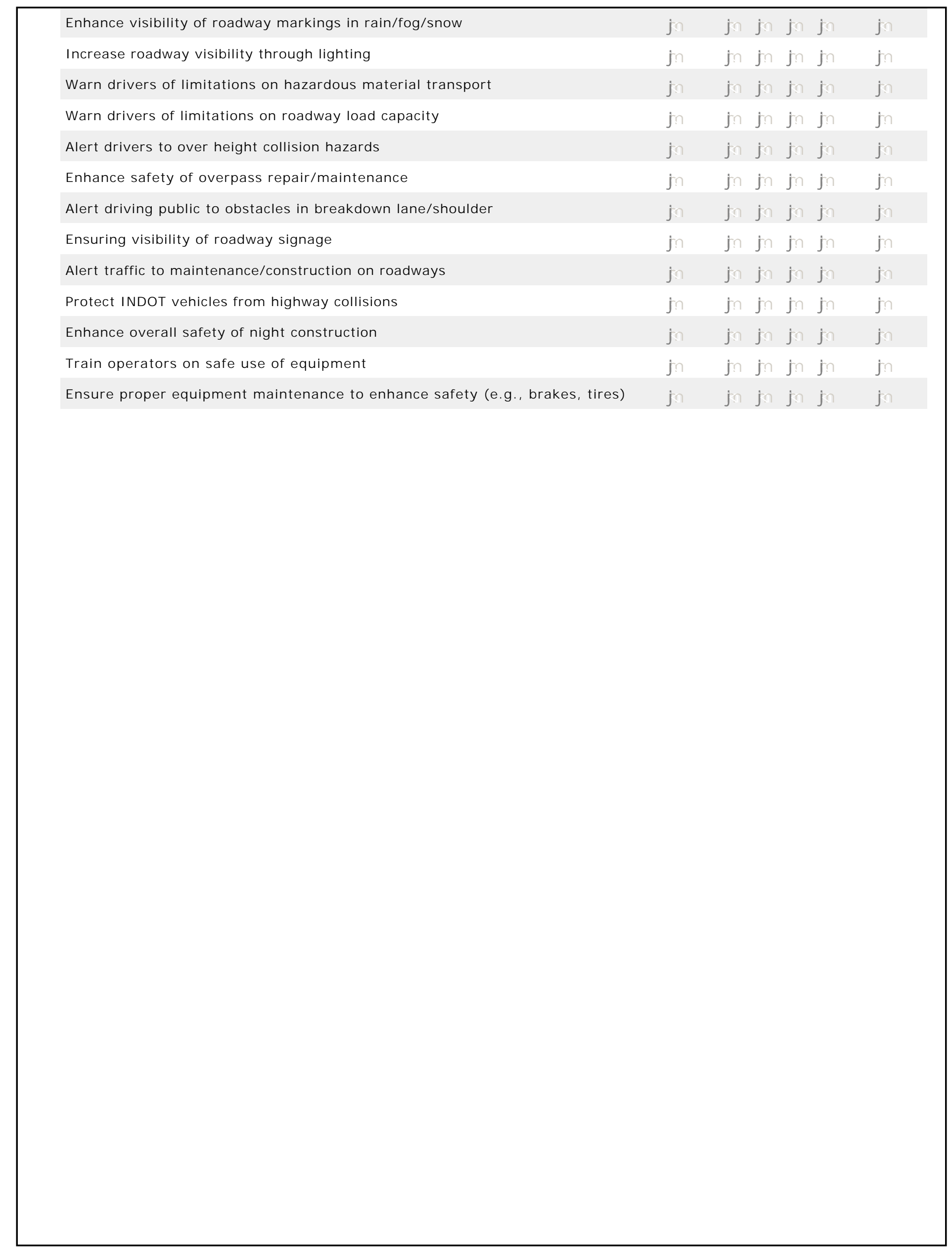




\section{Safety}

Using a 6 point scale, where 1 is "NOT SATISFIED" and 6 is "EXTREMELY SATISFIED" please state how SATISFIED you are with available solutions for each activity listed below (Note that selection of EXTREMELY SATISFIED indicates that you are pleased with the current solution for the task and that you do not believe it needs to be changed or improved):

\section{How SATISFIED are you with available tools, methods or technologies to:}

$\begin{array}{llllll}\text { NOT } & & & & \text { EXTREMELY } \\ \text { SATISFIED } & 2 & 3 & 4 & 5 & \text { SATISFIED }\end{array}$

Maintain awareness of DOT worker location in the field 1

Optimize working conditions

Enhance crane safety

Document job site safety inspections

Make workers more visible on construction sites

Alert site workers to highway boundaries

Alert machinery operators to highway boundaries

Alert site workers to overhead hazards

Alert site workers/machinery operators to ground instability

Enhance worker fall protection

Enhance worker noise protection

Increase awareness of chemical hazards

Ensure availability/accessibility of material safety data sheet

Protect workers from falling objects

Limit severity of fall hazards/injuries

Eliminate tripping hazards

Enhance worker awareness of location of other workers

Minimize/control electrical hazards

Enhance awareness of site wind conditions

Alert workers to slope instability

Provide emergency response in the event of an accident

Maintain/update safety procedures

Prevent worker/auto collisions

Reduce traffic speed in roadway work areas

Detour traffic around project

Document all accidents

Limit auto/structure collision severity

Limit/eliminate divided highway collisions

Prevent or limit going off road/over embankments

Increase driver awareness of potential roadway hazards

Increase ability to provide drivers with real time information

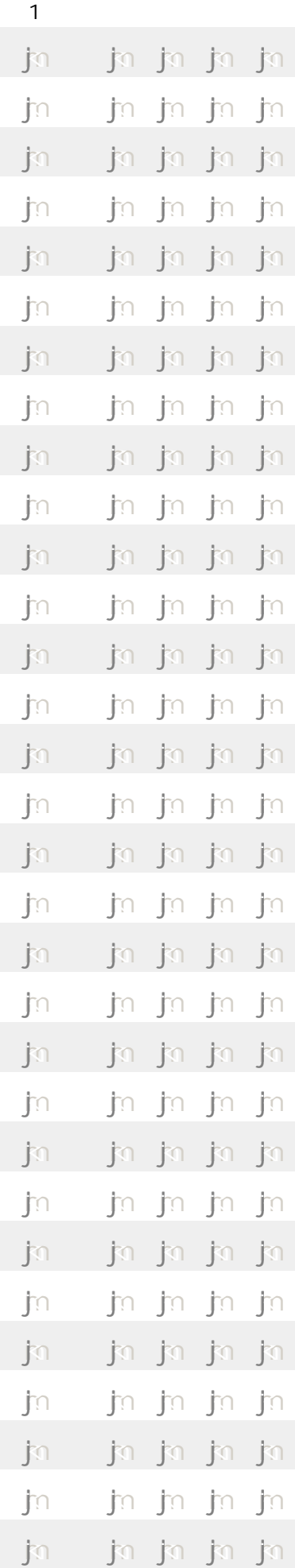


Alert drivers to weather related hazards

Enhance visibility of roadway markings in rain/fog/snow

Increase roadway visibility through lighting

Warn drivers of limitations on hazardous material transport

Warn drivers of limitations on roadway load capacity

Alert drivers to over height collision hazards

Enhance safety of overpass repair/maintenance

Alert driving public to obstacles in breakdown lane/shoulder

Ensuring visibility of roadway signage

Alert traffic to maintenance/construction on roadways

Protect INDOT vehicles from highway collisions

Enhance overall safety of night construction

Train operators on safe use of equipment

Ensure proper equipment maintenance to enhance safety (e.g., brakes, tires)

3. Please list any additional tasks that you believe are an I MPORTANT part of Safety. Please also include how SATI SFIED you are with the existing solutions for these tasks. 


\section{Structural Engineering}

Using a 6 point scale, where 1 is "NOT IMPORTANT" and 6 is "EXTREMELY IMPORTANT" please state how

IMPORTANT each activity listed below is in your day to day role:

\section{How I MPORTANT is it for you to:}

Monitor corrosion of steel in reinforced concrete 1

Monitor corrosion of steel structures

Evaluate box beam post-tensioning

Monitor joints in bridges

Monitor bridge deflections

Perform non-destructive evaluation of steel connections

Protect bridges from steel corrosion

Calculate working loads for structures

Determine extreme events that could impact design (e.g. Fifty-year flood)

Design bridges

Design emergency support structures

Improve rail crossing smoothness

Improve rail crossing warnings

Inspect bridges

Model wind loading effects

Model freeze thaw effects

Determine thermal effects on bridge deck stability and alignment

Perform finite element analysis

Utilize CAD rendered 3-D drawings

Review sub-contracted design works

Check/validate project compliance with codes

Perform in-situ/in-field sensing of structures

Install field instrumentation

Monitor field instrumentation

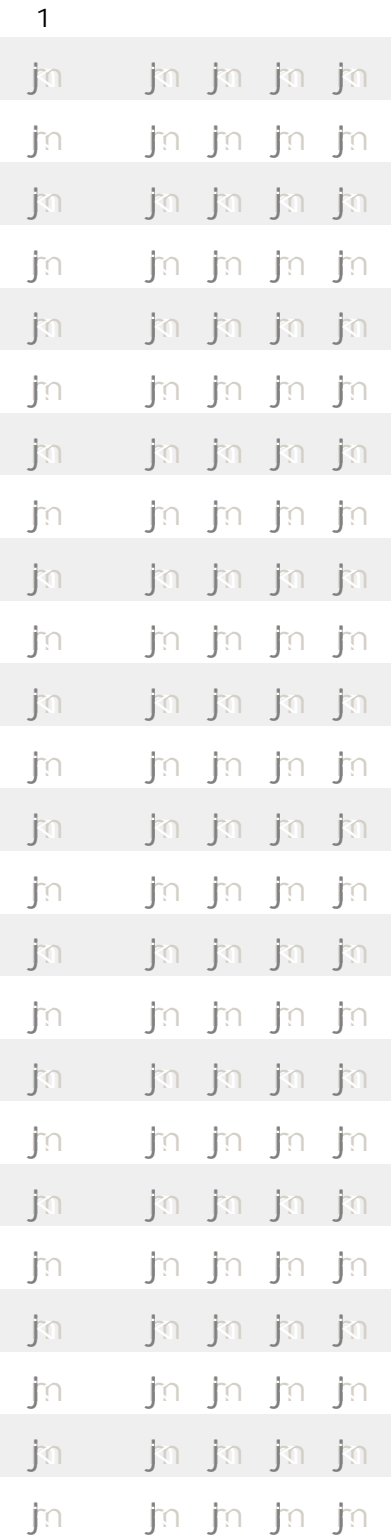




\section{Structural Engineering}

Using a 6 point scale, where 1 is "NOT SATISFIED" and 6 is "EXTREMELY SATISFIED" please state how SATISFIED you are with available solutions for each activity listed below (Note that selection of EXTREMELY SATISFIED indicates that you are pleased with the current solution for the task and that you do not believe it needs to be changed or improved):

\section{How SATISFIED are you with available tools, methods or technologies to:}

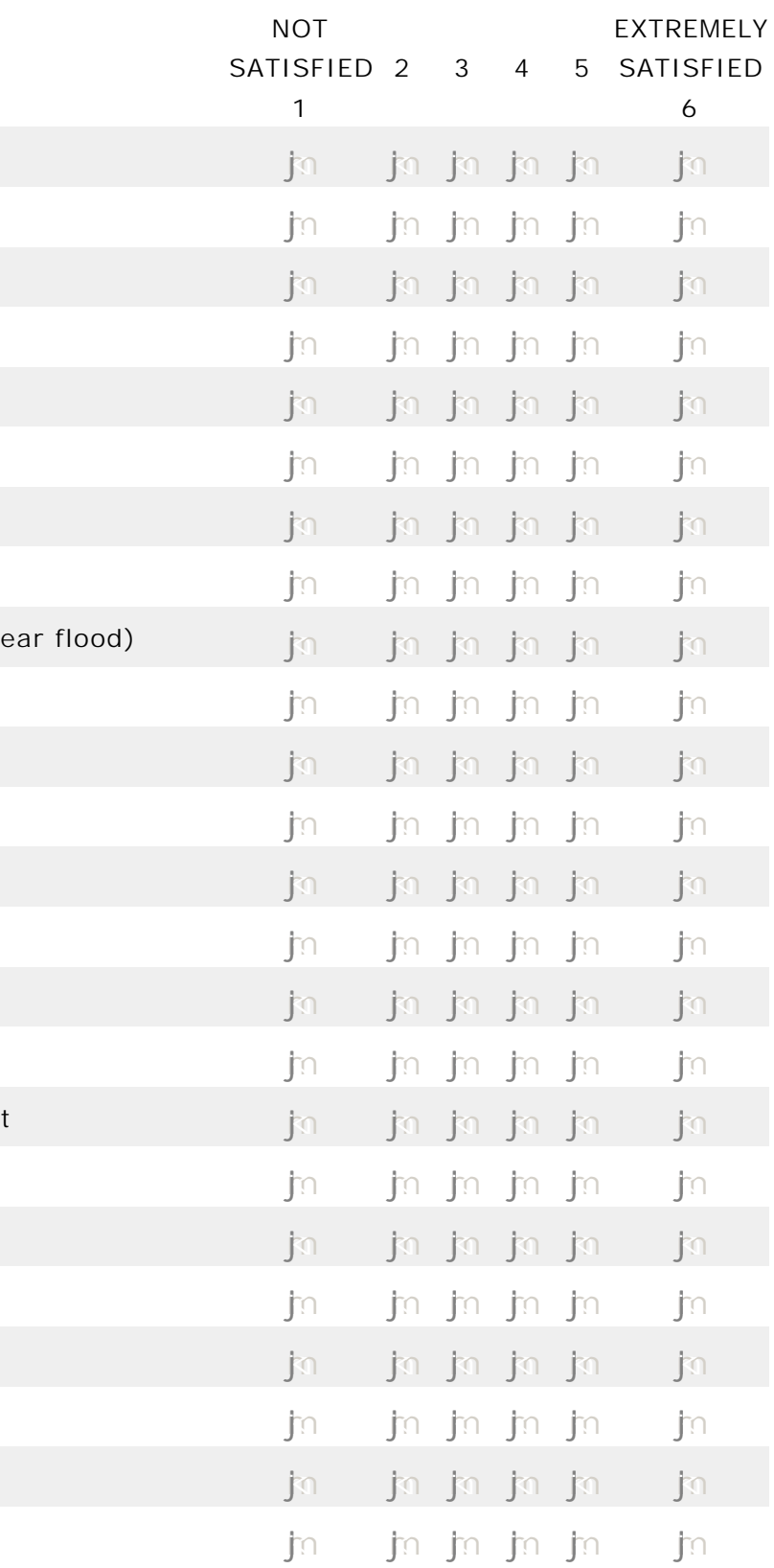

Monitor corrosion of steel in reinforced concrete

Monitor corrosion of steel structures

Evaluate box beam post-tensioning

Monitor joints in bridges

Monitor bridge deflections

Perform non-destructive evaluation of steel connections

Protect bridges from steel corrosion

Calculate working loads for structures

Determine extreme events that could impact design (e.g. Fifty-year flood)

Design bridges

Design emergency support structures

Improve rail crossing smoothness

Improve rail crossing warnings

Inspect bridges

Model wind loading effects

Model freeze thaw effects

Determine thermal effects on bridge deck stability and alignment

Perform finite element analysis

Utilize CAD rendered 3-D drawings

Review sub-contracted design works

Check/validate project compliance with codes

Perform in-situ/in-field sensing of structures

Install field instrumentation

Monitor field instrumentation

6

3. Please list any additional tasks that you believe are an I MPORTANT part of Structural Engineering. Please also include how SATI SFI ED you are with the existing solutions for these tasks. 


\section{Traffic Management}

Using a 6 point scale, where 1 is "NOT IMPORTANT" and 6 is "EXTREMELY IMPORTANT" please state how

IMPORTANT each activity listed below is in your day to day role:

\section{How I MPORTANT is it for you to:}

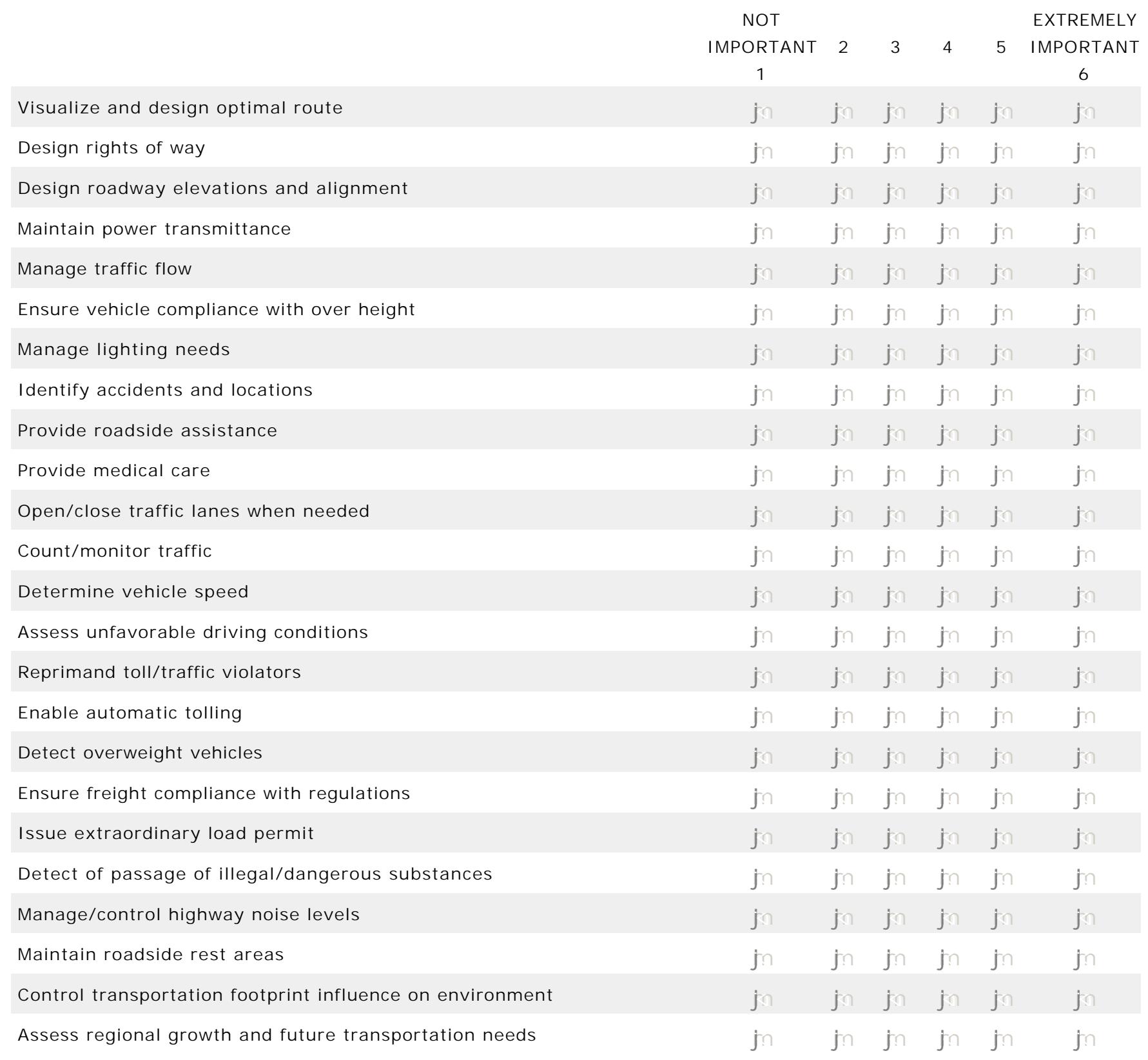




\section{Traffic Management}

Using a 6 point scale, where 1 is "NOT SATISFIED" and 6 is "EXTREMELY SATISFIED" please state how SATISFIED you are with available solutions for each activity listed below (Note that selection of EXTREMELY SATISFIED indicates that you are pleased with the current solution for the task and that you do not believe it needs to be changed or improved):

\section{How SATI SFI ED are you with available tools, methods or technologies to:}

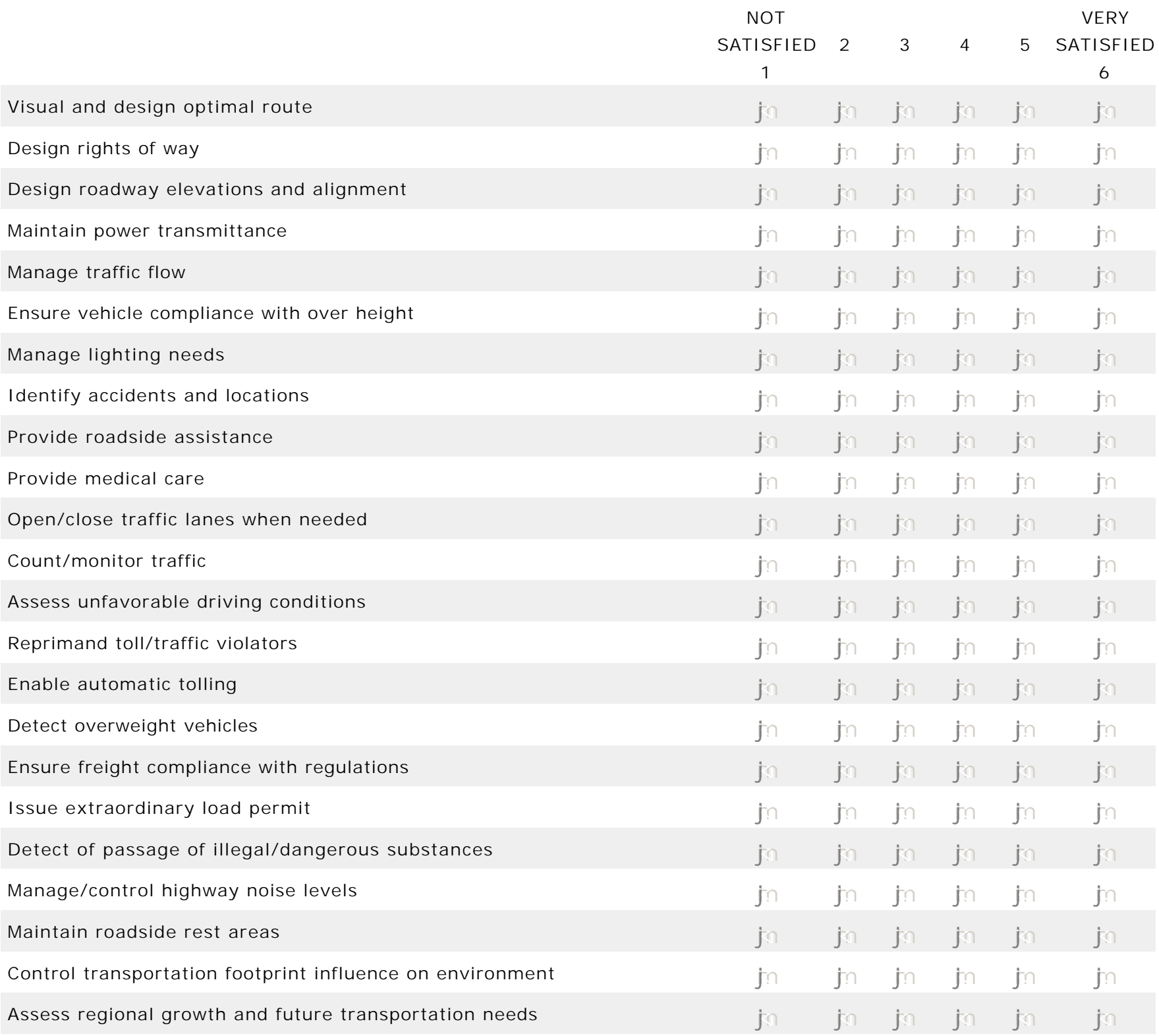

3. Please list any additional tasks that you believe are an I MPORTANT part of Traffic Management. Please also include how SATI SFI ED you are with the existing solutions for these tasks. 
Appendix D

Marketing Templates 
As described in section 5.6 of this report, the adoption of technologies must follow a staged process that very much resembles the previously discussed marketing purchase funnel, in which consumers (here technology "adopters") must be provided with a delicate balance of pertinent information to drive decision-making at each stage of the process. Thus, this appendix presents samples of internal marketing templates that could be used to drive technology adoption decisions throughout INDOT. Each of these templates, namely, the "Technology Overview", the "Technology Benefit Analysis", the "Technology Evaluation Plan", and the "Technology Adoption Rationale" drive decision making at different stages and thus the information necessary to complete each template varies in content and intent. Each of these templates is described below.

The Technology Overview is designed to convey only the essence of a new technology, that is, the key fundamental aspects of a technology that may improve current practices across INDOT. The intent is to drive awareness of a new technology among Advisory Group members, communicating only the information necessary to answer the question: should we investigate this technology? Therefore, the information captured by this template is related to the sources of a potential technology, the capabilities of a potential technology, the needs addressed by a technology, the functional areas that will benefit from a technology, the benefits that a technology will provide, and the technologies and processes that the technology might enhance and/or replace.

The Technology Benefit Analysis intends to capture a more detailed to drive consideration of a novel technology, and thus represents a means to link needs and solutions with the Connect and Develop-like portal discussed in section 5.2 as a potential vehicle for the distribution of the template. The template includes information such as the capabilities of the new technology, the benefits of a new technology, cost-benefit analysis of implementing a new technology, short and long term goals and objectives for the technology's implementation, as well as key action items to implement the technology.

The Technology Evaluation Plan intends to drive the evaluation of a potential new technology by describing in much more detail than the two previously described templates. The Technology Implementation Plan strives to guide the potential decision maker through an evaluation process that will lead INDOT to make a "purchase" (here an "adoption") decision regarding a new technology. Thus, in addition to the information presented in the previously discussed templates, the Technology Evaluation Plan strives to capture the insights such as the distribution of evaluation tasks and responsibilities among personnel, success measures and their corresponding means, cost, importance and ease of testing, as well as benefits to both INDOT and the public.

Finally, the Technology Adoption Rationale template intends to drive adoption and retention by end users of a new technology. In other words, once a technology has been evaluated the template will serve as a vehicle to drive broadened use. Therefore, the information that the template strives to capture includes, once again, the capabilities of the technology and the needs that it (the technology) can address, and in addition, the proven success measures and relevant outcomes, benefits to the public, key contacts to learn more about the technology and testimonials from these contacts, as well as a marketing plan for the technology. 


\section{Technology Overview ${ }^{1}$}

\begin{tabular}{|c|c|c|}
\hline Name of the potential technology: & & \\
\hline The source for this technology is: & & \\
\hline This technology is capable of: & & \\
\hline $\begin{array}{l}\text { The important and unsatisfied } \\
\text { needs that this technology may } \\
\text { address are: }\end{array}$ & & \\
\hline $\begin{array}{l}\text { The functional areas that will } \\
\text { benefit from the technology are: }\end{array}$ & $\begin{array}{l}\text { Transportation Planning, Finance and Policy } \\
\text { Program Engineering and Pavement } \\
\text { Design and Production } \\
\text { Construction and Contracts } \\
\text { Traffic Safety and Management } \\
\text { Maintenance and operations }\end{array}$ & $\begin{array}{l}\square \\
\square \\
\square \\
\square \\
\square \\
\square\end{array}$ \\
\hline $\begin{array}{l}\text { The benefits that this technology } \\
\text { will provide are: }\end{array}$ & & \\
\hline $\begin{array}{l}\text { The technologies and processes } \\
\text { that the technology might replace } \\
\text { include: }\end{array}$ & & \\
\hline
\end{tabular}




\section{Technology Benefit Analysis ${ }^{1}$}

\begin{tabular}{|l|l|}
\hline Name of the potential technology: & \\
\hline This technology is capable of: & \\
\hline $\begin{array}{l}\text { The important and unsatisfied } \\
\text { needs that the technology may } \\
\text { address are: }\end{array}$ & \\
\hline
\end{tabular}

Benefited functional areas, current practices and proposed process

\begin{tabular}{|l|l|}
\hline $\begin{array}{l}\text { The functional areas that will } \\
\text { benefit from the technology are: }\end{array}$ & $\begin{array}{l}\text { Transportation Planning, Finance and Policy } \\
\text { Program Engineering and Pavement } \\
\text { Design and Production } \\
\text { Construction and Contracts } \\
\text { Traffic Safety and Management } \\
\text { Maintenance and operations }\end{array}$ \\
\hline $\begin{array}{l}\text { The technologies and processes in } \\
\text { the above functional areas that } \\
\text { might be enhanced and/or } \\
\text { replaced by the technology } \\
\text { include: }\end{array}$ & \\
\hline $\begin{array}{l}\text { The technology can be acquired } \\
\text { by: }\end{array}$ & \\
\hline
\end{tabular}




\section{Technology Benefit Analysis ${ }^{1}$}

Cost-benefit analysis and funding source of the implementation of the new technology

The potential costs associated with the technology are:

The potential benefits associated with the technology are:

The short term goals and objectives for the technology's implementation are:

1.

2.

3.

The long term goals and objectives for the technology's implementation are:

1.

2.

3.

Key action items to pursue the new technology include:

1.

2.

3. 


\section{Technology Evaluation Plan $^{1}$}

\begin{tabular}{|l|l|}
\hline Name of the potential technology: & \\
\hline This technology is capable of: & \\
\hline $\begin{array}{l}\text { The important and unsatisfied needs } \\
\text { that the technology may address are: }\end{array}$ & \\
\hline
\end{tabular}

The short term goals and objectives for the technology's implementation are:

1.

2.

3.

4.

The long term goals and objectives for the technology's implementation are:

1.

2.

3. 


\section{Technology Evaluation Plan ${ }^{1}$}

Issues to assess to justify pursuit of the technology include:

1.

2.

3.

4.

5.

Success measures, key tests to conduct, ease of testing and relevant (preliminary) data

\begin{tabular}{|c|c|c|c|c|c|c|}
\hline Success measure & Key test & $\begin{array}{l}\text { Significance/ } \\
\text { Impact }\end{array}$ & $\begin{array}{l}\text { Ease of } \\
\text { testing }\end{array}$ & Cost & Rank & $\begin{array}{l}\text { Relevant } \\
\text { data } \\
\text { (attached } \\
\text { files) }\end{array}$ \\
\hline & & & & & & \\
\hline & & & & & & \\
\hline & & & & & & \\
\hline & & & & & & \\
\hline & & & & & & \\
\hline
\end{tabular}

Partners, personnel, tasks and responsibilities in the adoption and implementation of the technology

\begin{tabular}{|l|l|l|l|}
\hline Stakeholder & Expectations & Tasks & Responsibilities \\
\hline & & & \\
\hline & & & \\
\hline & & & \\
\hline & & & \\
\hline
\end{tabular}




\section{Technology Evaluation Plan $^{1}$}

\section{Benefits to INDOT}

The functional areas that will benefit from the technology are:

Transportation Planning, Finance and Policy Program Engineering and Pavement Design and Production

Construction and Contracts

Traffic Safety and Management

Maintenance and operations

The technologies and processes in the above functional areas that might be enhanced and/or replaced by the technology include:

The technology can be acquired by:

Benefits to the public

\begin{tabular}{|l|l|l|}
\hline Benefit to the public & Type of benefit & Importance \\
\hline & & \\
\hline & & \\
\hline & & \\
\hline & & \\
\hline & & \\
\hline
\end{tabular}




\section{Technology Evaluation Plan ${ }^{1}$}

Cost-benefit analysis and funding for evaluation of the new technology

The potential costs associated with evaluation of the technology are:

The potential benefits associated with evaluation are:

The suggested funding sources for evaluation are: 


\section{Technology Adoption Rationale ${ }^{1}$}

\begin{tabular}{|l|l|}
\hline Name of the potential technology: & \\
\hline This technology is capable of: & \\
\hline $\begin{array}{l}\text { The important and unsatisfied } \\
\text { needs that the technology has } \\
\text { been demonstrated to address } \\
\text { are: }\end{array}$ & \\
\hline
\end{tabular}

Success measures, key tests conducted, and outcomes

\begin{tabular}{|l|l|l|}
\hline Success measure & Key test conducted & Relevant data and outcomes \\
\hline & & \\
\hline & & \\
\hline & & \\
\hline & & \\
\hline & & \\
\hline & & \\
\hline
\end{tabular}




\section{Technology Adoption Rationale ${ }^{1}$}

Benefits to the public

\begin{tabular}{|l|l|l|}
\hline Benefit to the public & Type of benefit & Importance \\
\hline & & \\
\hline & & \\
\hline & & \\
\hline & & \\
\hline & & \\
\hline & & \\
\hline & & \\
\hline & & \\
\hline
\end{tabular}

Testimonials and key contacts to learn more

\begin{tabular}{|c|c|c|c|}
\hline Name & Phone & Email & Testimonial \\
\hline & & & \\
\hline & & & \\
\hline & & & \\
\hline & & & \\
\hline & & & \\
\hline & & & \\
\hline & & & \\
\hline
\end{tabular}

Marketing plan

INDOT personnel will be made aware of this technology by:

The public will be made aware of this technology by: 


\section{Appendix E}

Complete Listing of Job-survey Results 


\begin{tabular}{|c|c|c|c|c|c|c|}
\hline Rank & $\%$ Importance & $\begin{array}{l}\text { Importance } \\
\text { Response Count }\end{array}$ & \% Satisfaction & $\begin{array}{l}\text { Satisfaction } \\
\text { Response Count }\end{array}$ & I-S & Task \\
\hline 1 & 80.0 & 1 & 0.0 & 1 & 1.0 & Design erosion control systems \\
\hline 2 & 80.0 & 1 & 0.0 & 1 & 1.0 & Design water removal and control systems \\
\hline 3 & 100.0 & 1 & 20.0 & 1 & 1.0 & Perform seismic design \\
\hline 4 & 80.0 & 1 & 0.0 & 1 & 1.0 & Remediate land slides \\
\hline 5 & 80.0 & 1 & 20.0 & 1 & 1.4 & Design lateral earth support structures \\
\hline 6 & 80.0 & 1 & 20.0 & 1 & 1.4 & Design pavement sub-grades \\
\hline 7 & 80.0 & 1 & 20.0 & 1 & 1.4 & Design reinforced embankments \\
\hline 8 & 80.0 & 2 & 30.0 & 2 & 1.8 & Limit auto/structure collision severity \\
\hline 9 & 80.0 & 2 & 30.0 & 2 & 1.8 & Limit/eliminate divided highway collisions \\
\hline 10 & 80.0 & 2 & 30.0 & 2 & 1.8 & Prevent or limit going off road/over embankments \\
\hline 11 & 100.0 & 1 & 40.0 & 1 & 2.0 & Automate laboratory soil test \\
\hline 12 & 100.0 & 1 & 40.0 & 1 & 2.0 & Compare test results to design specifications \\
\hline 13 & 100.0 & 1 & 40.0 & 1 & 2.0 & Design foundations \\
\hline 14 & 100.0 & 1 & 40.0 & 1 & 2.0 & Specify soil testing programs \\
\hline 15 & 80.0 & 1 & 40.0 & 1 & 2.2 & Conduct drilling for soil profiling \\
\hline 16 & 80.0 & 1 & 40.0 & 1 & 2.2 & Create mix designs for pavements \\
\hline 17 & 60.0 & 1 & 20.0 & 1 & 2.2 & Design drill shafts \\
\hline 18 & 80.0 & 1 & 40.0 & 1 & 2.2 & Design earthwork \\
\hline 19 & 60.0 & 1 & 20.0 & 1 & 2.2 & Design sheet piles \\
\hline 20 & 80.0 & 1 & 40.0 & 1 & 2.2 & Examine soil stratigraphy \\
\hline 21 & 80.0 & 1 & 40.0 & 2 & 2.2 & Monitor bridge long-term deflections \\
\hline 22 & 64.0 & 5 & 28.0 & 5 & 2.3 & Evaluate box beam post-tensioning \\
\hline 23 & 88.0 & 5 & 44.0 & 5 & 2.3 & Protect bridges from steel corrosion \\
\hline 24 & 66.7 & 6 & 32.0 & 5 & 2.3 & Enhance visibility of roadway markings in rain/fog/snow \\
\hline 25 & 76.7 & 6 & 40.0 & 5 & 2.3 & Ensuring visibility of roadway signage \\
\hline 26 & 93.3 & 3 & 46.7 & 3 & 2.4 & Properly place signage (e.g., traffic lights, stop signs, speed limits) \\
\hline 27 & 86.7 & 3 & 46.7 & 3 & 2.4 & Obtain data on roadway utilization and traffic congestion \\
\hline 28 & 63.3 & 6 & 32.0 & 5 & 2.4 & Increase driver awareness of potential roadway hazards \\
\hline 29 & 64.0 & 5 & 36.0 & 5 & 2.5 & Monitor corrosion of steel in reinforced concrete \\
\hline 30 & 60.0 & 5 & 32.0 & 5 & 2.6 & Monitor joints in bridges \\
\hline 31 & 76.0 & 5 & 46.7 & 3 & 2.6 & Manage database and document \\
\hline 32 & 76.7 & 6 & 48.0 & 5 & 2.7 & Budget a roadway project \\
\hline 33 & 73.3 & 3 & 46.7 & 3 & 2.7 & Manage lighting needs \\
\hline 34 & 73.3 & 6 & 46.7 & 6 & 2.7 & Review sub-contracted design works \\
\hline 35 & 67.5 & 8 & 42.9 & 7 & 2.7 & Design storm drains \\
\hline 36 & 50.0 & 2 & 20.0 & 2 & 2.7 & Alert drivers to weather related hazards \\
\hline 37 & 63.3 & 6 & 40.0 & 4 & 2.7 & Provide emergency response in the event of an accident \\
\hline 38 & 62.9 & 7 & 40.0 & 5 & 2.7 & Repair and maintain bridge deck \\
\hline 39 & 73.3 & 6 & 48.0 & 5 & 2.7 & Investigate pavement failures \\
\hline 40 & 67.5 & 8 & 45.0 & 4 & 2.8 & Check/validate project compliance with codes \\
\hline 41 & 60.0 & 8 & 40.0 & 5 & 2.8 & Communicate with drivers/personnel in the field \\
\hline 42 & 68.0 & 5 & 46.7 & 3 & 2.8 & Regulate worker hours \\
\hline 43 & 63.3 & 6 & 44.0 & 5 & 2.9 & Document all accidents \\
\hline 44 & 63.3 & 6 & 45.0 & 4 & 2.9 & Increase roadway visibility through lighting \\
\hline 45 & 50.0 & 6 & 30.0 & 4 & 2.9 & Reduce traffic speed in roadway work areas \\
\hline 46 & 72.5 & 8 & 51.4 & 7 & 2.9 & Estimate project costs \\
\hline 47 & 60.0 & 10 & 43.3 & 6 & 2.9 & Identify potential delays in projects \\
\hline 48 & 60.0 & 6 & 43.3 & 6 & 2.9 & Prevent erosion \\
\hline 49 & 60.0 & 5 & 44.0 & 5 & 3.0 & Monitor corrosion of steel structures \\
\hline
\end{tabular}




\begin{tabular}{|c|c|c|c|}
\hline 50 & 70.0 & 8 & 52.0 \\
\hline 51 & 48.0 & 5 & 30.0 \\
\hline 52 & 93.3 & 3 & 60.0 \\
\hline 53 & 62.9 & 7 & 48.0 \\
\hline 54 & 51.4 & 7 & 36.7 \\
\hline 55 & 68.0 & 5 & 52.0 \\
\hline 56 & 46.7 & 6 & 30.0 \\
\hline 57 & 86.7 & 3 & 60.0 \\
\hline 58 & 53.3 & 6 & 40.0 \\
\hline 59 & 56.0 & 5 & 44.0 \\
\hline 60 & 56.7 & 6 & 45.0 \\
\hline 61 & 66.7 & 3 & 53.3 \\
\hline 62 & 66.7 & 3 & 53.3 \\
\hline 63 & 55.0 & 8 & 44.0 \\
\hline 64 & 80.0 & 3 & 60.0 \\
\hline 65 & 80.0 & 1 & 60.0 \\
\hline 66 & 80.0 & 1 & 60.0 \\
\hline 67 & 80.0 & 2 & 60.0 \\
\hline 68 & 80.0 & 3 & 60.0 \\
\hline 69 & 80.0 & 1 & 60.0 \\
\hline 70 & 80.0 & 6 & 60.0 \\
\hline 71 & 50.0 & 2 & 40.0 \\
\hline 72 & 50.0 & 6 & 40.0 \\
\hline 73 & 66.7 & 6 & 55.0 \\
\hline 74 & 55.6 & 9 & 46.7 \\
\hline 75 & 75.6 & 9 & 60.0 \\
\hline 76 & 40.0 & 5 & 25.0 \\
\hline 77 & 75.0 & 4 & 60.0 \\
\hline 78 & 56.0 & 5 & 48.0 \\
\hline 79 & 66.7 & 6 & 56.0 \\
\hline 80 & 82.9 & 7 & 63.3 \\
\hline 81 & 64.0 & 5 & 55.0 \\
\hline 82 & 52.0 & 5 & 45.0 \\
\hline 83 & 52.0 & 5 & 45.0 \\
\hline 84 & 53.3 & 3 & 46.7 \\
\hline 85 & 54.3 & 7 & 48.0 \\
\hline 86 & 64.0 & 5 & 56.0 \\
\hline 87 & 46.7 & 6 & 40.0 \\
\hline 88 & 46.7 & 6 & 40.0 \\
\hline 89 & 46.7 & 3 & 40.0 \\
\hline 90 & 80.0 & 5 & 64.0 \\
\hline 91 & 70.0 & 6 & 60.0 \\
\hline 92 & 54.3 & 7 & 50.0 \\
\hline 93 & 52.0 & 5 & 48.0 \\
\hline 94 & 60.0 & 5 & 55.0 \\
\hline 95 & 60.0 & 6 & 55.0 \\
\hline 96 & 66.7 & 3 & 60.0 \\
\hline 97 & 61.8 & 11 & 57.5 \\
\hline 98 & 46.7 & 9 & 44.0 \\
\hline 99 & 73.3 & 6 & 64.0 \\
\hline
\end{tabular}

\begin{tabular}{|c|c|c|}
\hline 5 & 3.0 & Ensure proper roadway runoff \\
\hline 4 & 3.0 & Store traffic data \\
\hline 3 & 3.0 & Identify accidents and locations \\
\hline 5 & 3.0 & Apply graphical software to road designs \\
\hline 6 & 3.0 & Increase ability to provide drivers with real time information \\
\hline 5 & 3.1 & Monitor sub-soil and storm water drainage \\
\hline 4 & 3.1 & Detour traffic around project \\
\hline 3 & 3.1 & Develop traffic forecasts for future roadway planning \\
\hline 4 & 3.1 & Prevent worker/auto collisions \\
\hline 5 & 3.1 & Perform in-situ/in-field sensing of structures \\
\hline 4 & 3.1 & Maintain/update safety procedures \\
\hline 3 & 3.1 & Count/monitor traffic \\
\hline 3 & 3.1 & Open/close traffic lanes when needed \\
\hline 5 & 3.1 & Prevent rust/corrosion of bridge steel members \\
\hline 3 & 3.2 & Assess unfavorable driving conditions \\
\hline 1 & 3.2 & Define mineralogy of sampled soil \\
\hline 1 & 3.2 & Determine particle size distribution of soils \\
\hline 2 & 3.2 & Formulate ways to prevent erosion \\
\hline 3 & 3.2 & Manage traffic flow \\
\hline 1 & 3.2 & Obtain soil samples \\
\hline 5 & 3.2 & Select and specify projects for pavement maintenance / rehabilitation \\
\hline 1 & 3.2 & Alert drivers to over height collision hazards \\
\hline 4 & 3.2 & Optimize working conditions \\
\hline 4 & 3.2 & Protect INDOT vehicles from highway collisions \\
\hline 6 & 3.2 & Design water removal and control \\
\hline 8 & 3.2 & Plan a roadway project \\
\hline 4 & 3.3 & Process traffic data \\
\hline 2 & 3.3 & Supervise work quality control \\
\hline 5 & 3.3 & Monitor field instrumentation \\
\hline 5 & 3.3 & Perform a preliminary roadway survey \\
\hline 6 & 3.3 & Assess bridge pier scour \\
\hline 4 & 3.3 & Design flow through bridge pilings \\
\hline 4 & 3.3 & Ensure compliance with specifications for projects \\
\hline 4 & 3.3 & Model freeze thaw effects \\
\hline 3 & 3.3 & Gain access to state and national design standards \\
\hline 5 & 3.3 & Identify bridge-vehicle collision \\
\hline 5 & 3.3 & Search government and/or DOT databases for information \\
\hline 4 & 3.3 & Alert driving public to obstacles in breakdown lane/shoulder \\
\hline 4 & 3.3 & Minimize/control electrical hazards \\
\hline 3 & 3.3 & Visualize and design optimal road route / alignment \\
\hline 5 & 3.4 & Manage email \\
\hline 6 & 3.4 & Apply Geographic Information System (GIS) technology \\
\hline 4 & 3.4 & Patch roadway cracks \\
\hline 5 & 3.4 & Install field instrumentation \\
\hline 4 & 3.4 & Format computers/data \\
\hline 4 & 3.4 & Manage pavement condition \\
\hline 3 & 3.4 & Design roadway elevations and alignment \\
\hline 8 & 3.5 & Review project plans (confirm that a project meets specifications /plans) \\
\hline 5 & 3.5 & Determine quantity take-offs for construction materials \\
\hline 5 & 3.5 & Scope a roadway project \\
\hline
\end{tabular}




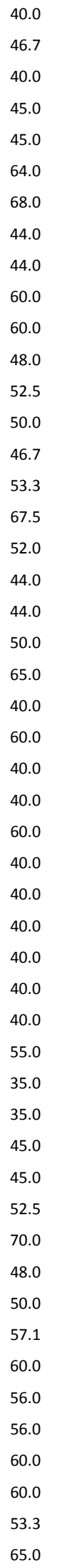

Alert machinery operators to highway boundaries

Repave roads

Manage storage of vehicles and equipment

Eliminate tripping hazards

Observe overflow to facilitate modeling

Detect corroded pipes in the ground

Manage online access to INDOT information systems

Establish project contingencies

Fill potholes

Ensure worker safety

Model water flow in infrastructure systems

Assess financial risk

Ensure proper equipment maintenance to enhance safety (e.g., brakes)

Alert site workers to overhead hazards

Acquire permits

Visualize and design optimal route

Design culverts

Maintain awareness of DOT worker location in the field

Determine thermal effects on bridge deck stability and alignment

Monitor bridge live load deflections

Manage project cash flow

Inspect bridges

Alert site workers to highway boundaries

Alert traffic to maintenance/construction on roadways

Determine site grade

Enhance awareness of site wind conditions

Ensure and supervise job safety

Monitor proper use of ad-mixtures during roadway installation

Perform ground modification (e.g., grouting, dynamic compaction)

Perform ground retention (e.g., geo-grids, geo-textiles)

Perform non-destructive evaluation of steel connections

Warn drivers of limitations on hazardous material transport

Warn drivers of limitations on roadway load capacity

Enhance overall safety of night construction

Analyze fuel cost for vehicle fleet

Track vehicle fleet

Enhance safety of overpass repair/maintenance

Perform routine equipment maintenance

Train operators on safe use of equipment

Enable project management through software applications

Paint bridges

Enhance worker fall protection

Design detention ponds

Manage projects (define and identify critical path)

Clear snow

Prevent icing on bridges

Place/repair guard rails

Determine extreme events that could impact design (e.g. 50-year flood)

Apply Computer Aided Design (CAD) technology

Maintain road markings 


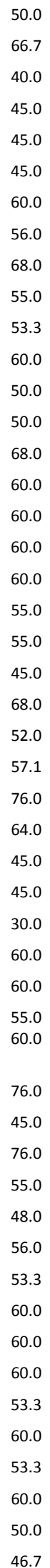

Monitor silt collection

Determine vehicle speed

Employ warning systems to prevent accidents

Alert workers to slope instability

Enable buddy systems for INDOT personnel during work activities

Enhance worker awareness of location of other workers

Settle worker disputes

Salt roads

Install/update computer hardware

Place/repair signal lights

Assess regional growth and future transportation needs

Deice

Alert site workers/machinery operators to ground instability

Place roadway safety equipment (e.g. cones)

Prepare and approve pavement projects for contract letting

Coordinate specifications, provisions and designs

Limit severity of fall hazards/injuries

Provide medical care

Plow

Ensure awareness of road conditions by driving public

Protect workers from falling objects

Place/repair bridge lighting

Propose pavement structure-related specifications and special provisions

Compact soil

Monitor overflow conditions at roadway crossings

Maintain secure data storage

Manage passwords

Maintain fleet vehicles

Perform in field repairs of vehicles/machinery

Harvest power remotely

Make workers more visible on construction sites

Place/repair road signage

Manage traffic diversion

Ensure secure communications/data transfer between roadway sensors and monitoring stations

Monitor pavement condition (e.g. roughness, friction)

Manage vehicle/equipment replacement and auction

Develop software for INDOT use

Monitor warranties for a project

Model wind loading effects

Estimate earth-moving costs (earth-works)

Calculate working loads for structures

Design rights of way

Detect overweight vehicles

Document job site safety inspections

Ensure freight compliance with regulations

Ensure vehicle compliance with over height

Issue extraordinary load permit

Perform quality control on site

Enhance worker noise protection

4.1 Monitor bridge long-term deformations 


\begin{tabular}{|c|c|c|}
\hline 40.0 & 6 & 55.0 \\
\hline 40.0 & 6 & 55.0 \\
\hline 31.4 & 7 & 45.0 \\
\hline 40.0 & 6 & 56.0 \\
\hline 40.0 & 6 & 56.0 \\
\hline 40.0 & 6 & 56.0 \\
\hline 32.7 & 11 & 47.5 \\
\hline 60.0 & 5 & 72.0 \\
\hline 80.0 & 1 & 80.0 \\
\hline 36.0 & 5 & 52.0 \\
\hline 80.0 & 1 & 80.0 \\
\hline 20.0 & 1 & 20.0 \\
\hline 80.0 & 1 & 80.0 \\
\hline 80.0 & 1 & 80.0 \\
\hline 80.0 & 1 & 80.0 \\
\hline 80.0 & 1 & 80.0 \\
\hline 80.0 & 1 & 80.0 \\
\hline 80.0 & 1 & 80.0 \\
\hline 43.3 & 6 & 60.0 \\
\hline 52.0 & 5 & 68.0 \\
\hline 33.3 & 6 & 50.0 \\
\hline 36.7 & 6 & 55.0 \\
\hline 28.6 & 7 & 44.0 \\
\hline 37.1 & 7 & 56.0 \\
\hline 92.0 & 5 & 84.0 \\
\hline 36.0 & 5 & 55.0 \\
\hline 28.6 & 7 & 45.0 \\
\hline 36.7 & 6 & 56.0 \\
\hline 40.0 & 6 & 60.0 \\
\hline 40.0 & 1 & 60.0 \\
\hline 40.0 & 6 & 60.0 \\
\hline 40.0 & 6 & 60.0 \\
\hline 40.0 & 3 & 60.0 \\
\hline 31.4 & 7 & 50.0 \\
\hline 25.0 & 4 & 40.0 \\
\hline 26.0 & 10 & 42.5 \\
\hline 33.3 & 3 & 53.3 \\
\hline 33.3 & 3 & 53.3 \\
\hline 32.0 & 5 & 52.0 \\
\hline 53.3 & 6 & 72.0 \\
\hline 30.0 & 6 & 50.0 \\
\hline 30.0 & 6 & 50.0 \\
\hline 26.7 & 6 & 45.0 \\
\hline 28.6 & 7 & 48.0 \\
\hline 34.3 & 7 & 56.0 \\
\hline 51.4 & 7 & 71.4 \\
\hline 46.7 & 6 & 68.0 \\
\hline 33.3 & 6 & 55.0 \\
\hline 25.7 & 7 & 45.0 \\
\hline 26.7 & 3 & 46.7 \\
\hline
\end{tabular}

4.1

4.1

4.1

4.1

4.1

4.1

4.1

4.1

4.1

4.1

4.1

4.1

4.1

4.1

4.1

4.1

4.1

4.1

4.1

4.2

4.2

4.2

4.2

4.

4.

4.2
Place/repair barricades

Prevent water damage on bridges

Remove trash from shoulders and roadsides

Define roadway alignment

Repair/maintain bridge side rails

Test placed materials for alignment with design specifications

Gather/give feedback on pending legislative policies

Synchronize data/communications between multiple locations

Design retaining structures

Maintain geographic information

Monitor landslides or slope stability

Monitor strength of concrete for infrastructure projects

Obtain undisturbed soil samples

Perform constant rate of strain test on sampled soil

Perform in-site strength test on soil (e.g., SPT blow count)

Perform Ko consildated triaxial test on sampled soil

Perform unconfined compression test on sampled soil

Test soil Atterberg limits

Write or review change orders

Construct/manage communication networks

Enhance crane safety

Train operators for safety/impact truck usage

Monitor overheight/overweight vehicles

Order vehicle/equipment replacement parts

Manage software licenses

Perform finite element analysis

Clean bridge side rails

Utilize CAD rendered 3-D drawings

Clear roadways of accidents

Determine soil classification

Ensure availability/accessibility of material safety data sheet

Increase awareness of chemical hazards

Provide roadside assistance

Excavate

Write and mail invoices

Communicate pending policy/legislative decisions to the driving public

Manage/control highway noise levels

Prepare and approve projects for contract letting

Secure/transfer electronic funds

Estimate hydraulic gradient at project sites

Install digital displays

Maintain median

Maintain landscaping

Manage contractor selection

Order material

Design bridges

Design under-pavement drainage systems

Manage receipt of materials

Relocate excavated soil

Coordinate (sub) contractors 


\begin{tabular}{|c|c|c|c|c|c|c|}
\hline 250 & 26.7 & 3 & 46.7 & 3 & 4.3 & Distribute funds to sub-contractors \\
\hline 251 & 28.6 & 7 & 50.0 & 4 & 4.4 & Process materials \\
\hline 252 & 20.0 & 5 & 35.0 & 4 & 4.4 & Monitor traffic speed \\
\hline 253 & 16.0 & 5 & 25.0 & 4 & 4.4 & Monitor traffic flow and congestion \\
\hline 254 & 25.0 & 4 & 46.7 & 3 & 4.4 & Confirm contractor insurance \\
\hline 255 & 28.6 & 7 & 52.0 & 5 & 4.4 & Manage material inventory \\
\hline 256 & 92.0 & 5 & 88.0 & 5 & 4.4 & Manage information using databases \\
\hline 257 & 35.0 & 4 & 60.0 & 1 & 4.4 & Protect in-place construction \\
\hline 258 & 35.0 & 4 & 60.0 & 3 & 4.4 & Verify completed work and ensure payment \\
\hline 259 & 22.0 & 10 & 42.5 & 8 & 4.4 & Ensure policy awareness for driving public \\
\hline 260 & 23.3 & 6 & 45.0 & 4 & 4.4 & Procure materials for projects in timely and efficient manner \\
\hline 261 & 30.0 & 6 & 55.0 & 4 & 4.5 & Transport tools and equipment \\
\hline 262 & 22.9 & 7 & 45.0 & 4 & 4.5 & Drill hole for signage \\
\hline 263 & 20.0 & 4 & 40.0 & 3 & 4.5 & Confirm contractor bonds \\
\hline 264 & 60.0 & 1 & 80.0 & 1 & 4.5 & Determine site geology \\
\hline 265 & 60.0 & 1 & 80.0 & 1 & 4.5 & Investigate landslides (identify areas of potential rock fall) \\
\hline 266 & 60.0 & 1 & 80.0 & 1 & 4.5 & Obtain Shelby tube soil samples \\
\hline 267 & 20.0 & 1 & 40.0 & 1 & 4.5 & Select proper ad-mixtures for concrete/asphalt designs \\
\hline 268 & 40.0 & 3 & 66.7 & 3 & 4.5 & Maintain power transmittance \\
\hline 269 & 25.0 & 4 & 50.0 & 4 & 4.5 & Improve rail crossing smoothness \\
\hline 270 & 25.0 & 4 & 50.0 & 4 & 4.5 & Improve rail crossing warnings \\
\hline 271 & 36.0 & 5 & 64.0 & 5 & 4.5 & Design emergency support structures \\
\hline 272 & 26.7 & 3 & 53.3 & 3 & 4.5 & Control transportation footprint influence on environment \\
\hline 273 & 26.7 & 3 & 53.3 & 3 & 4.5 & Detect of passage of illegal/dangerous substances \\
\hline 274 & 26.7 & 3 & 53.3 & 3 & 4.5 & Manage accounts (e.g., track billings and payment history) \\
\hline 275 & 16.0 & 5 & 35.0 & 4 & 4.6 & Collect traffic data for modeling \\
\hline 276 & 31.4 & 7 & 60.0 & 4 & 4.6 & Prevent INDOT vehicles from rolling when unattended \\
\hline 277 & 63.3 & 6 & 84.0 & 5 & 4.6 & Design pavement cross sections \\
\hline 278 & 25.0 & 4 & 53.3 & 3 & 4.6 & Manage legal issues (e.g., access to right of way) \\
\hline 279 & 30.0 & 2 & 60.0 & 1 & 4.6 & Monitor traffic flow \\
\hline 280 & 64.0 & 5 & 85.0 & 4 & 4.6 & Develop websites for internal and/or external audiences \\
\hline 281 & 20.0 & 4 & 46.7 & 3 & 4.6 & Distribute funds to general contractors \\
\hline 282 & 20.0 & 2 & 46.7 & 3 & 4.6 & Limit freeze thaw on embankments \\
\hline 283 & 20.0 & 7 & 48.0 & 5 & 4.7 & Communicate specific and sudden situations to drivers \\
\hline 284 & 52.0 & 5 & 80.0 & 5 & 4.7 & $\begin{array}{l}\text { Use Geographic Information System (GIS) technology in monitoring, } \\
\text { mapping, or navigation applications }\end{array}$ \\
\hline 285 & 17.1 & 7 & 44.0 & 5 & 4.7 & Provide real-time information to drivers \\
\hline 286 & 72.0 & 5 & 90.0 & 4 & 4.7 & Use Computer Aided Design (CAD) technology \\
\hline 287 & 33.3 & 3 & 66.7 & 3 & 4.7 & Manage electronic payments \\
\hline 288 & 20.0 & 6 & 50.0 & 4 & 4.7 & Operate cranes \\
\hline 289 & 23.3 & 6 & 55.0 & 4 & 4.7 & Remove debris \\
\hline 290 & 16.7 & 6 & 45.0 & 4 & 4.7 & Assess site conditions for crane use \\
\hline 291 & 26.7 & 6 & 60.0 & 4 & 4.7 & Install new bulbs in roadway light fixtures \\
\hline 292 & 8.0 & 5 & 25.0 & 4 & 4.8 & Monitor/detect pedestrians at crosswalks \\
\hline 293 & 8.0 & 5 & 25.0 & 4 & 4.8 & Observe red light violations \\
\hline 294 & 20.0 & 6 & 52.0 & 5 & 4.8 & Manage capital (verifying contractor bonds/finances for project phases) \\
\hline 295 & 25.0 & 4 & 60.0 & 2 & 4.8 & Coordinate (sub)contractors \\
\hline 296 & 20.0 & 3 & 53.3 & 3 & 4.8 & Maintain roadside rest areas \\
\hline 297 & 15.0 & 4 & 45.0 & 4 & 4.8 & Ensure driver awareness of directions (e.g., highway signage) \\
\hline 298 & 12.0 & 5 & 40.0 & 4 & 4.8 & Model traffic flow and behavior \\
\hline 299 & 12.0 & 5 & 40.0 & 4 & 4.8 & Optimize traffic flow \\
\hline
\end{tabular}




4
5
4

4

2

1

1

1

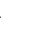

1

1

1

1

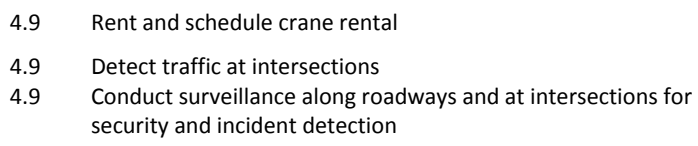

N/A Monitor deterioration of concrete infrastructure 


$\begin{array}{lllllll}350 & \text { N/A } & 0.0 & \text { N/A } & 0.0 & \text { N/A } & \text { Negotiate bids } \\ 351 & \text { N/A } & 0.0 & \text { N/A } & 0.0 & \text { N/A } & \text { Negotiate material prices } \\ 352 & \text { N/A } & 0.0 & \text { N/A } & 0.0 & \text { N/A } & \text { Oversee aggregate transport within State } \\ 353 & \text { N/A } & 0.0 & \text { N/A } & 0.0 & \text { N/A } & \text { Oversee concrete pours } \\ 354 & \text { N/A } & 0.0 & \text { N/A } & 0.0 & \text { N/A } & \text { Oversee material testing } \\ 355 & \text { N/A } & 0.0 & \text { N/A } & 0.0 & \text { N/A } & \text { Perform quality testing on project materials } \\ 356 & \text { N/A } & 0.0 & \text { N/A } & 0.0 & \text { N/A } & \text { Rent land or building } \\ 357 & \text { N/A } & 0.0 & \text { N/A } & 0.0 & \text { N/A } & \text { Rent or pay for maintenance of large scale computer/systems } \\ 358 & \text { N/A } & 0.0 & \text { N/A } & 0.0 & \text { N/A } & \text { Rent or pay for maintenance of office equipment } \\ 359 & \text { N/A } & 0.0 & \text { N/A } & 0.0 & \text { N/A } & \text { Review submitted bids } \\ 360 & \text { N/A } & \text { N/A } & 0.0 & 0.0 & \text { N/A } & \text { Schedule rental or maintenance of large scale computers/systems } \\ 361 & \text { N/A } & \text { N/A } & 0.0 & \text { N/A } & \text { Select aggregate type } \\ 362 & \text { N/A } & 0.0 & 0.0 & \text { N/A } & \text { N/A } & \text { Test concrete compressive strength } \\ 363 & \text { N/A } & 0.0 & \text { Test concrete slump }\end{array}$

